\title{
Archaeological excavations in St Giles' Cathedral Edinburgh, 1981-93
}

by Mark Collard*, John A Lawson $†$ and Nicholas Holmes $\ddagger$

*Cotswold Archaeology, Building 11, Kemble Enterprise Park, Cirencester, GL7 6BQ $\dagger$ City of Edinburgh Council Archaeology Service, Huntly House Museum, 142 Canongate, Edinburgh EH8 8DD

$\$$ National Museums of Scotland, Chambers Street, Edinburgh EH1 1JF

with contributions by

David Henderson, Roderick P McCullagh, Derek Hall, George Haggarty, Julie Franklin, Thomas Addyman, Robin Murdoch and Pamela Graves 
Published by the Society of Antiquaries of Scotland, www.socantscot.org.uk with Historic Scotland, www.historic-scotland.gov.uk and the Council for British Archaeology, www.britarch.ac.uk

Editor Debra Barrie

Produced by Archetype Information Technology Ltd, www.archetype-it.com

ISBN: 0903903911

ISSN: $1473-3803$

Requests for permission to reproduce material from a $S A I R$ report should be sent to the Director of the Society of Antiquaries of Scotland, as well as to the author, illustrator, photographer or other copyright holder.

Copyright in any of the Scottish Archaeological Internet Reports series rests with the SAIR Consortium and the individual authors.

The maps are reproduced from Ordnance Survey material with the permission of Ordnance Survey on behalf of The Controller of Her Majesty's Stationery Office. CCrown copyright 2001. Any unauthorized reproduction infringes Crown copyright and may lead to prosecution or civil proceedings. Historic Scotland Licence No GD 03032G, 2002.

The consent does not extend to copying for general distribution, advertising or promotional purposes, the creation of new collective works or resale. 


\section{Contents}

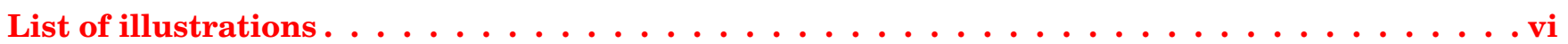

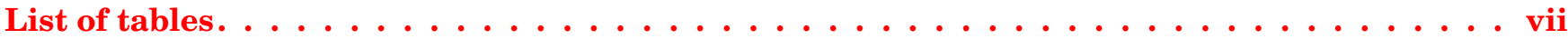

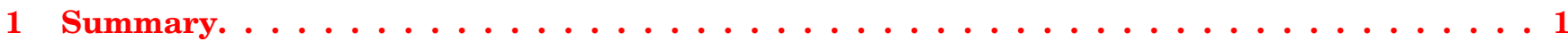

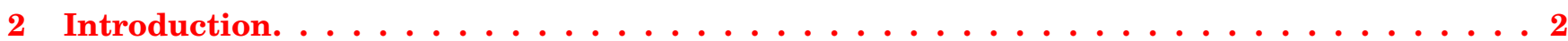

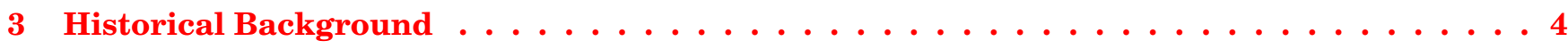

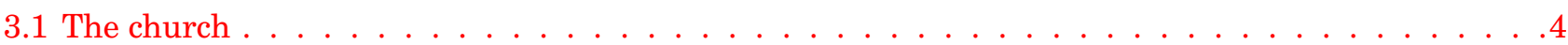

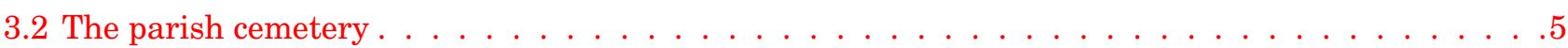

3.3 The hospital of St Giles' $\ldots \ldots \ldots \ldots \ldots \ldots$

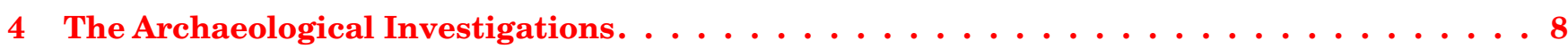

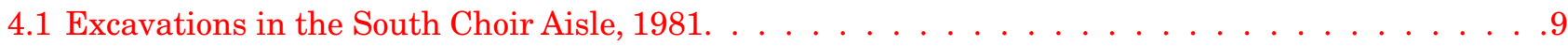

4.1 .1 Period $1: ? 12$ th century . . . . . . . . . . . . . . . . . . . .9

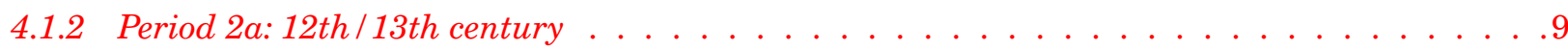

4.1.3 Period 2b: 13th/14th century . . . . . . . . . . . . . . . . . . . 10

4.1 .4 Period 3a: late 14th to mid-15th century . . . . . . . . . . . . . . . . . . 11

4.1.5 Period 3b: mid-15th century to the Reformation . . . . . . . . . . . . . . . . 14

4.1 .6 Period 4: Reformation to $1981 \ldots \ldots \ldots \ldots$

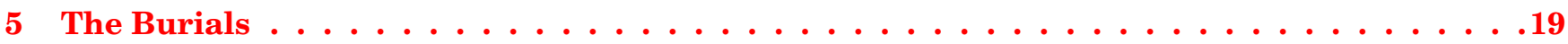

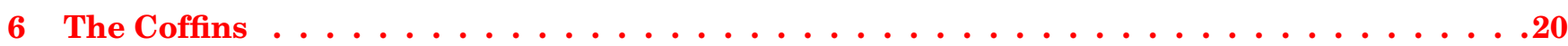

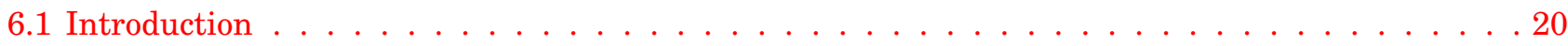

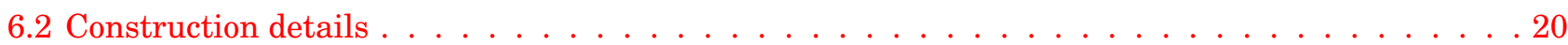

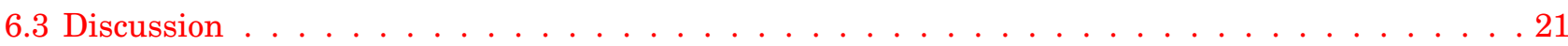

7 The Coffin Wood by $\operatorname{Rod} P$ McCullagh $\ldots \ldots \ldots \ldots \ldots \ldots$

7.1 Methodology . . . . . . . . . . . . . . . . . . . . . . . . . 23

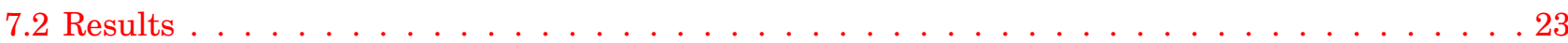

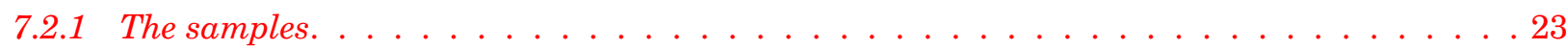

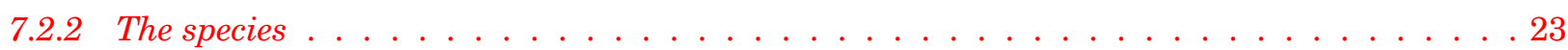

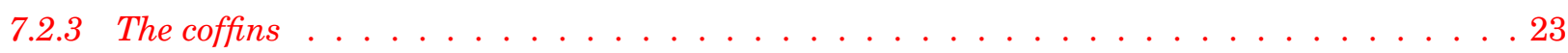

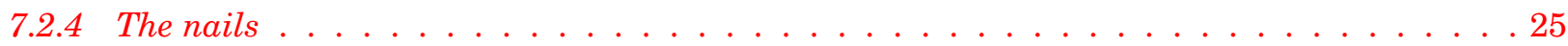

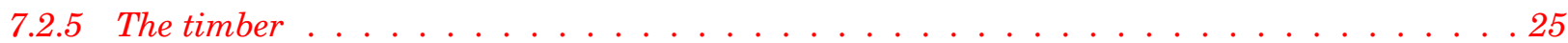

8 The Human Bones by David Henderson . . . . . . . . . . . . . . . . . . . . . 27

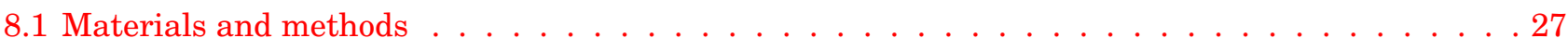

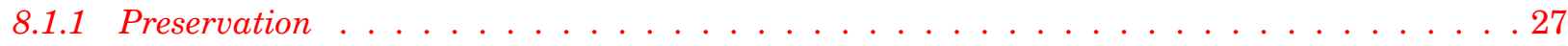




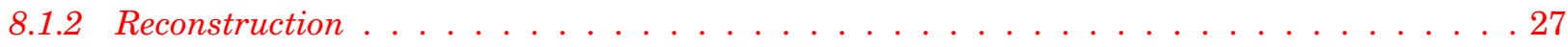

8.1 .3 Age estimation . . . . . . . . . . . . . . . . . . . . 27

8.1 .4 Sex estimation . . . . . . . . . . . . . . . . . . . 28

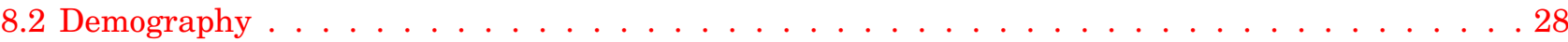

8.2 .1 Number of individuals . . . . . . . . . . . . . . . . . . . . . . . . 28

8.2 .2 Age and sex. . . . . . . . . . . . . . . . . . . . . . . . . 29

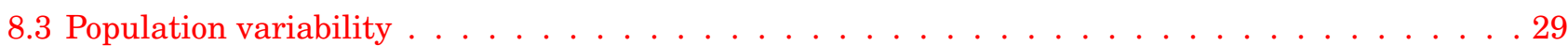

8.3 .1 Non-metric traits . . . . . . . . . . . . . . . . . . . . . . . . 29

8.3 .2 Body size and indices. . . . . . . . . . . . . . . . . . . . . . . . . . . 29

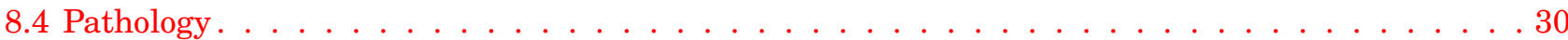

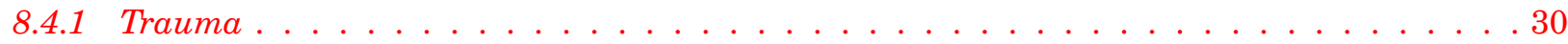

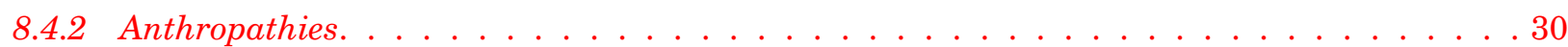

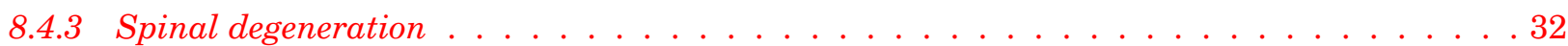

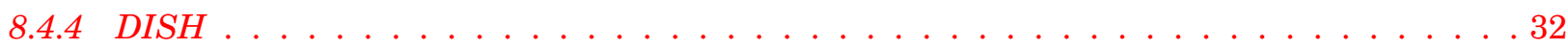

8.4 .5 Other spinal pathologies . . . . . . . . . . . . . . . . . . . 33

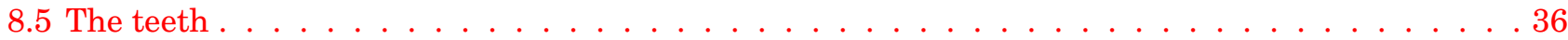

8.5 .1 Dental pathology . . . . . . . . . . . . . . . . . . . 36

8.5 .2 Childhood morbidity. . . . . . . . . . . . . . . . . . . . 37

8.5 .3 Dental disease . . . . . . . . . . . . . . . . . . . . . . 37

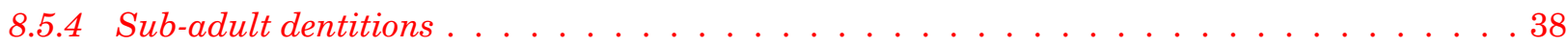

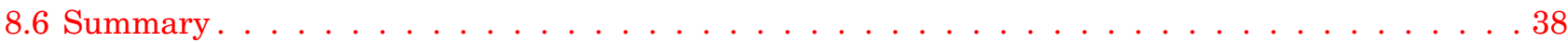

9 Other Investigations . . . . . . . . . . . . . . . . . . . . . . . . . .

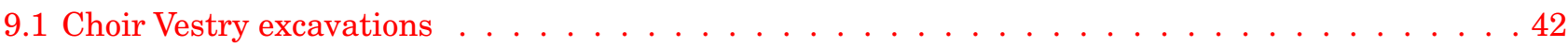

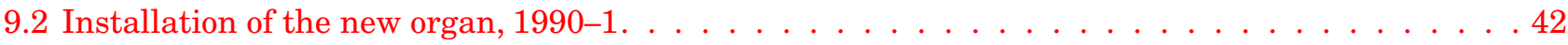

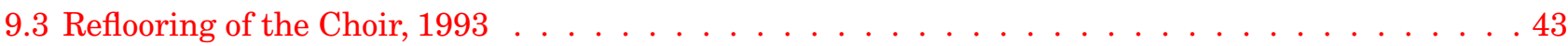

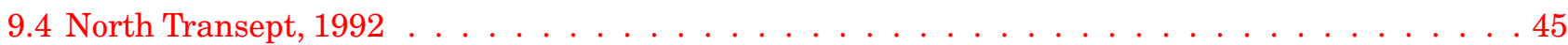

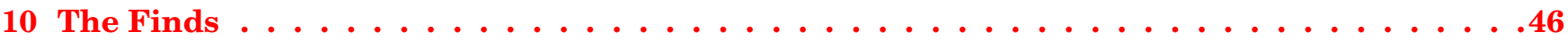

10.1 The pottery by Derek Hall \& George Haggarty. . . . . . . . . . . . . . . . . . . . . . . . . . . 46

10.1.1 South Choir Aisle, 1981 . . . . . . . . . . . . . . . . . . . . . . . . . 46

10.1.2 Choir Vestry excavation (1981) and geotechnical trial pits (1977) . . . . . . . . . . . . 50

10.1.3 Conclusions. . . . . . . . . . . . . . . . . . . . . . . . . . 50

10.2 The ceramic building material by Derek Hall . . . . . . . . . . . . . . . . . . . . . 51

10.2 .1 Floor tile . . . . . . . . . . . . . . . . . . . . . . . . . . 51

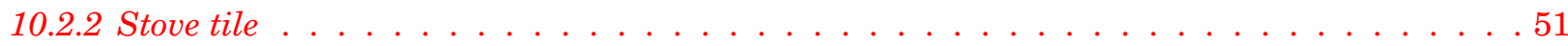

10.3 Coins and jetons by Nicholas Holmes. . . . . . . . . . . . . . . . . . . . . . . . . . 51

10.4 Other finds by Julie Franklin \& Mark Collard. . . . . . . . . . . . . . . . . . . . . . . . . . . 52

10.4 .1 Copper alloy . . . . . . . . . . . . . . . . . . . . . . . . 52

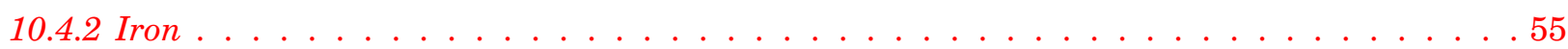

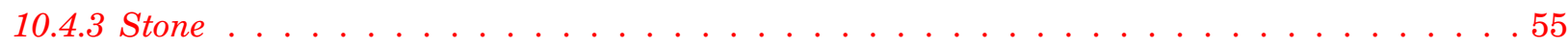

10.4.4 Bone objects (with bone identification by David Henderson) . . . . . . . . . . . . . 56

10.4.5 Vessel glass by Robin Murdoch. . . . . . . . . . . . . . . . . . . . . . . . . . . 56

10.4.6 Window glass and lead by Pamela Graves . . . . . . . . . . . . . . . . . . . . 57

10.4.7 Worked stone and building materials by Thomas Addyman . . . . . . . . . . . . . . 62 
11 The Faunal Remains by David Henderson . . . . . . . . . . . . . . . . . . 63

11.1 Methods . . . . . . . . . . . . . . . . . . . . . . . . 63

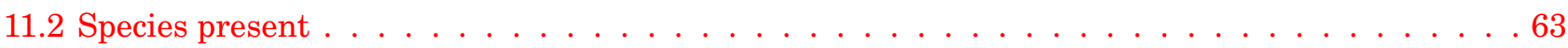

11.3 Distribution of skeletal elements . . . . . . . . . . . . . . . . . . . . . . 64

11.4 Age at slaughter . . . . . . . . . . . . . . . . . . . . . 64

11.5 Butchery. . . . . . . . . . . . . . . . . . . . . . 64

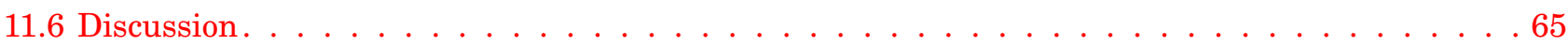

12 The Molluscs by John A Lawson . . . . . . . . . . . . . . . . . . . 66

13 Discussion by Mark Collard \& John A Lawson . . . . . . . . . . . . . . . . . . . . 67

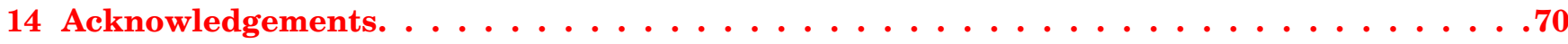

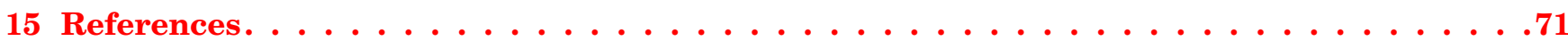




\section{List of illustrations}

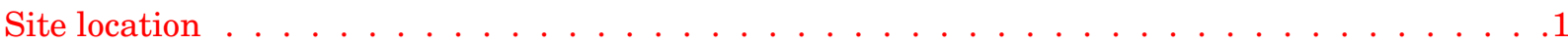

St Giles' Cathedral, Edinburgh, from the east . . . . . . . . . . . . . . . . . . . . .

Location of archaeological investigations, $1977-93 \ldots \ldots \ldots$

Schematic phased plan of the development of the medieval church

(after Addyman \& Kay 2001) . . . . . . . . . . . . . . . . . . . . . . . . . . .4 St Giles' Cathedral, Edinburgh as depicted on Gordon of Rothiemay's Bird's Eye View of

Edinburgh, 1647 . . . . . . . . . . . . . . . . . . . . . . . 6 St Giles' Cathedral, Edinburgh as depicted on William Edgar's Map of Edinburgh, 1742 . . . . . 7

Section through Period $2 \mathrm{a}$ ditch $(\mathrm{C} 249) \ldots \ldots \ldots \ldots$ Section across Period 2a ditch (C249) and relationship with Period 3a east wall footings $(\mathrm{C} 246) \ldots \ldots \ldots \ldots \ldots \ldots$

Period 2a, Burial Phase $1 \ldots \ldots \ldots$

Burial Phase 1 graves cut into clay platform (C126), looking west . . . . . . . . . . . . . . . 10

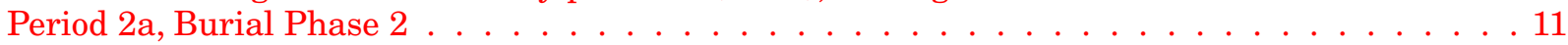

Period 2b, Burial Phase $3 \ldots \ldots \ldots \ldots \ldots \ldots$

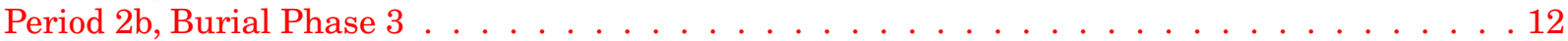

Skeleton 31 showing 'baton' on pelvis . . . . . . . . . . . . . . . . . . . . . . . . 13

'Baton' in situ on feet of Skeleton $43 \ldots \ldots$. . . . . . . . . . . . . . . . . . 13

Section through Period 3a construction trench (C151) for south wall (C149) . . . . . . . . . . . 14

Period 3a, Burial Phase $4 \ldots \ldots$. . . . . . . . . . . . . . . . . . . . 14

Section of 1977 trial pit TP4 . . . . . . . . . . . . . . . . . . . . . . . . . 15

Section across robber trench $(\mathrm{C} 251)$ of east wall $(\mathrm{C} 246) \ldots \ldots \ldots \ldots \ldots$

Footings of east wall of original presbytery (C246) in base of robber trench (C251) . . . . . . 16

Period 3, Burial Phases 4 and $5 \ldots \ldots \ldots \ldots$. . . . . . . . . . . . . . . . . . . . . .

Period 3, Burial Phase 5 . . . . . . . . . . . . . . . . . . . . . 17

Underpinning of south wall in Period $3 b \ldots \ldots \ldots \ldots \ldots$

Coffin 31 , showing vertical end slats at foot end of coffin . . . . . . . . . . . . . 21

Coffin 46, showing slats in base of grave after removal of skeleton . . . . . . . . . . . . . 21

Coffin 46, showing lid in situ over skeleton . . . . . . . . . . . . . . . . . . . . . . . . . 22

Plot of sex and pathology of excavated skeletons by period . . . . . . . . . . . . 31

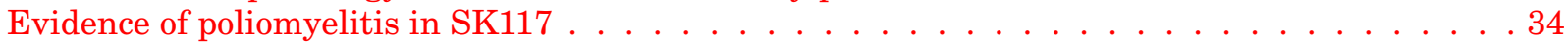

Evidence of osteosarcoma in SK110 . . . . . . . . . . . . . . . . . . . . 36

Plan of South Transept showing features recorded in 1981 (Choir Vestry excavations)

and $1990-1$ (organ foundation excavations) $\ldots \ldots \ldots \ldots$. . . . . . . . . . . . . . . .

Section across South Transept, information from 1981 Choir Vestry excavations and

1990-1 organ foundation excavations. . . . . . . . . . . . . . . . . . . . 43

The Choir 1992: plan of recorded features . . . . . . . . . . . . . . . . . . . . . .44

Pottery: East Coast White Gritty Ware; South Choir Aisle, 1981 . . . . . . . . . . . . . . . . 46

Pottery and cannel coal counters . . . . . . . . . . . . . . . . . . . . 47

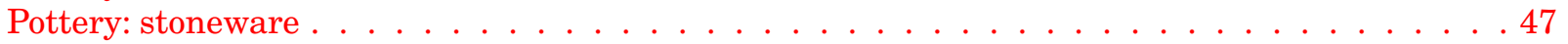

Pottery: Anglo-Dutch wares . . . . . . . . . . . . . . . . . . . . . . . . . . 48

Pottery: 14 th/15th-century crucible sherd with cloth impression on interior surface. . . . . . . . 48

Pottery: East Coast White Gritty Ware; Choir Vestry, 1981 . . . . . . . . . . . . . . . . . . . 49

Ceramic building material: stove tile 15 th-17th century; C25 . . . . . . . . . . . . . 49

Metalwork: Copper alloy and silver . . . . . . . . . . . . . . . . . . . . .53

Metalwork: Iron . . . . . . . . . . . . . . . . . . . . . . . . . 55

Bone objects $(1 \& 2)$ and beads $(3-5$ : bone, glass and stone $) \ldots \ldots \ldots \ldots$

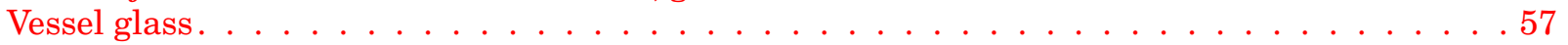

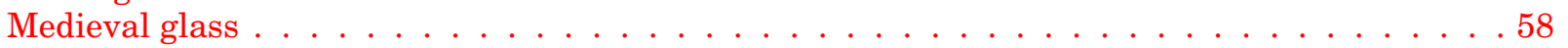

Metalwork: Lead came. . . . . . . . . . . . . . . . . . . . . . . . . . . 59

Architectural fragment: 12th-century Romanesque grotesque corbel or beakhead,

reused in foundation (C256) of east wall of South Aisle . . . . . . . . . . . . . . 60

Architectural fragments: 19th-century foliate cast-plaster ornamental fragments. . . . . . . . 61 


\section{List of tables}

Position of wood and species by coffin. . . . . . . . . . . . . . . . . . . . 24

Identifiable elements of the coffin . . . . . . . . . . . . . . . . . . . . . . . 25

Sex distribution by period . . . . . . . . . . . . . . . . . . . . 28

Age distribution of the in situ inhumations by period . . . . . . . . . . . . . . . . 28 Average estimated height in metres (Periods $2 \mathrm{a}$ and $2 \mathrm{~b}$ amalgamated because

of low numbers of adults in Burial Phase 3 ) . . . . . . . . . . . . . . . . . . . . . . . 29

Numbers of fractures recorded . . . . . . . . . . . . . . . . . . . . . 30

Individual skeletons with extra-spinal arthritis (percentage of total in age class in brackets) . . 32

Joints most commonly affected by severe osteoarthritis (eburnation) . . . . . . . . . . . . . . 32

Position of rotated teeth. L, left side; R, right side . . . . . . . . . . . . . . . . . . 36

Catalogue of recovered skeletons, giving estimated age, sex, estimated height and major pathology . . . . . . . . . . . . . . . . . . . . . . . 39

Animal bone NISP and MNI by period . . . . . . . . . . . . . . . . . . . . . 663

Percentage of MNI . . . . . . . . . . . . . . . . . . . . . . . . . 64

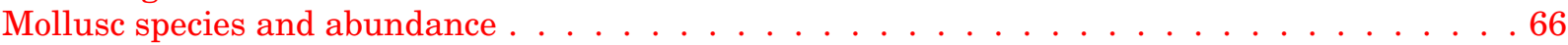




\section{Summary}

The report describes the results of excavations in 1981, ahead of development within the South Choir Aisle of St Giles' Cathedral, and subsequent archaeological investigations within the kirk in the 1980s and 1990s. Three main phases of activity from the 12 th to the mid-16th centuries were identified, with only limited evidence for the post-Reformation period. Fragmentary evidence of earlier structural remains was recorded below extensive landscaping of the natural steep slope, in the form of a substantial clay platform constructed for the 12th-century church. The remains of a substantial ditch in the upper surface of this platform are identified as the boundary ditch of the early ecclesiastical enclosure. A total of 113 in situ burials were excavated; the earliest of these formed part of the external graveyard around the early church. In the late 14th century the church was extended to the south and east over this graveyard, and further burials and structural evidence relating to the development of the kirk until the 16th century were excavated, including evidence for substantive reconstruction of the east end of the church in the mid15th century. Evidence for medieval slat-bottomed coffins of pine and spruce was recovered, and two iron objects, which may be ferrules from pilgrims' staffs or batons, were found in 13th/14th-century burials.

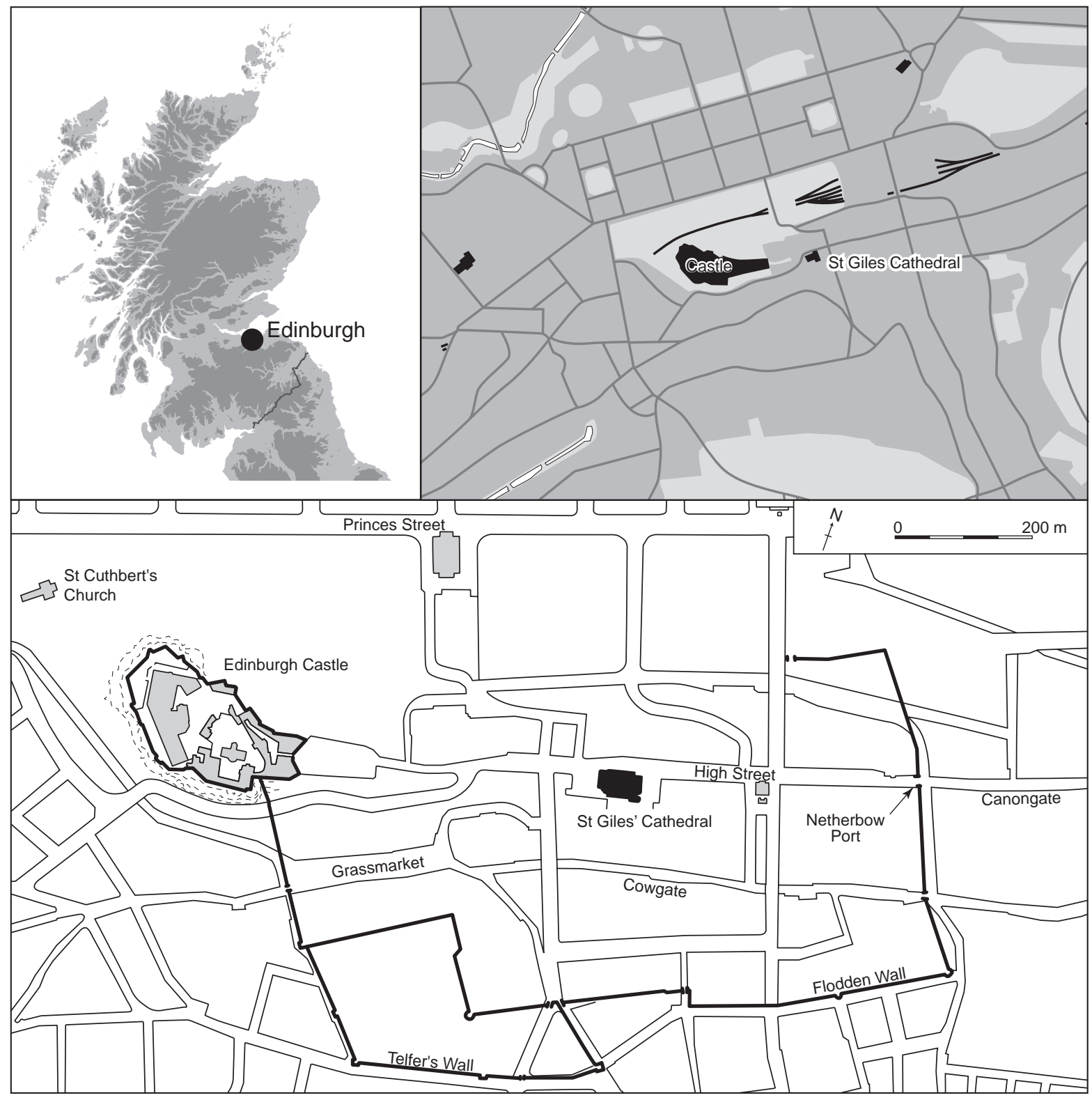

Illus 1 Site location 


\section{Introduction}

St Giles' Cathedral lies the heart of Edinburgh's medieval Old Town and, as the parish kirk since the 12 th century, has dominated the urban and religious landscape of the burgh for almost a thousand years (illus 1; illus 2). Little structured archaeological investigation had been carried out, either inside the church or in its immediate environs, until 1981, when plans for the construction of a staircase in the South Choir Aisle leading down to rooms below offered opportunity for detailed archaeological excavation.

At the invitation of the Minister and Kirk Session of St Giles', excavations (Holmes 1981), in advance of the construction of the new staircase, were directed by Nicholas Holmes on behalf of Edinburgh City Museums and Galleries, and financial support was provided by the Scottish Development Department (Inspectorate of Ancient Monuments) and by the
St Giles' Renewal Fund. The results of this excavation, and the finds from it, form the bulk of this report.

In addition, in the years while the report on these excavations was in preparation, a number of smaller investigations were carried out. Later in 1981, a limited excavation was carried out in the South Choir Vestry below the South Transept by Peter Raisen and Derek Hall (illus 3). During the early 1990s, several small interventions below the floor of the cathedral and outside the northern side of were either carried out directly or monitored by staff from the City of Edinburgh Council Archaeology Service (illus 3) (Collard 1991; Johnston 1992; Collard 1993). While these areas were small, they have provided useful supplementary archaeological and topographical information about the medieval development of the site of St Giles'.

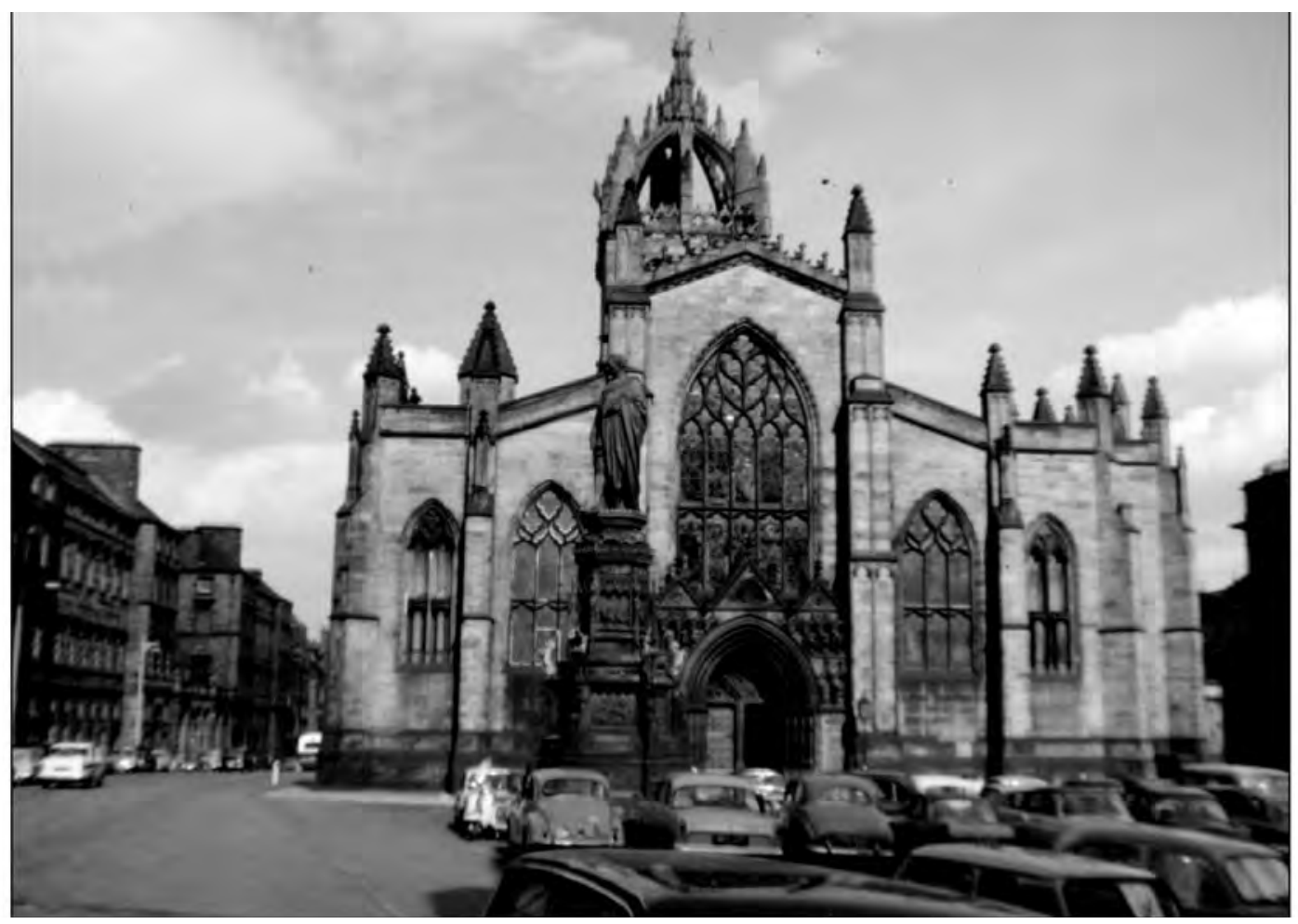

Illus 2 St Giles' Cathedral, Edinburgh, from the east 


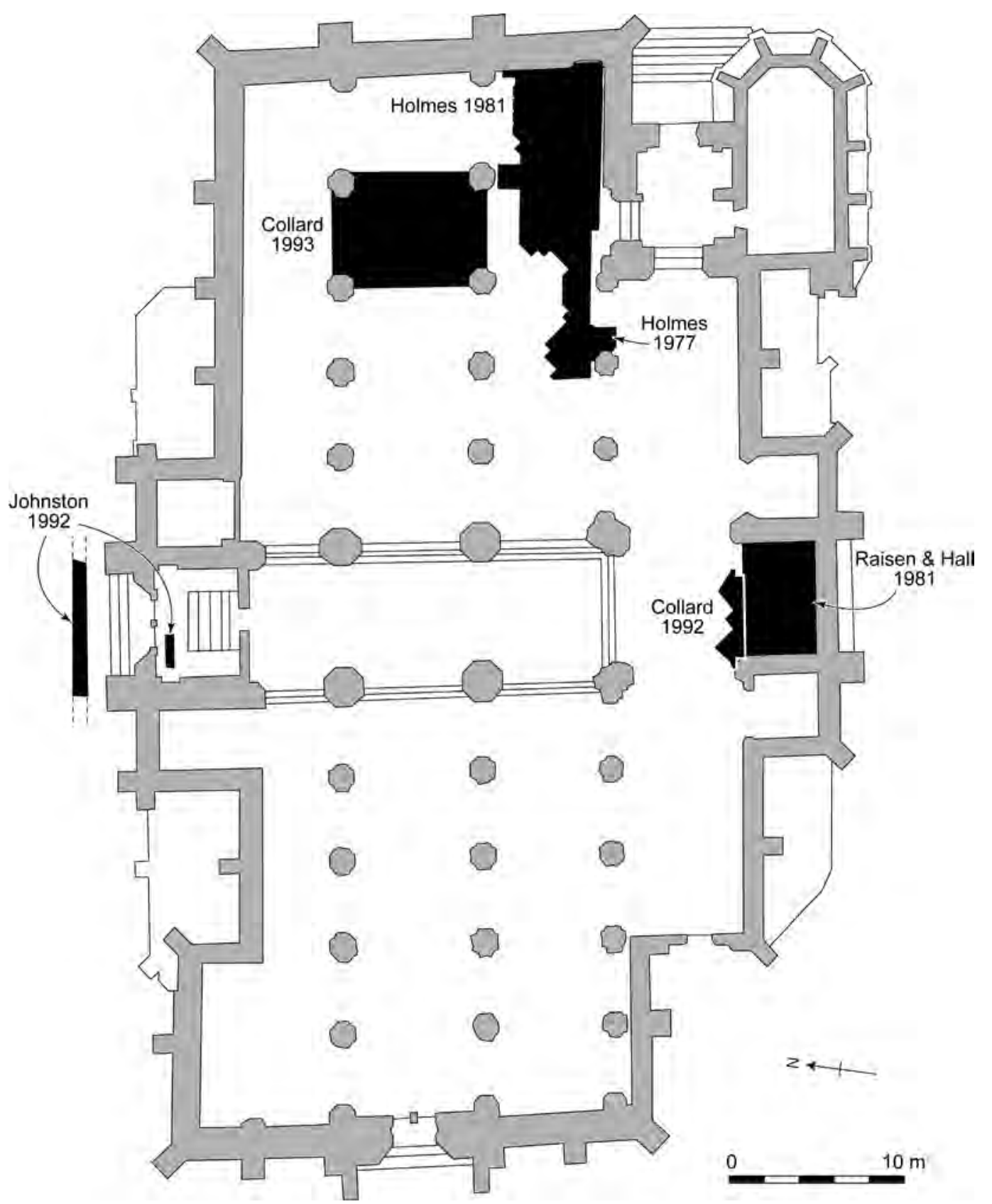

Illus 3 Location of archaeological investigations, 1977-93 


\section{Historical Background}

(derived from Gifford et al. 1984, 102-18; Addyman \& Kay 2001, 8; Brown 2001, 11-15, figs 6-18)

\subsection{The church}

It is generally accepted that St Giles' was the parish church of the royal burgh of Edinburgh from the 12 th century, that it was founded during the reign of Alexander I (1107-24) or David I (1124-53) and that it was newly built on its site. No trace now remains of the form of the Romanesque church which was probably begun soon after the founding of the burgh around 1130, and certainly before 1178 , the earliest documentary reference. It has been suggested that this early church occupied the area now covered by the western part of the current building, with a simple aisleless nave terminating in an apsidal east end on the site of the later crossing, or alternatively it was a two-cell structure with an apsidal east end to the chancel extending further to the east.

The church was burned during the English attack on Edinburgh in 1385 and the contract for the addition of new chapels in 1387, the earliest documentary source for building work at the church, reveals that the nave had then, as now, five bays and was aisled; it stood to the west of a central tower with north and south transepts which did not project beyond the aisles of the nave or the Choir. The Choir itself is likely to have been completed by 1419 , when the Town Council made a first, unsuccessful, application for the church to be granted collegiate status. In 1467 a second
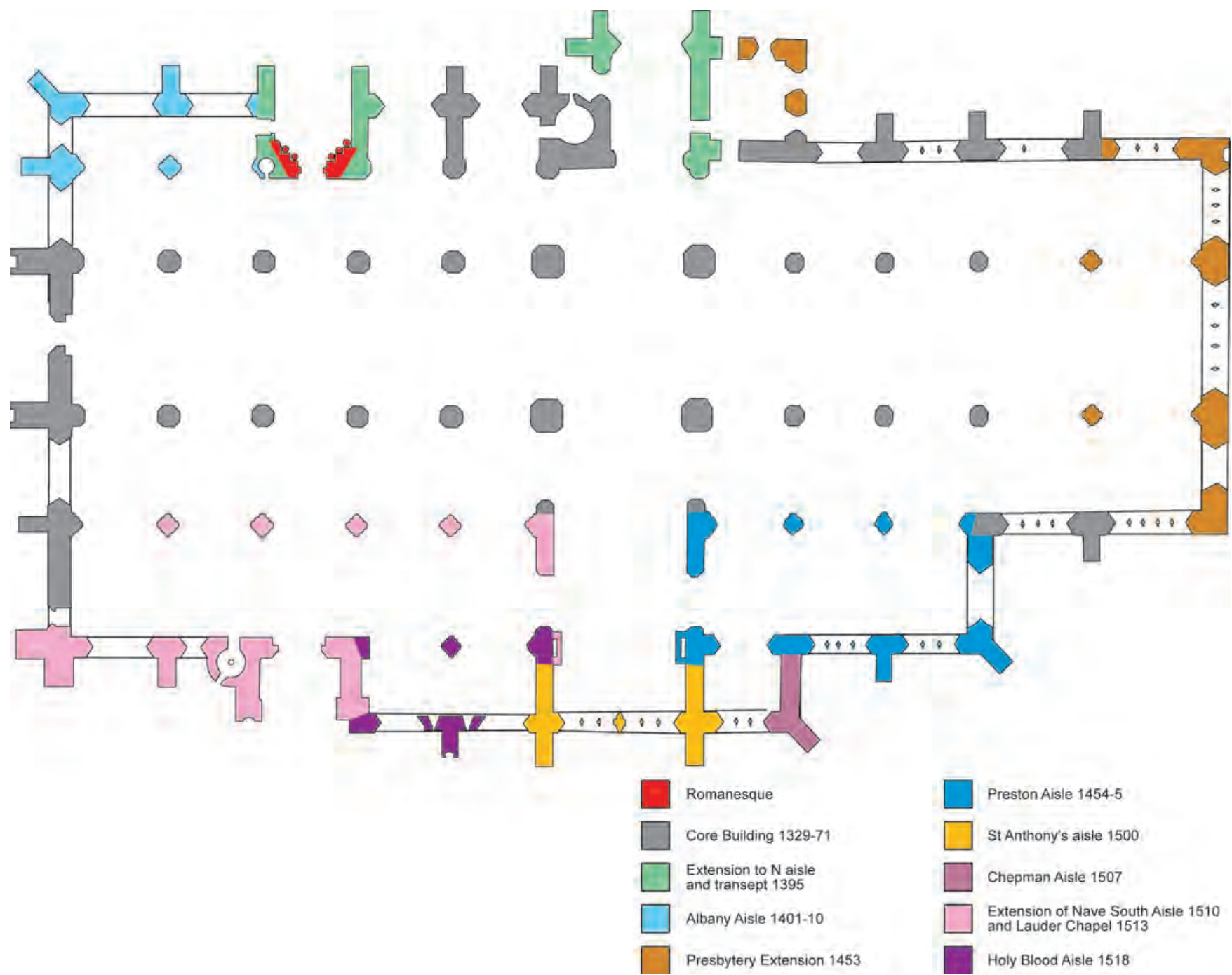

Illus 4 Schematic phased plan of the development of the medieval church (after Addyman \& Kay 2001) 
such petition was successful, and it is known that by then the Choir had been remodelled. Heraldic evidence suggests that this took place from $c$ 1453. It was formerly believed that the remodelling at this time took the form of the addition of a complete extra (fifth) bay at the east end, as well as of a clerestory over the central aisle, but the excavation in 1981 revealed the former not to be the case (see below).

At various times over the late 14th, 15th and early 16th centuries, chapels and aisles were added around the basic form core on both north and south sides (the 'complete' medieval church is shown in illus 4 as a phased plan of development). After the Reformation, the church was stripped of its internal screens and furnishings, and may have become a single open space, with the exception of the westernmost three bays of the nave, which provided accommodation for the Town Council, supplementary to the Tolbooth. The church was subsequently sub-divided in different forms over the 16th and 17th centuries, before all partitions were finally swept away in 1879 . The area of the Choir itself was relatively unaffected by the erection and removal of various partitions within the church in the 16th and 17th centuries, but it did not escape some effects of the two 19thcentury 'restoration' campaigns, by William Burn in 1829-33 and by Hay and Henderson from 1871 to 1883 .

The church now in existence is of late Gothic form; the core is a crossing with a bell tower above, an aisled nave of five bays, transepts of one bay and a presbytery of five bays.

\subsection{The parish cemetery}

For more than 450 years, St Giles' served as the parish burial ground for the whole of the burgh, with burials inside the kirk for the wealthy and privileged, and outside for the greater part of the population. Now completely hemmed in to the south by the later buildings of the Law Courts and Parliament House, it is difficult to visualize the scale of the medieval kirkyard which, at its greatest extent, covered almost 0.5 ha. The church originally stood at the top of a substantial open plot stretching down to the Cowgate valley, containing the house and garden of the Vicar (later the Provost) in the lower part and the parish cemetery immediately to the south of the kirk. The part of this site used for burial was extended twice in the late 15th century by the Provost of St Giles'. In 1477, because 'my parishioners ... when they die have no place of burial within or without the Church in my parish', he granted 'part of his garden lying contiguous to his manse... extending to the southern street commonly called the Cowgate' (BOEC, 208). In 1496, he again felt obliged to convey land to the church, this time the northern part of his manse and land (BOEC,
208). The depiction of the kirkyard on Gordon of Rothiemay's view of 1647 (illus 5) clearly shows the extent of the site (even after construction of Parliament House in the $1630 \mathrm{~s}$; also see illus 6 , William Edgar's Map of Edinburgh 1742).

Later building works have uncovered burials, some in coffins, across the full extent of the cemetery. During the construction of the Thistle Chapel in 1910 , a wall, 3ft $(0.90 \mathrm{~m})$ thick was uncovered, running north-south towards the southern side of the church; this was interpreted as the original east wall of the kirkyard. Uncoffined burials were also excavated, $c 1.25 \mathrm{~m}$ below the level of Parliament Square (Inglis 1909, 227, fig 1).

In 1562, Queen Mary conveyed the lands of the Greyfriars to the Town Council to be used as a public cemetery, and burial at St Giles' seems to have gradually declined, until the construction of Parliament House and the levelling of Parliament Square in July 1639 brought an end to use of the burial ground.

Within the church itself evidence for pre-Reformation burial is well-documented by accounts of the discovery and removal of skeletons from the church. The density of use is confirmed by a report in The Scotsman from Friday 28 June 1872 which reports an early example of archaeological research and observation as part of the restoration programme then in progress:

During yesterday workmen were engaged in making a series of openings in the floor of the High Church, with a view if possible, to determine whether or not any crypt or vault exists under the building.

In the course of yesterday's digging, a large quantity of human remains was turned up. Indeed it was made manifest that the whole area of the church is charnel house crowded with the relics of humanity.

For the most part the remains appear to be at a depth of two or three feet and those found in the upper stratum had all the appearance of having been disturbed at some distant date ... In two or three places fragments of coffins were discovered but these were mostly at a greater depth than the loose bones, and, as far as we observed, confined to the east end of the church.

In only one case were the bones of a skeleton found in such a position that they had never been disturbed. This was at the bottom of a pit fully four feet deep, sunk near the north-eastern corner of the area. In close proximity to the bones were traces of a coffin, and it seemed as if the body in question had been the lowest of several which had been buried one over the other.

From the half dozen or so of pits opened yesterday there were taken about a couple of cartloads of skulls and miscellaneous bones.

During the course of the restoration works by Chambers and Hay, there are several reports of such discoveries. In the Choir in 1873: 


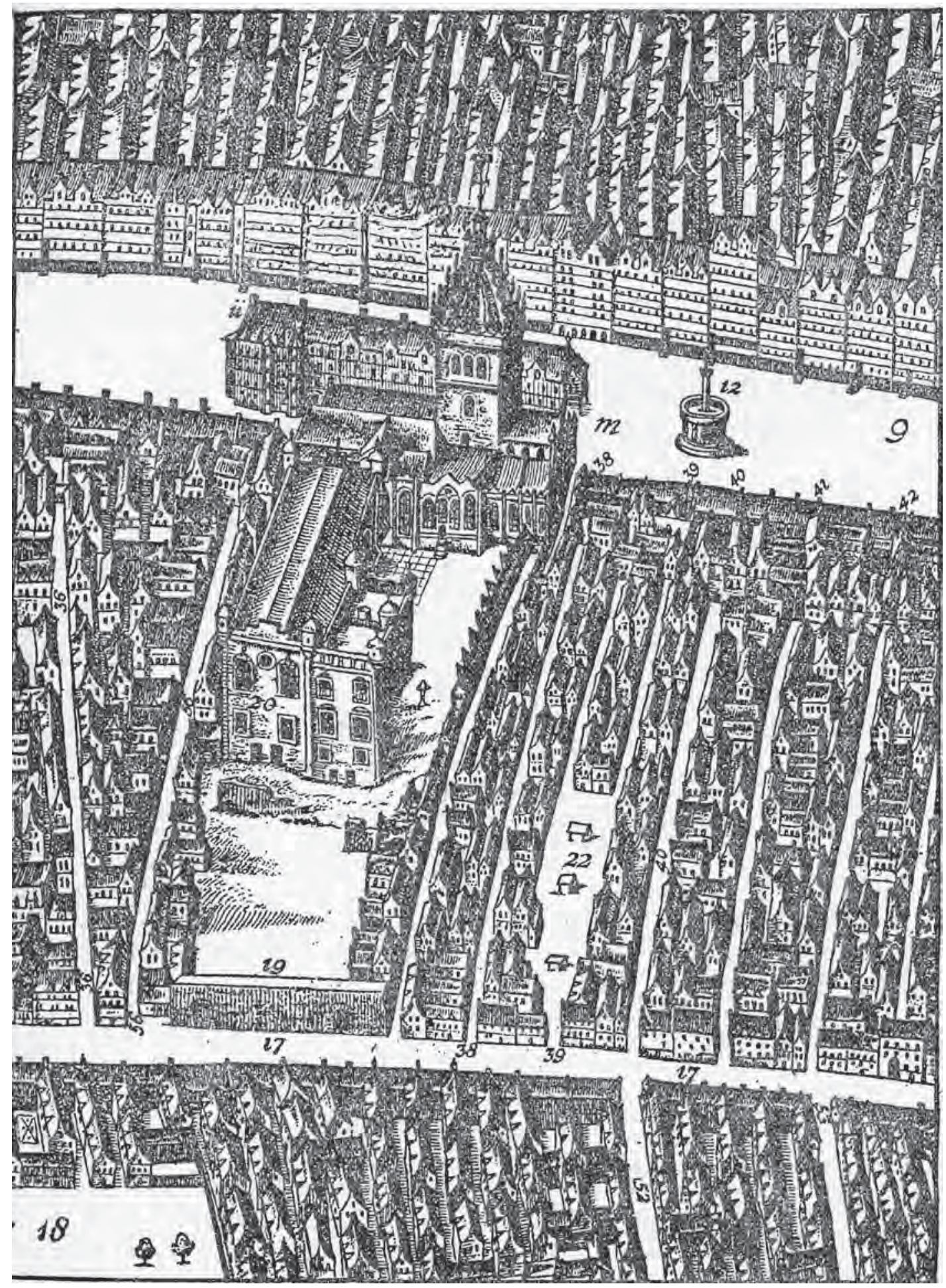

Illus 5 St Giles' Cathedral, Edinburgh as depicted on Gordon of Rothiemay's Bird's Eye View of Edinburgh, 1647

... the floor was trenched to a depth of several feet. No vaults were discovered but there was an immense quantity of human remains ... A large number of large grave-stones which had served as pavement, on which the professional devices of craftsmen were rudely carved (Chambers 1888).

In the Preston Aisle, in 1879, 'By the lifting of the floor a hideous scene of decaying mortal remains was disclosed ... (Chambers 1888)' and, in 1880, in the South Transept and the adjoining aisles to the west:

... the trenchings and excavations that took place over the floor of the southern aisles need not be particularly described. The quantity of bones dug up was immense, the whole probably amounting to five tons in weight (Chambers 1888). 


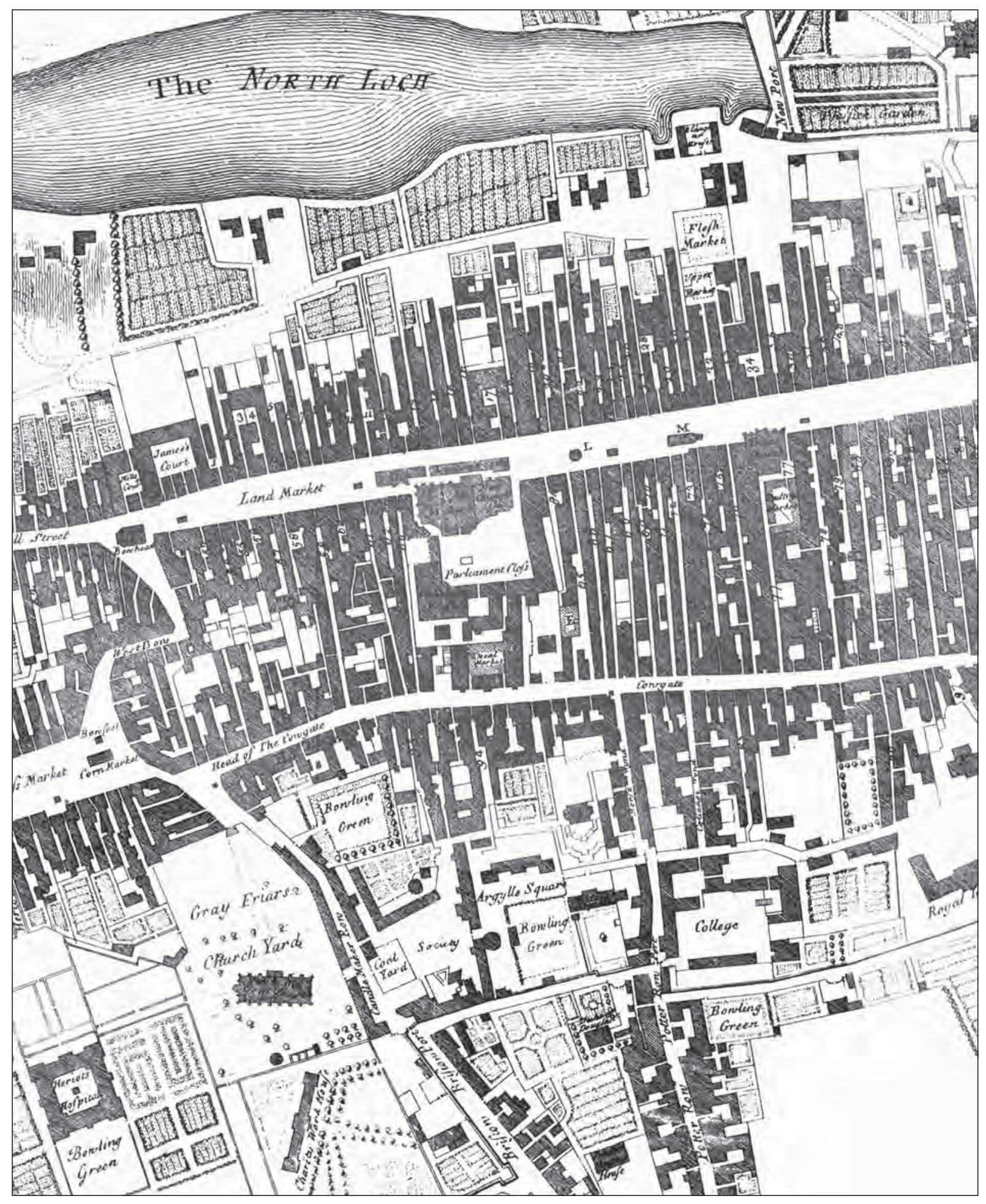

Illus 6 St Giles' Cathedral, Edinburgh as depicted on William Edgar's Map of Edinburgh, 1742

\subsection{The hospital of St Giles'}

There are references to a hospital within the cemetery of St Giles' during the 16th century. It was first mentioned in 1541 , then in $1544 \times 1547$ when it was burned by the English and again in 1566 when a charter describes it as being ruinous and in need of repair. It has been suggested that this foundation was only a residence for the provost and curate of St Giles'; however, this view is considered inaccurate by some (Cowan \& Easson 1976, 176). The hospital is believed to have lain in the area between the south side of the church and the current buildings of the High Court to the south, although no physical evidence has been recovered and the type of institution it served is unknown (though see Discussion below). 


\section{The Archaeological Investigations}

Throughout this report, excavated contexts are referred to by the prefix $C$, skeletons by SK and special finds by SF. Contexts from areas other than the South Choir Aisle excavations are also prefixed by the code ESG and the year of investigation, or ECV for the 1981 excavation in the Choir Vestry.

For the main excavations in the South Choir Aisle, four broad chronological periods of activity could be defined, three of which (Periods 1-3) date from the 12 th to mid-16th centuries. The excavated evidence included structural remains relating to the development of the medieval kirk, and a total of 113 in situ burials. Period 4 encompasses the centuries from the Reformation to the 20th century.

Within the report, these chronological periods are prefixed by P (ie P1-4). Within Periods 2 and 3, five discrete episodes of burials could also be identified as phases, and these are prefixed by BP (ie BP1-5).

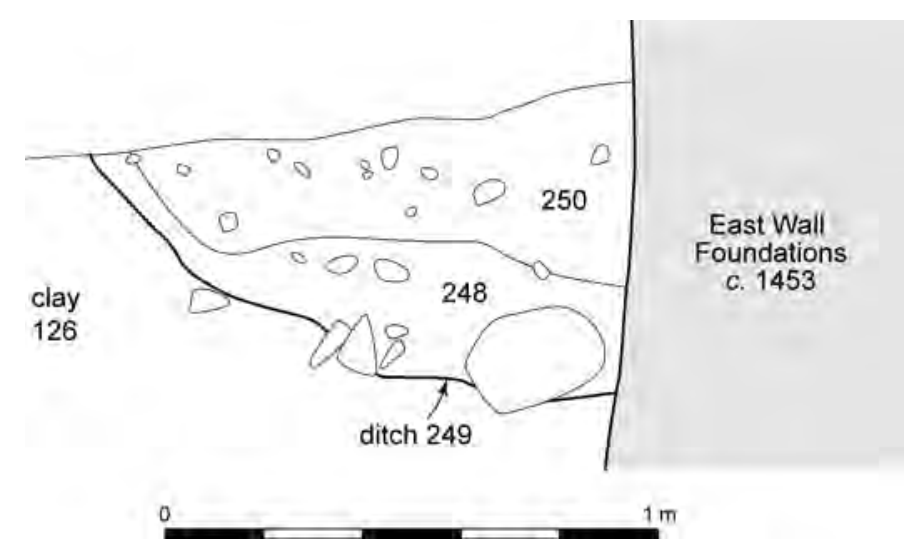

Illus 7 Section through Period 2 a ditch (C249)

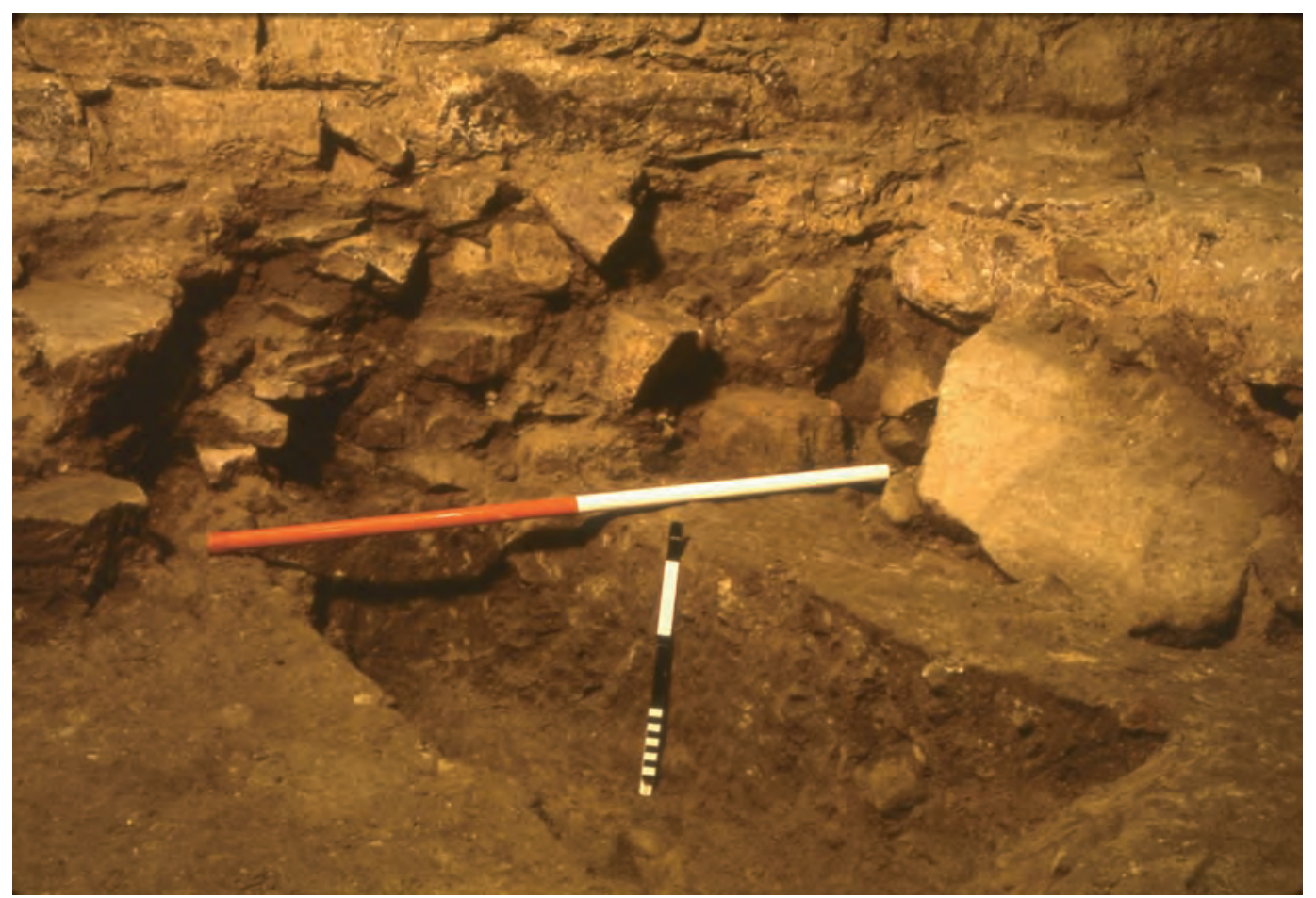

Illus 8 Section across Period 2a ditch (C249) and relationship with Period 3a east wall footings (C246) 


\subsection{Excavations in the South Choir Aisle, 1981}

\subsubsection{Period 1: ?12th century}

After the conclusion of the archaeological excavation, underpinning of the foundations of the east and south walls of the church was carried out by building contractors. During this work, two flat stone slabs with mortar between them were discovered by the contractors at a depth of some $5 \mathrm{~m}$ below the modern church floor level (at $c 84.35 \mathrm{~m}$ AOD), and almost beneath the standing east wall. As the conditions (a metre-wide trench, cut against the

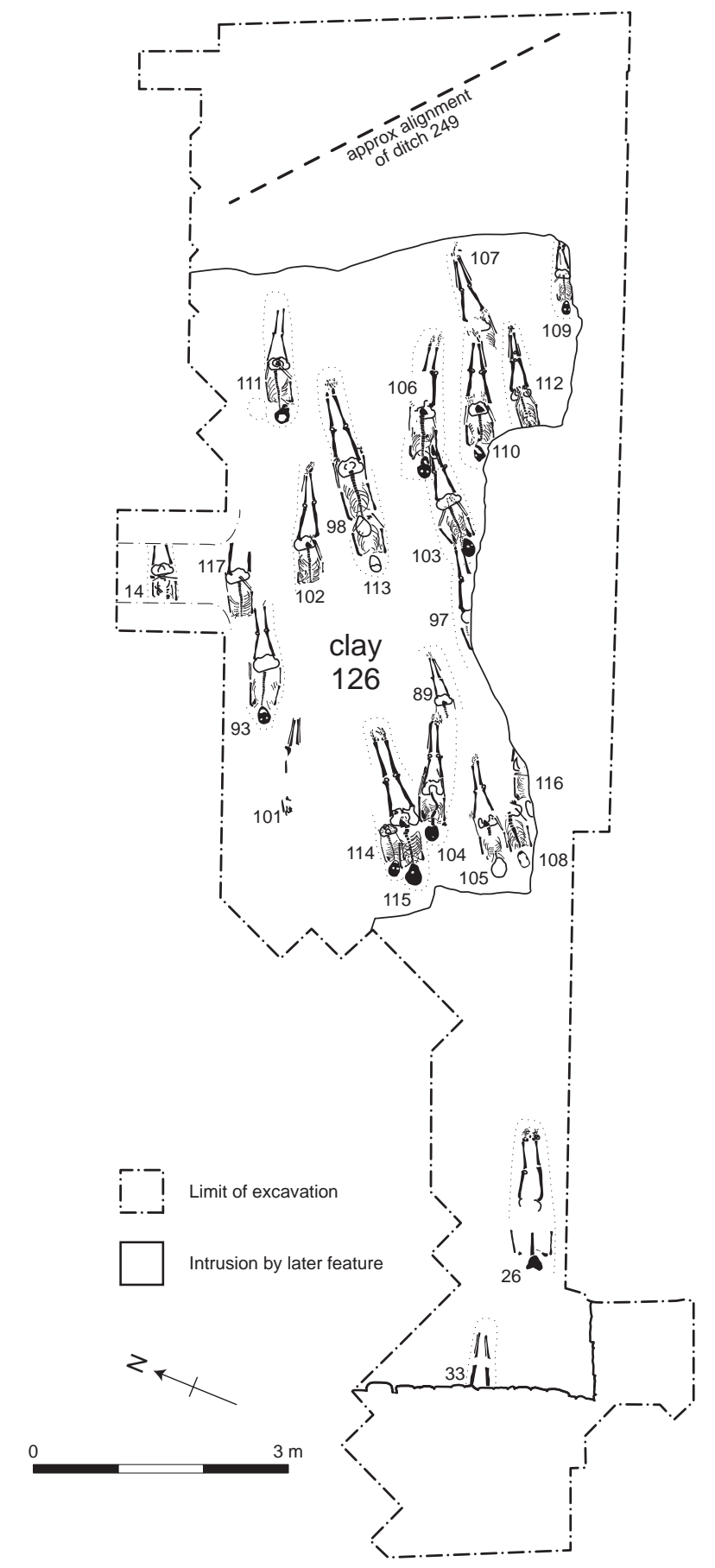

Illus 9 Period 2a, Burial Phase 1 inner face of the $\mathrm{E}$ wall of the church) were unsuitable for further archaeological investigation, it was impossible to record anything but their presence and that they were sealed by clay deposit (C126). No evidence to assist in dating the remains was recovered or observed.

\subsubsection{Period 2a: 12th/13th century (illus 7-10)}

Above the stone slabs was a deep deposit of boulder clay (C126), of varying depth across the site, with an upper surface sloping slightly downwards towards the south. Although the clay was excavated in a number of places to a depth of a metre at the conclusion of the excavation and was then considered to be natural, the presence of the mortared stones beneath it, and the clearly redeposited character of similar material encountered in the South Transept (below), show that it was in fact redeposited. No dating material was recovered from the clay.

The earliest feature post-dating this deposit was represented by the heel of a ditch (C249; illus 7), located at the bottom of the foundation trench of the original, late 14th-century, east wall of the present church building (illus 8 ). This ditch heel ran approximately north-west to south-east, emerging from beneath the existing east wall of the church, and ran across the base of the construction trench at a slight angle, distinctly different from the alignment of the existing church building (illus 9). It would be illogical to assume that this was dug and refilled at the time of the laying of the foundations, and it must therefore be regarded as the surviving portion of a ditch dug from pre-church ground level and partially destroyed by the digging of the construction trench for the earliest east wall of the extended medieval church. It did not share the same alignment as any of the later church buildings and its course would eventually have taken it outside the line of the robber trench to both north and south (beyond the excavated area). Its original dimensions were not ascertainable, as its eastern edge lay beneath the east wall of the church but at the point where it was sectioned it survived to a depth of $0.7 \mathrm{~m}$ and was filled with layers of hard grey clay and soft grey/brown clay, separated by a thin layer of yellow sand (C248). The surface of the redeposited boulder clay (C126) to the west of the ditch section was almost $2 \mathrm{~m}$ higher than the bottom of the trench. The excavator considered that, if allowance were made for the probable presence of soil deposits above the boulder clay, and for the surviving depth of the ditch heel, the ditch when dug must have approached $3 \mathrm{~m}$ in depth. However, the absence of such soil deposits within the excavated area may suggest a slightly shallower but still substantial ditch, $c 2.70 \mathrm{~m}$ deep and of considerable width.

The redeposited boulder clay (C126) formed the matrix for the earliest sets of excavated burials, totalling 44 (illus 9). Of these, 15 were definitely assignable to the first phase of burial (BP1) of the cemetery, and were cut directly into the surface of the 


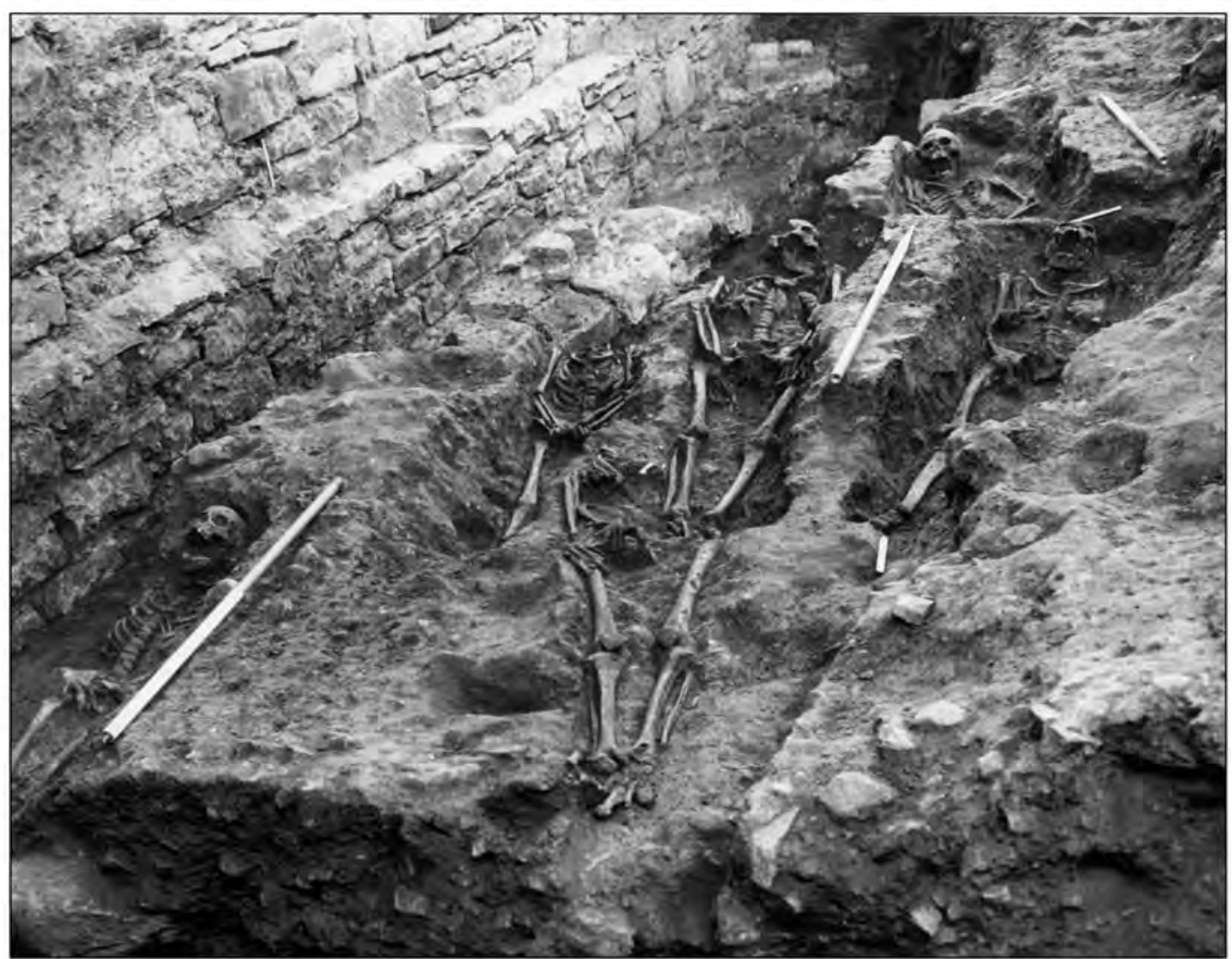

Illus 10 Burial Phase 1 graves cut into clay platform (C126), looking west

boulder clay, with no evidence for any accumulated or deposited soil or other material over the upper surface of the clay (illus 10). Two alignments were discernible within the burials: one, shared by most of the burials, was at right angles to the line of the ditch (C249); the other was that of the church building.

The fills of the graves of this early phase were sealed by a thin layer of soft, light brown silt (C175), containing midden material including East Coast White Gritty Ware pottery, some medieval tile and a small quantity of animal bone. This layer was only located in the southern (downhill) area of the site, particularly towards the south-east, and on its surface was an area of stone chippings apparently forming a path (C196), again apparently aligned at right angles to the ditch.

A further 19 graves (BP2; illus 11) were then cut into the boulder clay from above $\mathrm{C} 175$ and $\mathrm{C} 196$, and in the area to the north, where these layers were not found, were a further ten graves which could fall into either phase, and which have been assigned to Burial Phases 1-2. Again all these graves had one or other of the two alignments identified in BP1, with those aligned on the ditch again the majority.

\subsubsection{Period 2b: 13 th/14th century (illus 12; illus 13)}

All these deposits and graves were sealed by substantial deposits of dark loamy soil, the upper limits of which, as excavated, formed a more or less horizontal surface across the site. It was clear, however, that this had been produced by levelling at the time of the construction of the late medieval church in the 14th century, and the original upper level and surface topography of these deposits is unknown. There were clear variations in the character of the deposits but it was clear that they formed a single episode of landforming and make-up in level of the cemetery area. A great deal of midden material (C84) was found incorporated within the make-up at the eastern area of the excavated trench and a rather lesser concentration at the west end (C39). In the central area, the soil was almost completely without finds (C31). These variations, and the clear presence of other discrete deposits within the excavated area in this period, demonstrate that the artefactual and faunal material recovered, including more than 200 sherds of medieval East Coast White Gritty Ware, fragments of medieval floor tile and a piece of a late 13th- to mid-14th-century glass vessel, should be considered as imported to the site as part of a clear episode of deliberate raising of the ground level in this area.

Into this deposit were cut the graves for 30 burials (BP3, illus 12; illus 13). As with the graves of BP1 and BP2, these burials showed slight variations in alignment, but most skeletons again were apparently aligned on the ditch as the dominant feature.

Two burials (illus 13, SK31 and SK43), which lay immediately adjacent to each other, were notable for the presence of identical unusual finds within the 


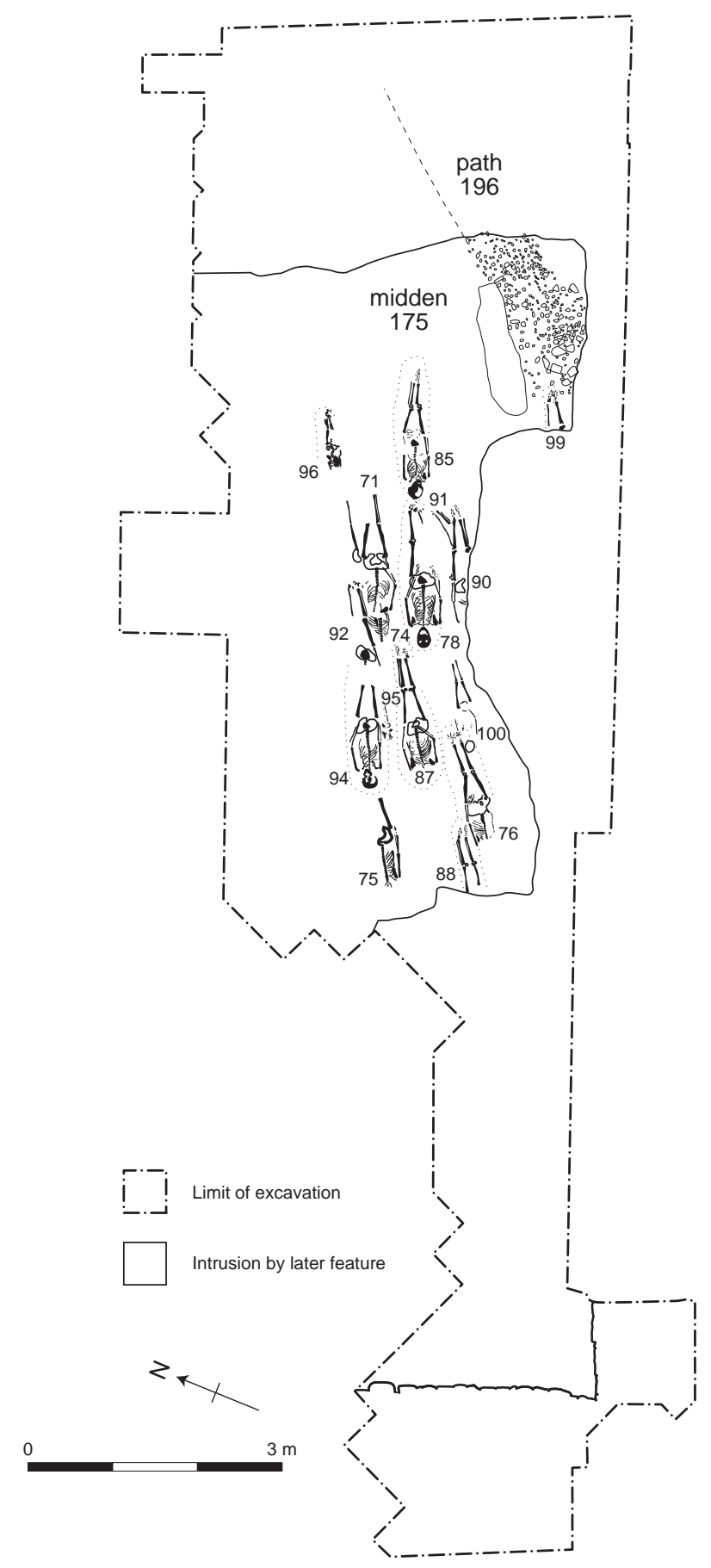

Illus 11 Period 2a, Burial Phase 2

grave fills. Each contained a wooden baton within the grave fill, in direct association with the body; for SK31 (a female), it lay on the pelvis (illus 14), perhaps originally held in the hands; the baton with SK43 (a male) lay on the feet (illus 15). SK31 was contained in a wooden coffin, but SK43 was not.

The earliest stone-built feature within the excavated area, dating from before the extension of the church, was part of a mortared wall (C24) running north-south at a point just to the east of the junction of the third and fourth bays of the later aisle. Its width was $c 0.6 \mathrm{~m}$, and only $c 0.5 \mathrm{~m}$ of its length had survived later demolition and robbing.

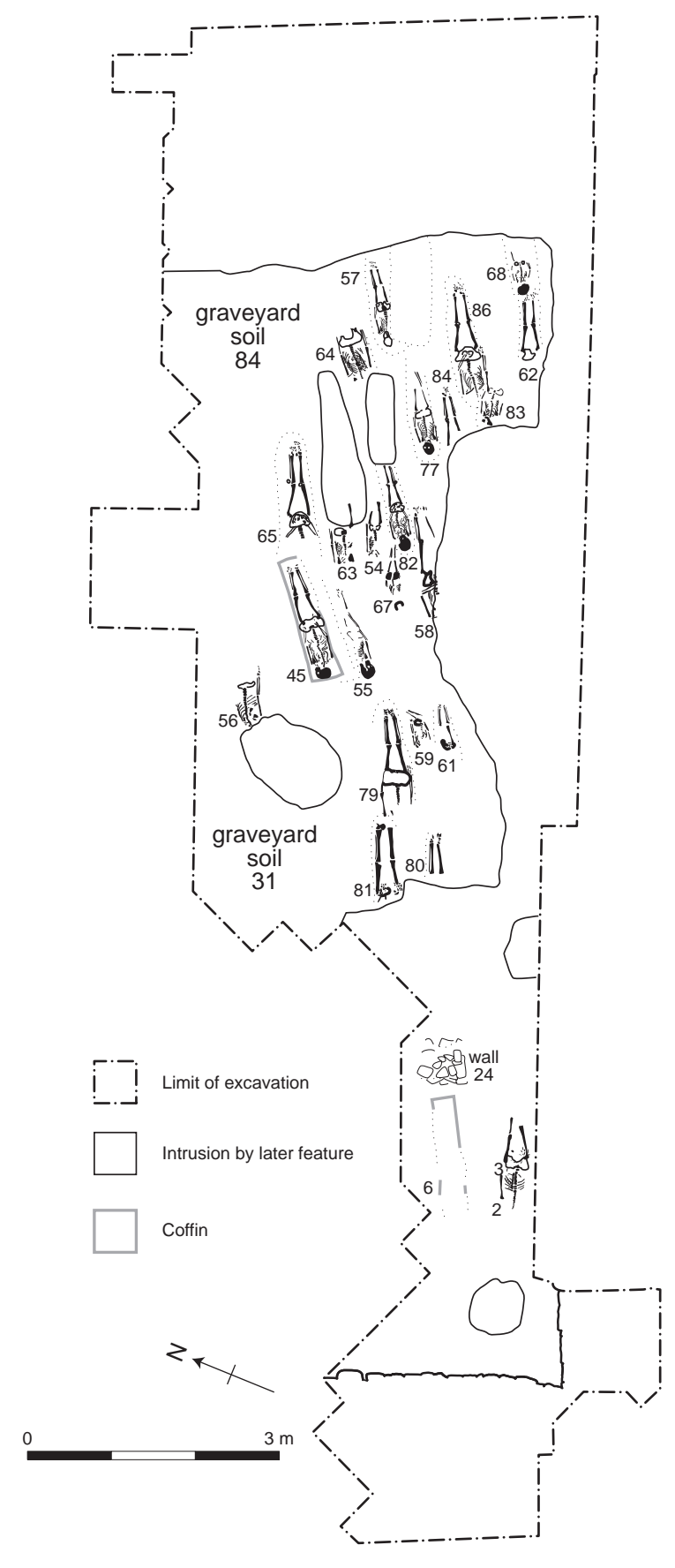

Illus 12 Period 2b, Burial Phase 3

The foundations of the later, south wall of the aisle butted up against its east face, with the remains of the earlier structure incorporated into the foundations at that point. Burials dating from after the construction of the church (Period 3 below) had been cut through by a trench for the robbing of wall C24.

\subsubsection{Period 3a: late 14th to mid-15th century (illus 16-20)}

Sealing all the burials and deposits of the cemetery of Period 2 were deposits associated with the extension 


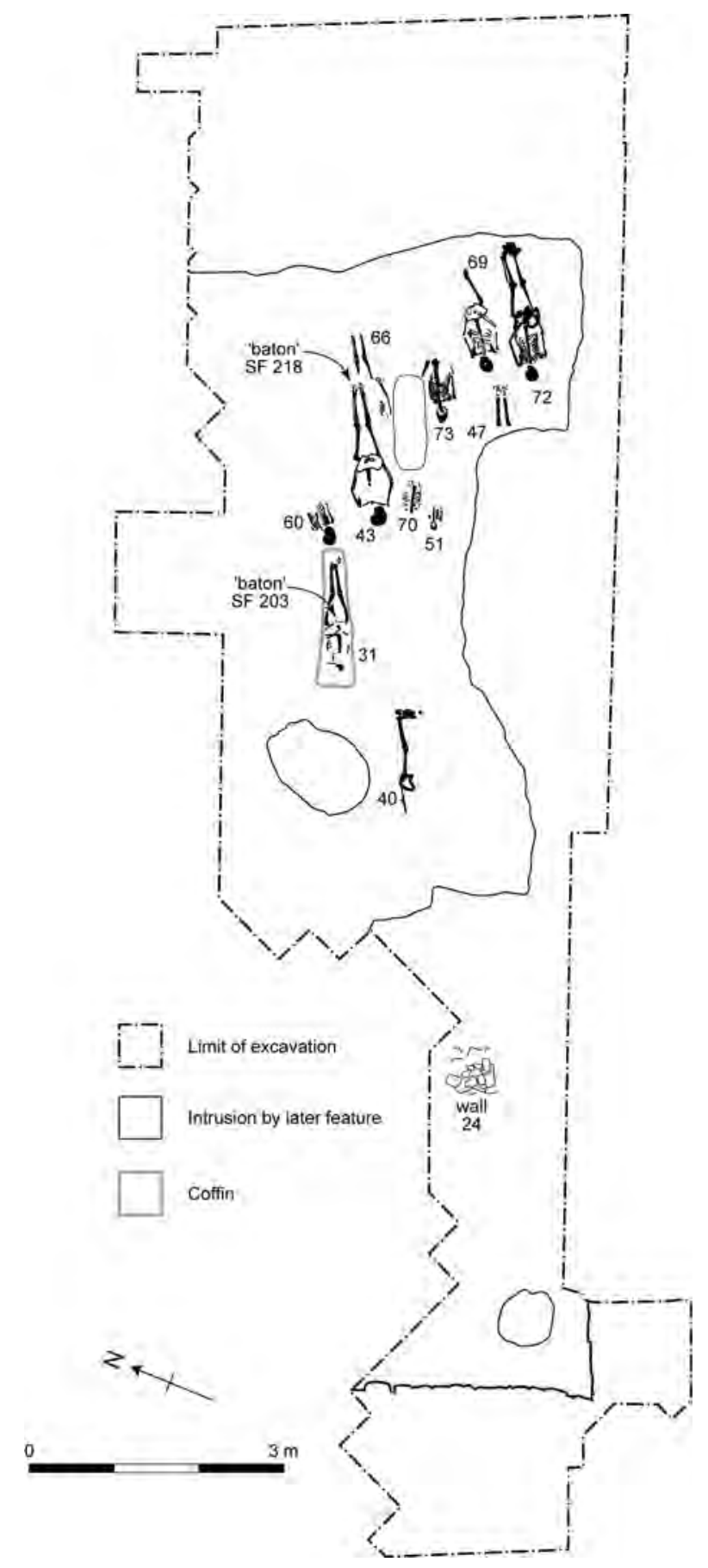

Illus 13 Period 2b, Burial Phase 3

of the medieval church to the south and east. These deposits had suffered a considerable amount of disturbance as a result both of later alterations to the church building and of the insertion of burials within the church, beneath the floor of the aisle. As far as could be deduced, the sequence of events and associated features/levels was as follows.

The foundations of the south wall (C149; illus 16) of the Choir Aisle were exposed at one point only in the main excavation, for reasons of structural safety. The foundation trench (C151) cut through the deposits of Period 2 and was $c 0.65 \mathrm{~m}$ wide at the top at this point, tapering to $c 0.30 \mathrm{~m}$ at its base, with a surviving depth of $c 1.10 \mathrm{~m}$. Four rubble masonry foundation courses projected $0.10 \mathrm{~m}$ from the face of the wall above. The original south wall was also seen in a geotechnical trial pit in 1977 (shown as TP wall 3 on illus 17, and in section on illus 18).

To the east, the ditch (C249) must have been filled in at this period at the latest, because when the church was first extended to include this area, its east wall stood approximately $2.5 \mathrm{~m}$ to the west of its present position, directly over the fill of the ditch. The foundation trench (C9) for this original east wall of the south aisle extended $2.9 \mathrm{~m}$ westwards from the face of the later (current) east wall, tapering inwards at the west face to $2.5 \mathrm{~m}$ at its base, which lay $c 2.0$ $2.5 \mathrm{~m}$ below the level from which it had been cut. At the bottom of the trench, only the lowest foundation course (C246) of the wall had survived intact with its facing stones, although above this, in the south-east corner of the trench, a mass of stones, mortar and clay forming the wall core survived above foundation level (illus 19; illus 20). Pink sandstone blocks predominated in this structure, but there were also a few very large fragments of grey whinstone. Some of the large stones forming the western facing edge of the foundation course had been re-used from an earlier structure, including one with a face carved on one end. This carving had suffered some mutilation, but its large eyes and the surviving part of the nose identify it as a grotesque mask corbel of 12thcentury Romanesque work (see illus 45 below).

The western face of this original east wall corresponds exactly with the projected length of the original presbytery, using the bay width of the westernmost (third, fourth and fifth bays) of the rest of the aisle as the unit of measurement (this projection is shown on illus 17), confirming that the aisle was extended as a single planned event, at the same time as the rest of the Choir.

At the same time as the construction of this wall, when the extended Choir and Choir Aisle were first constructed, a moderately deep layer of soil (C10 and C22) had clearly been deposited across the excavated area before the floor was laid down to raise the level of the interior, presumably to match the existing level of the interior of the rest of the church. The exact original depth of this make-up, comprising imported loam with many stones, including building stone fragments, and hence the contemporary ground level, could not be established, as much had been removed or disturbed during 19th-century alterations to the building. C10 and C22 contained quantities of artefactual material which is presumed to derive from elsewhere in the burgh. The deposits also continued to have artefacts incorporated with them, as coins from the second half of the 15thcentury and 16th-century pottery were recovered from $\mathrm{C} 22$, a result of the continued reworking of the deposits during later phases of burial.

Within this newly extended church, the soil deposits represented by contexts $\mathrm{C} 10$ and $\mathrm{C} 22$ formed the matrix for burials of BP4, which included the earliest of those inserted within the church. A 


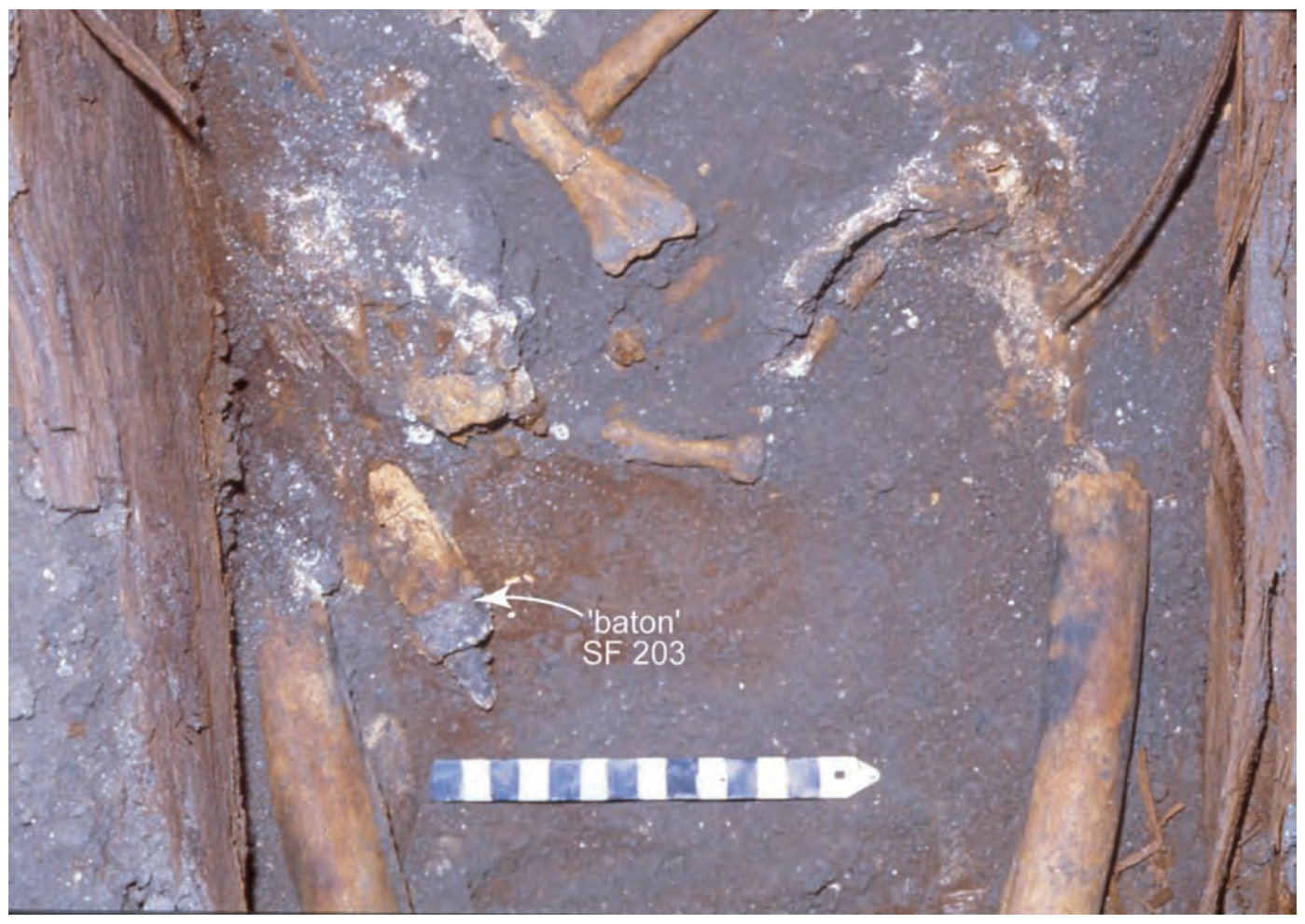

Illus 14 Skeleton 31 showing 'baton' on pelvis

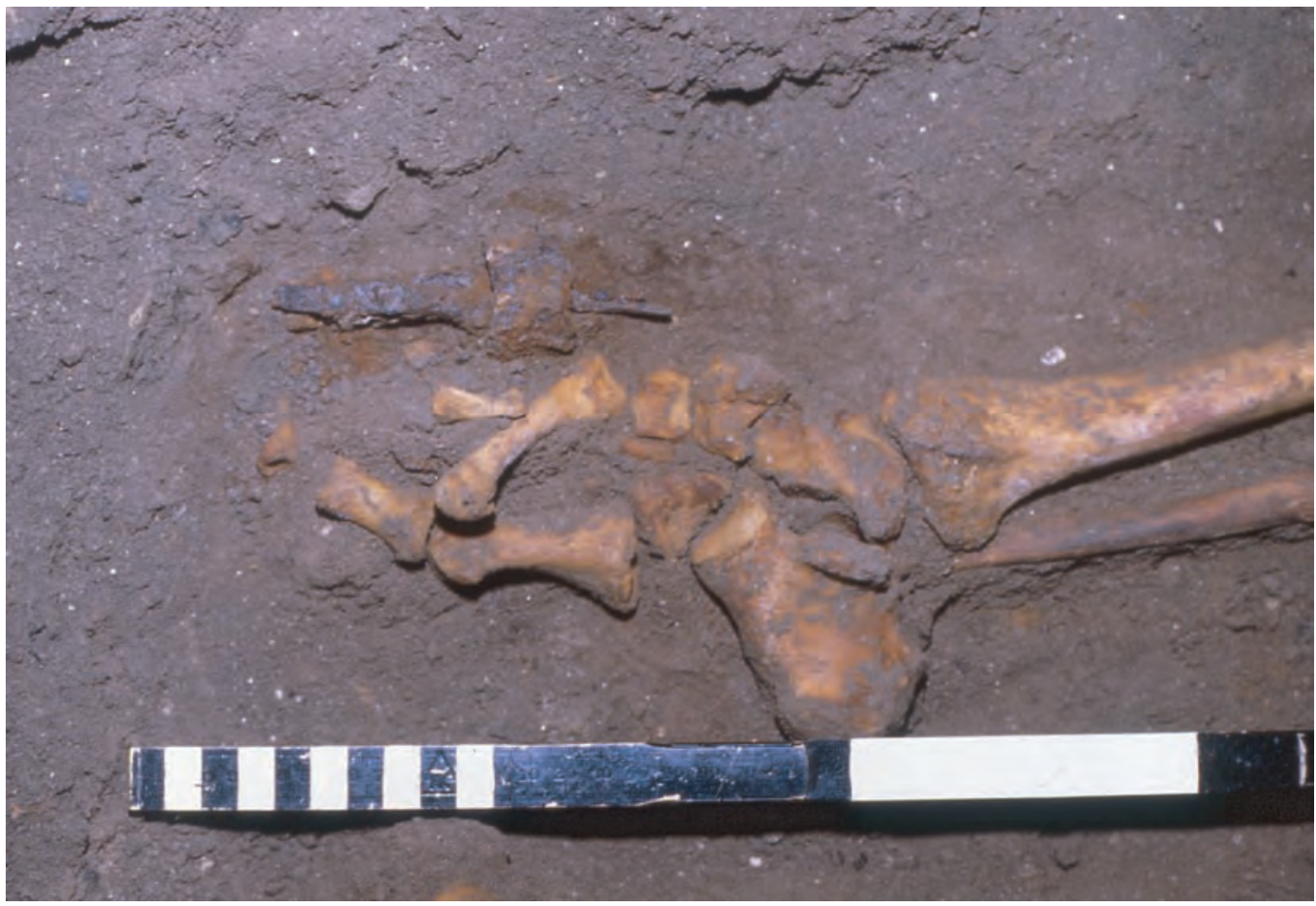

Illus 15 'Baton' in situ on feet of Skeleton 43

later burial phase (BP5, illus 21; illus 22) could be distinguished from BP4, but only where burials had been inserted into the backfilled material within the robber trench of the earlier east wall constructed in this phase. It seems certain that some of these BP4 burials were contemporary with these BP5 interments and, within reports elsewhere, $\mathrm{BP} 4$ is assigned to Period 3 in general.

All the burials inserted after the construction of this part of the church were aligned on the axis of the building, and in most cases they were interred in rows, with clear division and lack of intercut- 


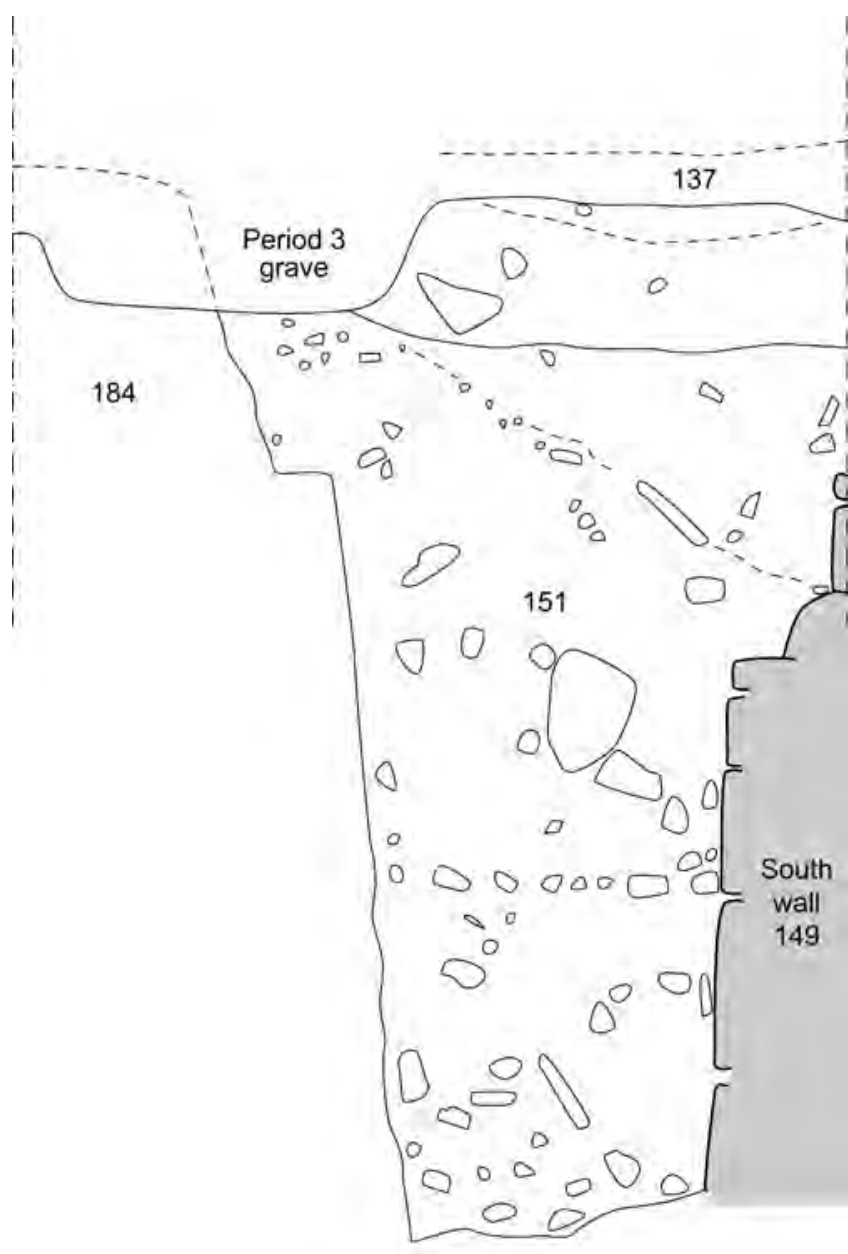

6)

Illus 16 Section through Period 3 a construction trench (C151) for south wall (C149)

ting, indicative of the marking of graves. One area centrally placed against the face of original east wall was clear of burials and this may indicate the site of an altar (illus 17).

A squarish stone slab (C52), located adjacent to the south wall near the west end of the third bay, is likely to have served as a plinth for a statue or monument. The slab measured $c 0.55 \mathrm{~m}$ square and $0.25 \mathrm{~m}$ deep and rested on a mortared rubble foundation. Its upper surface was $0.64 \mathrm{~m}$ below the level of the modern church floor, perhaps giving an indication of the level of the contemporary church floor.

\subsubsection{Period 3b: mid-15th century to the Reformation (illus 17; illus 18; illus 21; illus 22; illus 23)}

The original east wall (C246) was demolished and robbed down to the lowest levels of its foundations. In its lower levels, the primary fills of the robber trench comprised mostly loose clays with much

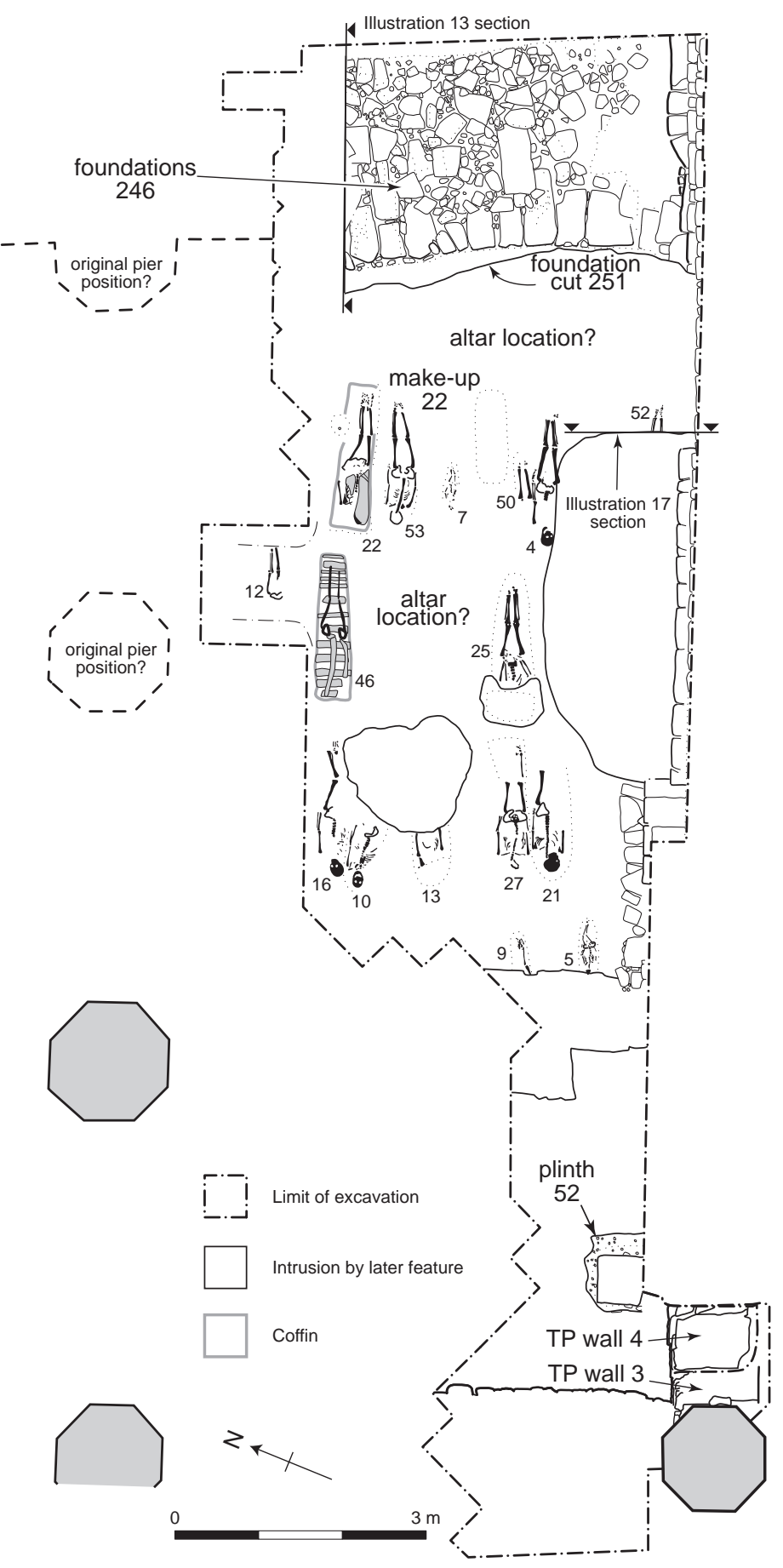

Illus 17 Period 3a, Burial Phase 4

fragmentary ashlar (C184, C244), while the upper fills comprised a mixture of soft fine sand, mortar and soil with clear tip-lines indicating infilling from the west side. Most importantly, a very worn billon penny of James I or II (1424-60) (see Section 10.3 Coins and Jetons, catalogue no 1) was found in the backfill (C231) of the robber trench. Although it is unfortunate that it has not been possible to date this item more accurately, it does provide a terminus post quem of the mid-15th century for this event. This rebuilding was associated with the enlargement of the two eastern bays of the aisle, which 


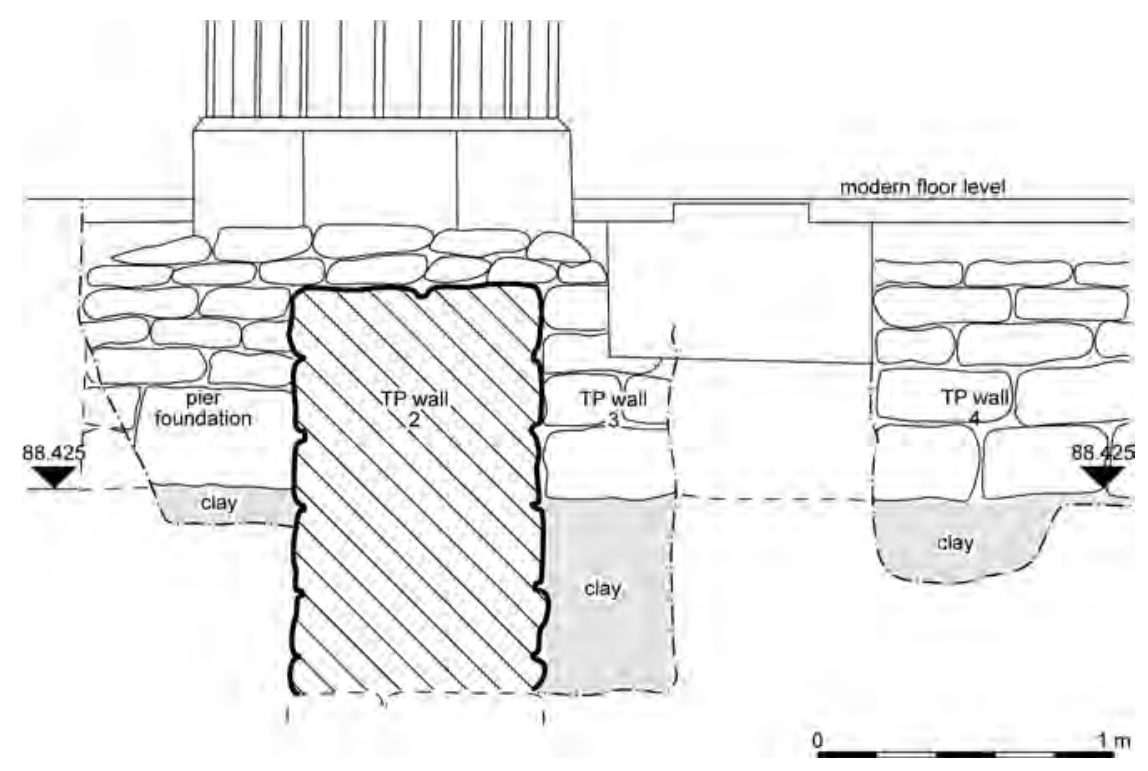

Illus 18 Section of 1977 trial pit TP4

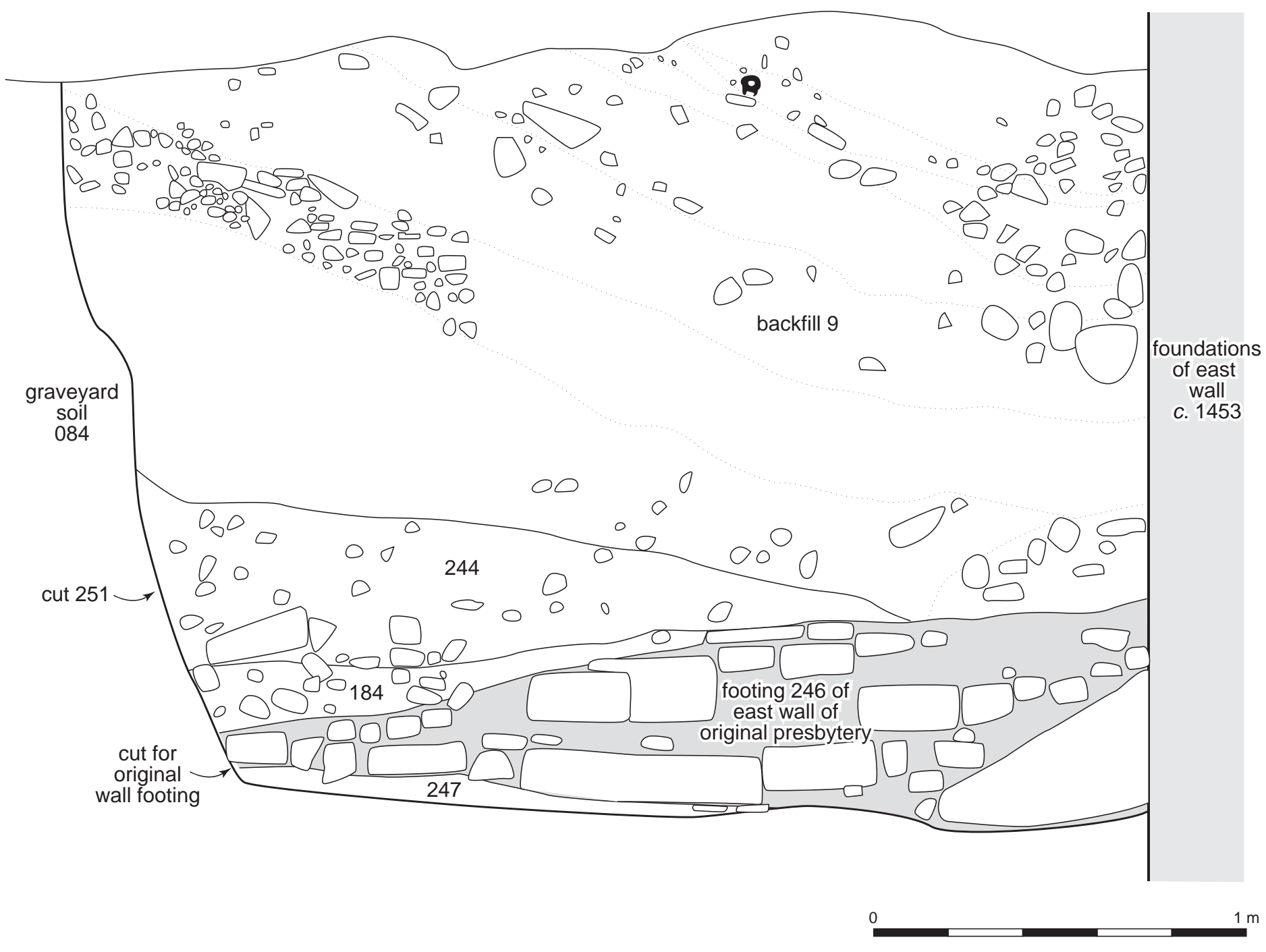

Illus 19 Section across robber trench (C251) of east wall (C246) 


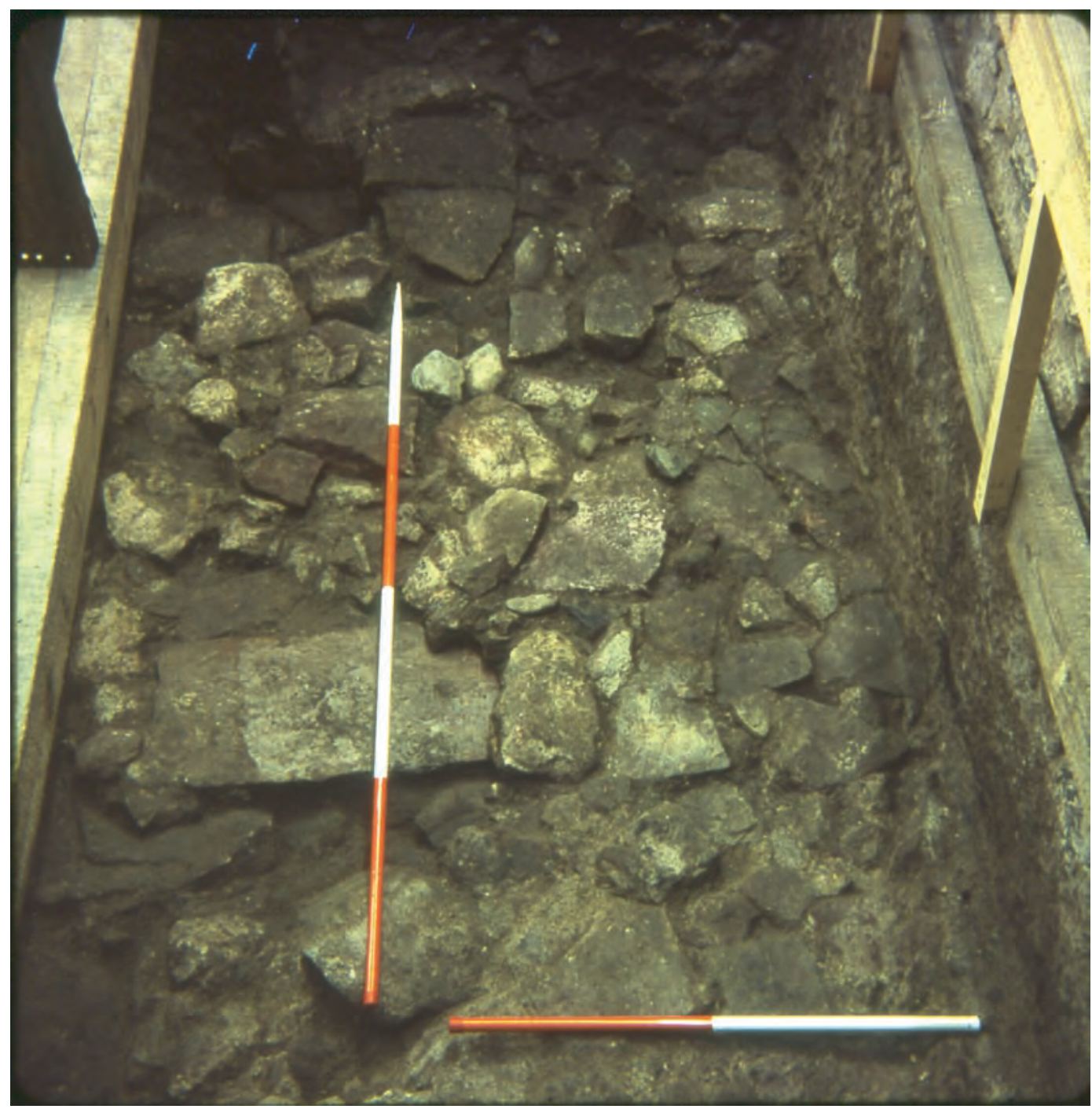

Illus 20 Footings of east wall of original presbytery (C246) in base of robber trench (C251)

were furnished with columns more elaborate than their predecessors which still stand in the bays further west. A date of $c 1453$ has been derived from the heraldry on the column capitals of the extended Choir and this fits well with the date of the coin.

The east wall was in fact moved only a small distance to the east, where it still forms the eastern wall of the kirk. The west face of the present east wall of the church overlapped and was founded upon the east face of the earlier foundation. A trial pit dug outside the church revealed that the bottom of the eastern part of the foundations of the present wall are set at a level almost $1 \mathrm{~m}$ below that of the western part, and $0.46 \mathrm{~m}$ below that of the original wall. (The bottom of the foundations of the first wall was located at $86.45 \mathrm{~m} \mathrm{OD}$; the top of this foundation below the west face of the existing wall at $86.98 \mathrm{~m}$ $\mathrm{OD}$; and the bottom of the east face of the foundations of the existing wall at $85.99 \mathrm{~m}$ OD.)

Cut into the uppermost fill of the robber trench was a discrete group of 14 burials (BP5), arranged as to form an undisturbed rectangular area measuring $c 2 \mathrm{~m} \times 1.5 \mathrm{~m}$ against the east wall and straddling the east-west axis of the aisle. This area again presumably marked the position of a pre-Reformation altar against the east wall of the aisle. To the west, within the body of the aisle, a clear space was visible within the arrangement of the burials of BP4 where no interments were made and this may also be interpreted as the possible position of an altar within the Aisle (illus 17; illus 21).

The construction of the Preston Aisle to the south of the Choir Aisle is conventionally dated to the same period as the remodelling of the eastern end of the church, $c$ 1454-55; this would have required demolition of part of the southern wall of the South Choir Aisle. Evidence for this lay beyond the scope of the main excavation but, in a geotechnical trial pit dug in 1977 (illus 18; illus 21), the stratigraphic relationship between the original southern wall (illus 21, TP wall 4) and the foundation (illus 18, TP walls 1 and 2) of the northernmost column of the entrance to the Preston Aisle was clear, with the foundation demonstrably later. Other evidence for structural works related to this phase of construction was recorded in the 1981 excavations in the form of two ashlar 


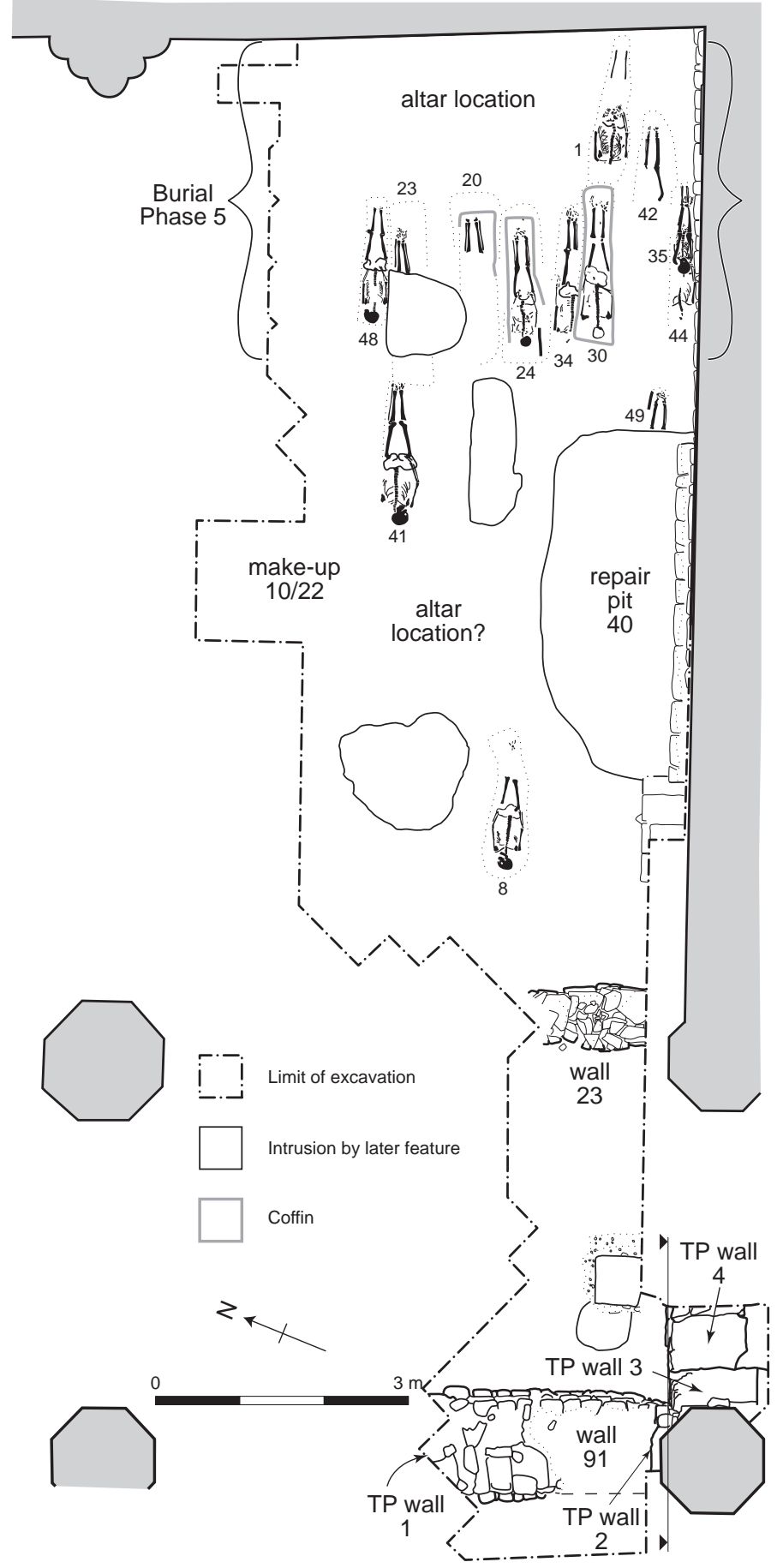

Illus 21 Period 3, Burial Phases 4 and 5

masonry walls (illus 21; C91 and C23) supported on mortared rubble foundations, which had been constructed between the pairs of columns of the Choir and the new opening to the Preston Aisle at the junctions of the second and third, and third and fourth bays of the Aisle. These walls clearly did not form part of the original construction of this part of the church, as their construction trenches were found to cut through Period 3 burials which were themselves demonstrably later than the construction of the south wall, and it seems probable that

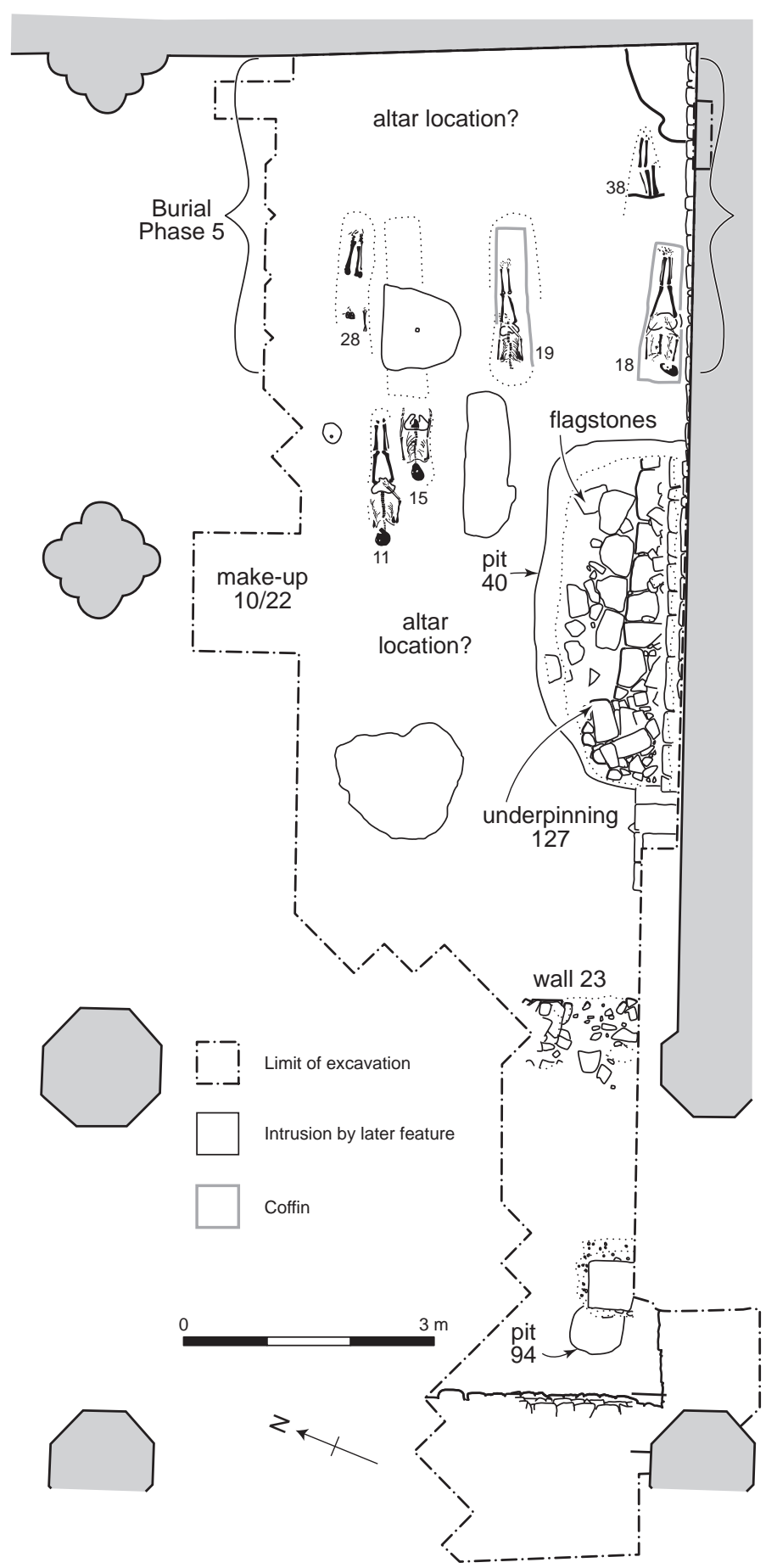

Illus 22 Period 3, Burial Phase 5

they were built as additional buttressing to the column foundations, below ground level, when the south wall was demolished in this area to allow for the construction of the Preston Aisle to the south. This theory is supported by the fact that no such foundation grid wall was considered necessary at the junction of the fourth and fifth bays, in which area the south wall was not demolished. Both stood to almost the level of the present church floor, suggesting that the floor in this area was at more or less its present level after the date of their construction. 


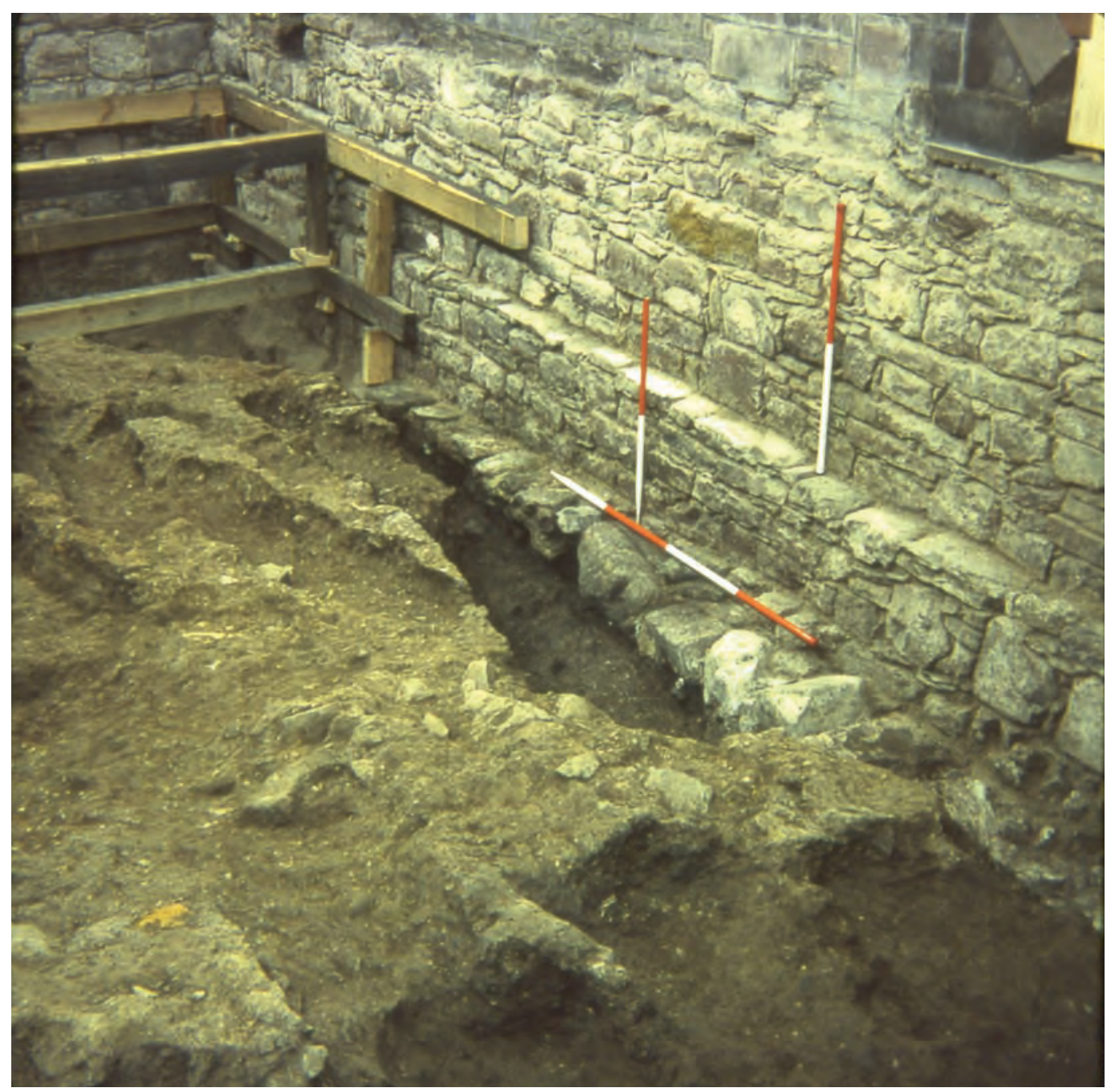

Illus 23 Underpinning of south wall in Period $3 b$

Subsequently, part of the south wall of the church appeared to have been underpinned at some stage (illus 23). A large pit (C40) had been dug adjacent to the wall beside the wall across the junction of the fourth and fifth bays, and within this pit an extra course of masonry had been inserted below the lowest foundation course of the wall, and a buttress of mortared stone $(\mathrm{C} 127 / \mathrm{C} 163)$ had been built at an angle against the foundations (illus 22; illus 23). There were also a number of flagstones at the bottom of the pit, which may have served simply as a solid floor for those employed in the underpinning. Evidence for the necessity of this underpinning could be seen in the form of cracks both in the wall above and in the roof of the aisle in this area. No burials had subsequently been inserted into the infill of the pit.

\subsubsection{Period 4: Reformation to 1981}

There was no evidence that burials were interred in the South Choir Aisle following the Reformation, and all the dating evidence recovered from the burials of Period 3 confirms this, with no datable material later than the mid-16th century. Most of the highest deposits overlying the Period 3 deposits below the modern church floor level were removed by contractors before the excavations commenced. These late deposits comprised dust and dry soil, with quantities of loose human bones, clearly disturbed when other burials had been inserted. Victorian brick-built heating ducts crossed the area at this level. Where small amounts of these late deposits were left on the site, they were found to contain fragments of plaster from the William Burn refurbishment of 1829-33, removed from the interior of the church during the 1879-83 restoration by Hay and Henderson.

A large area in the north-west corner of the site had been subject to disturbance at a relatively late date, including the digging of a large, shallow, irregular pit (C13; not illustrated). The purpose of this is unknown, but it had the effect of disturbing burials to a level below that affected by 19th-century work. 


\section{The Burials}

The total number of graves recorded by the excavators was 117 , but of these only 113 contained bones included in the report on the skeletal material (see Section 8 - The Human Bones). Three skeletons were too fragmentary to be lifted and one proved to be part of a later burial. Within this description, only the latter (SK36) and SK37, which could not be phased, are excluded from this general discussion.

The remaining 115 burials included 44 attributable to BP1 and BP2 (P2a), with 14 of these definitely belonging to $\mathrm{BP} 1$, being sealed by the earliest midden layer (C175). Thirty belonged to BP3 (P2b), sealed by the deep midden deposit (C84), and a further two could only be ascribed to BP1-3 and one to BP2-3. Of 37 burials within the church (BP4-5), 14 were definitely of BP5, being cut into deposits post-dating the enlargement of the east end of the church. One burial, the fragmentary number 70 , could only be attributed to BP3-5.

Separate reports (below) provide analyses of both the timber and the methods of construction employed in the manufacture of wooden coffins, as well as of the skeletal material. Illustration 30 (see Section 8.2.2 Age and sex; and Section 8.4 - Pathology) shows the distribution of skeletons by sex and pathology for Periods $2 \mathrm{a}, 2 \mathrm{~b}$ and 3 . This section exists to draw together a few pieces of general information about the burials. Full details and illustrations of each burial are in the site archive.

Evidence of wooden coffins was found in a maximum of only 23 of the 117 graves (c 20\%), this evidence ranging from extensive timber remains to the survival of varying numbers of iron nails (in the case of SK40 (BP3), only one nail, which may well have been redeposited). The use of coffins does not appear to have become common until the late 14th century, after the construction of the late medieval church, with 17 (44\%) of the BP4-5 burials containing evidence of coffins, against only four or five (16\%) of those of BP3, and just one (2\%) of the earliest two burial phases. The apparent marked increase in coffin burials occurring within the church of the late 14 th to mid-16th century may reveal more about the social and economic status of people buried in the Lady Aisle of the High Kirk than of a change in burial fashion. Most of the other graves contained varying numbers of copperalloy pins and/or lace tags. These items suggested that bodies were normally buried in shrouds and/ or in some form of bag or sack fastened with drawstrings. This pattern of the increasing use of coffins from the late medieval period onwards is also noted in the results from the 1988-97 excavations undertaken within the nave of Glasgow Cathedral (Driscoll 2002).

Grave-goods, ie items deliberately buried with bodies, were found in just two graves (SK43 and SK31), both from BP3 (P2b). In each case the remains of a pilgrim's wood and iron baton were recovered (see below). Coins were found in the backfilled material in four graves (SK8, SK18, SK19 and SK22), all BP4-5 (P3). 


\section{The Coffins}

The majority of this section has been extracted from the typescript of an unpublished article entitled 'Slat-bottom coffins from mediaeval Scotland' by W E Boyd, D W Hall and N M McQ Holmes which was prepared in the 1980s and never published, although some of the information within the paper, regarding coffins from the excavations from excavations at Whitefriars, Perth, was published in the monograph publication of that site (Hall 1989). The full text of the article is contained in the site archive.

Within this section, where reference is made for ease of understanding to coffin XX, the number quoted corresponds to the skeleton number (SK references) elsewhere in the report.

\subsection{Introduction}

There was a marked change in the practice of interment between those made in the external cemetery and those inserted below the floor of the extended church. Only seven of the earlier (Period 2) corpses (from 77 interments) were contained in wooden coffins, but 16 coffins were recovered from the 37 Period 3 burials within the church.

Certain evidence for the presence of coffins was recovered from at least 23 graves, but the amount of material surviving in its original location was in most cases too small to allow any conclusions to be drawn regarding the nature and construction of the coffins. Only five graves (SK31 and SK45 from Period 2b, BP3; SK22 and SK46 from Period 3, BP4; SK18 from Period 3b, BP5) contained remains substantial enough to be considered for further analysis.

It was clear in excavation and subsequent analysis that the coffins were of an unusual form for the medieval period. While the side-boards of the coffins ran longitudinally, as is commonly found, they were constructed with partially open bases formed by separate and spaced cross-boards ('slats'). Three coffins of similar form were excavated in 1982 at the Carmelite Friary, Perth, and have been reported on separately (Boyd 1989; Hall 1989).

\subsection{Construction details}

The five coffins examined were constructed from longitudinal side-boards but in one example (coffin 31 , illus 24), the end-board was formed from short upright boards. Although not all of the base-boards survived, the remains of eight were recovered from coffin 46 (illus 25), and the recorded spacing of these shows that only one was not recovered. For the other coffins, the spacing of those few base-boards which remained indicates a maximum of ten boards per coffin. The base-boards are of irregular width, as was the spacing between them, but the widths of the boards (see Table 2 below) and the spacings were broadly similar to each other.

The lids comprised one or more longitudinal boards, which in coffin 46 (illus 26) had collapsed in such a manner as to suggest the lid was originally ridged. It had collapsed onto the body, but the left side sloped sharply down from a ridge along the long axis of the coffin towards the side. The right side lay fairly flat. This suggests that the lid was made in two pieces, each sloping down from a central raised ridge. In this context it is worth noting that, in 1844 , a number of oak coffins 'straight at the sides but with their lids rising to a ridge in the centre' were found during excavations to the south of the Parliament House, within the bounds of the old St Giles' kirkyard (RCAHMS 1951, 25).

Unlike the examples from Perth (Hall 1989), the coffins at St Giles' were nailed together. All five of those analysed in detail produced an abundance of nails, mostly in situ, with minimum numbers ranging from 24 (coffin 45) to 60 (coffin 46). The wood remains have deteriorated too far to be able to show any evidence of corner jointing or how well the boards fitted together. Given the large number of nails used, it is unlikely that carpentered joints were used. The base-boards were nailed upwards into the overlying side-boards, usually with a pair of nails at either end of the base-board but in some cases with single nails. Occasionally, notably on some boards of SK46 (that which was most fully recovered), the pairs were augmented with a third, horizontal, nail. The end-boards on coffins 22 and 45 were attached, abutting onto the inner surface of the side-boards, using three horizontal nails at each side, one each at the top, middle and bottom, and driven through the sides into the end-boards. In coffin 31 , the end-boards, which were upright, abutted onto the ends of the side-boards and were nailed horizontally through the ends into the sides. The lids were attached to the coffin bodies using a small number of nails (usually about half a dozen), which were normally found at the ends and corners of the coffins. In coffins 18 and 22, nails were found between the legs of the skeletons (between thighs and calves), and these nails may originally have served to fasten lid-boards together. All the coffins tapered in width towards the feet end.

The St Giles' coffins, in contrast to those from Perth (Hall 1989), were articulated containers, and were probably portable. They appear, however, to have been relatively crudely built, and cannot be seen as finely craftsman-carpentered objects. They 


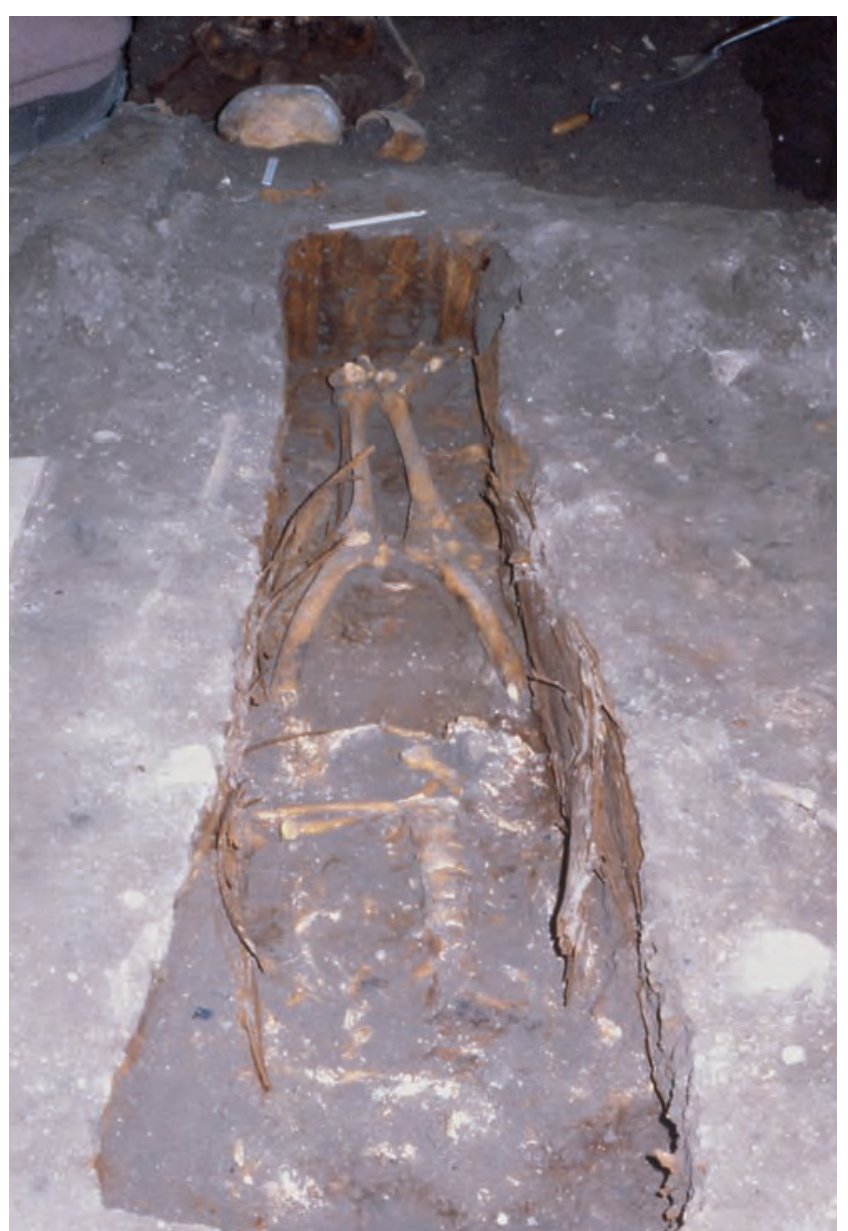

Illus 24 Coffin 31, showing vertical end slats at foot end of coffin

were crate-like containers, rather than enclosed boxes, and it may be that they were not intended to be carried for any great distance, and were intended more for static display. Unlike the Perth examples, they show no obvious evidence for the re-use of wood in their construction. The use of numerous small cross-boards, rather than larger longitudinal base-boards may possibly suggest, however, that the coffins were made cheaply, possibly even using woodworking off-cuts or ends from longer boards.

\subsection{Discussion}

While the coffins from St Giles' and the Carmelite Friary in Perth are similar in appearance, they are not of the same form, as the Perth examples were assembled in the grave and were not designed to be portable (Hall 1989). The St Giles' examples of portable, slat-bottomed coffins appear to be unique in medieval Britain. There are, however, parallels from non-British sites.

A number of well-preserved wooden coffins of various designs have been excavated from the church graveyard at Søndregate, Trondheim, Norway (Long 1975). These are, in some cases at least, articulated

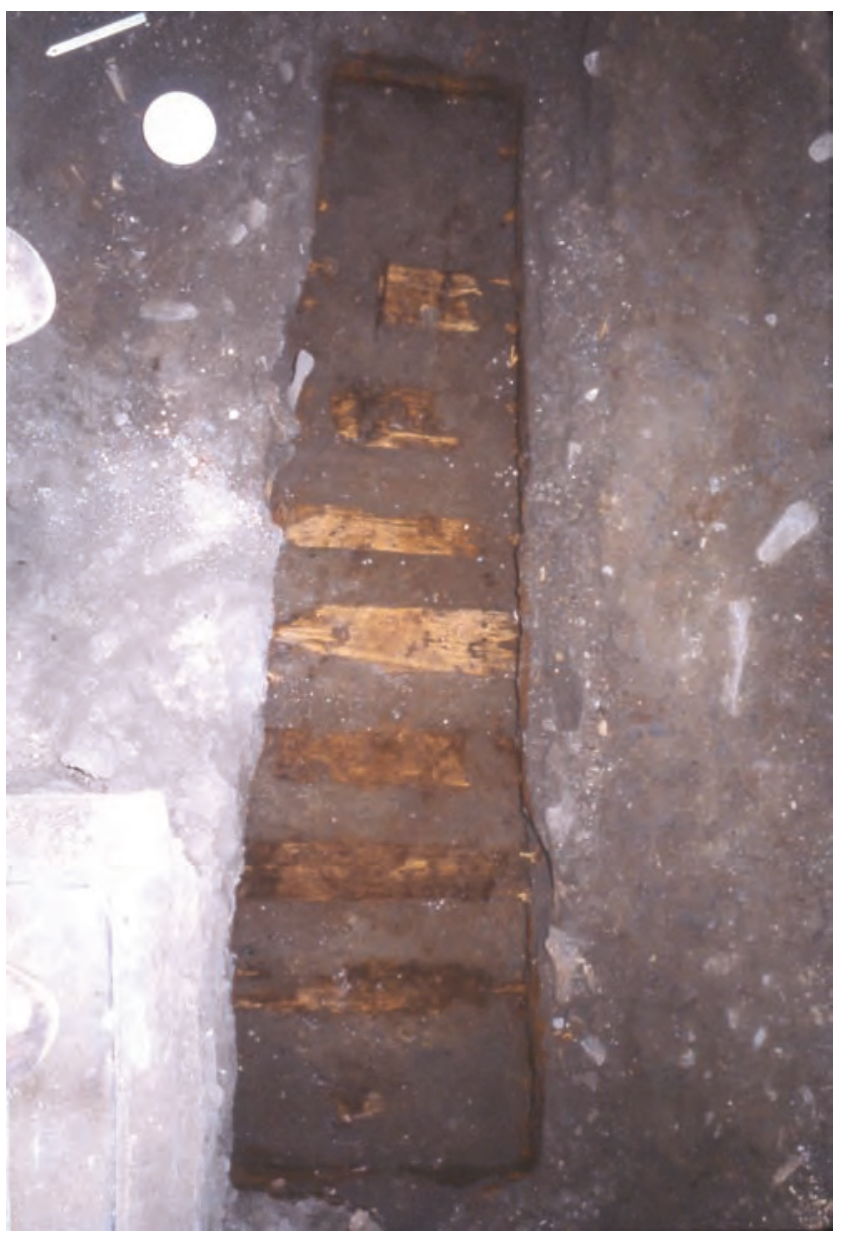

Illus 25 Coffin 46, showing slats in base of grave after removal of skeleton

and probably portable coffins which are fastened together entirely with wooden nails. The bases of two coffins consist of five or six cross-boards. The dating of these is uncertain, but they probably belong in the period from the 12 th to the 14 th century.

Similar wooden coffins have been excavated at a site within medieval Lund (Blomqvist \& Martensson 1963, chapters $2 \& 5$, figs $21,64 \& 85)$. Of the nearly 300 graves containing remains of wooden or stone coffins, five contained slat-bottom wooden coffins. These are of a variety of ages and exhibit varying construction techniques.

The earliest is associated with a stave church, dating from the 11 th or 12 th century, which was probably the predecessor of the later church of St Drotten. This early coffin has nine broad base-boards of uneven width, which are separated by narrow gaps. They are nailed, with metal nails, through from the base to the sides. The later coffins, associated with the church of St Drotten, include a pre-13thcentury example with four narrow base-boards set into holes in the coffin sides. An early 13th-century example - a child's coffin - is of similar construction, in this case with five cylindrical cross-slats set in holes in the sides. Two late medieval coffins, with no clear date, have four and two narrow cross-boards 


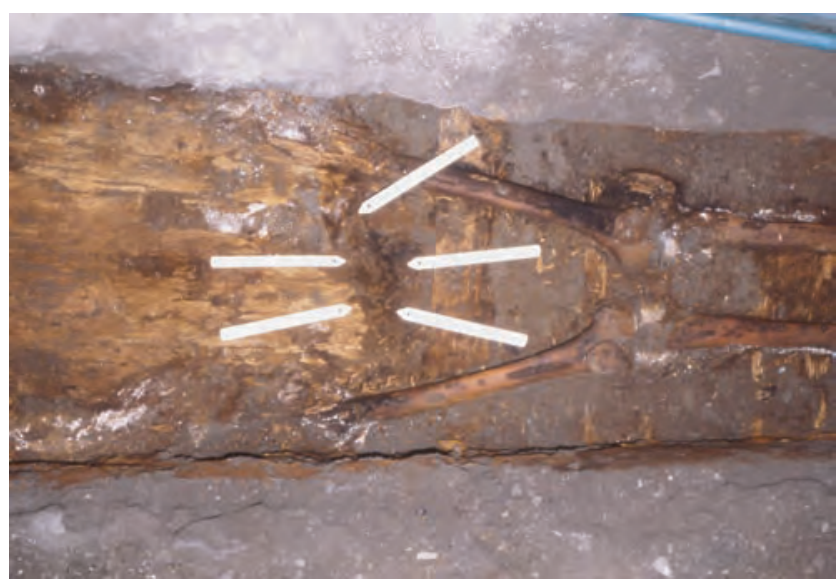

Illus 26 Coffin 46, showing lid in situ over skeleton nailed onto the base of the sides, the latter being another child's coffin. One coffin exhibits an intermediate style of construction, whereby the bottom board, running longitudinally, rests on three crossslats, which are apparently set in holes in the sides. From Blomqvist's \& Martensson's comments, these are not unexpected finds. On page 287 they state that '... it [the coffin in grave 282] was found in a late medieval level - a period to which this type of coffin would normally be assigned' (Blomqvist's \& Martensson 1963, 287). It is unclear whether they refer to the shape of the coffin (it is rectangular in plan rather than tapered), or to the presence of slat cross-boards, but it is clear that the slat-bottom coffins at Lund are one in a wide range of coffin construction techniques in medieval northern Europe. 


\section{The Coffin Wood by Rod P McCullagh}

This report considers wood recovered from the five coffins preserved to a degree sufficient to allow reconstruction (SK31 and SK45 from Period 2b, BP3; SK22 and SK46 from Period 3, BP4; SK18 from Period $3 \mathrm{~b}, \mathrm{BP5}$ ), and the wooden remains of two further coffins from burials SK24 and SK25 (both Period 3, BP4).

The coffin wood itself was preserved in both fossil and 'skeletal' forms (see below) and as such is normally considered impossible to identify. However, after an initial examination by the author, it was felt that identification to species was possible and that some comment could be made upon the original form of the coffins.

\subsection{Methodology}

The wood was preserved in two forms - as a fossil within the corrosion products of iron nails and as dessicated and shrunken cellulose skeletons. The two forms indicate contradictory decay regimens within the coffins, the one in which the iron nails corroded must have been aerobic, while the latter form indicates an anaerobic environment. The resulting preservation makes identification by normal procedures difficult. It is not possible to cut thin sections from either form so the use of a high-powered microscope is limited. The technique adopted is basically the same as for charcoal: fresh breaks are made in the specimen approximately aligned to the three planes necessary for identification. The fresh surfaces are then examined using a stereoscope (a Kyowa-2DZ) adapted to magnification of 190; this adaptation reduces the quality of the image and, in each case of doubt, a Nikon compound microscope (adapted to give incident light through the objective) was used. At all times identification was made using a published identification key (Schweingruber 1978) and confirmed by comparison to the reference slide collection of AOC Archaeology Limited.

Nomenclature of species follows Flora of the British Isles (Clapham et al. 1962). Despite various publications (such as Barber \& Crone 1991) there is no established nomenclature for wooden structural elements which is intelligible to an archaeological readership, and the terms used here are, it is hoped, reasonably self-explanatory.

\subsection{Results}

Wood from eight coffins was identified and described; a catalogue of this information has been deposited with the archive. A synthesized account appears below.

\subsubsection{The samples}

A total of 37 identifications were made, representing a minimum of 21 separate timbers. Eight identifications were of wood preserved as a fossil within the corrosion products of iron nails from coffin 24 .

\subsubsection{The species}

Only two types of wood had been used: Pinus silvestris (Scots pine) and Picea abies (spruce). There was no evidence for the use of oak (Quercus $\mathrm{sp}$ ) though this species was reported as present on site (Boyd et $a l$., unpublished data). The commonest type, Scots pine, is native to Scotland, while the spruce would have been imported from Northern Europe. Spruce has been identified from a coffin at Bordesley Abbey (Rahtz et al. 1983).

There is little evidence of a choice of species made on the basis of structural performance (see Table 1 ), except that the spruce was only used on baseboards. Both trees will produce timber that is easily split or sawn and neither wood is generally regarded as suitable for coffins; Corkhill (1979) lists chestnut, elm, hazel pine (an American red gum-type), oak and pitch pine as coffin woods.

\subsubsection{The coffins}

Only four coffins can be reconstructed in any form $(18,24,31$ and 46; Table 2). No evidence of dovetailed joints nor, in fact, of any sophistication in the construction was discovered. From the excavation record it is clear all the coffins were well nailed, indeed over-use of nails was suggested by coffin 46 (60 nails). Only slight evidence survived for the form of the lid (coffin 46). The principal component seems to have been slim, thin boards which were produced with the minimum of effort or expense.

Coffin 31, P2b, BP3 (illus 24) The single sample contained a large number of fragments from which two pieces were selected at random. Both species were represented in the assemblage, which also included a piece of bark. This was identified as probably spruce by a small area of preserved wood on its inner surface. Another fragment of spruce was pierced by small insect channels. It would seem probable that this coffin, or at least its end, was constructed with undressed timber.

Coffin 24, P3, BP4 (not illustrated) This coffin was mostly represented by wood preserved in the corrosion products of iron nails and represents the main assemblage of nails examined. Two fragments 
Table 1 Position of wood and species, by coffin

\begin{tabular}{|c|c|c|}
\hline Coffin number (SK) & Position of wood & Species* \\
\hline 11 & Scaffold & Pinus silvestris \\
\hline 18 & Base, 1st from $\mathrm{E}$ & Picus abies \\
\hline 18 & Base, 2nd from E & Pinus silvestris \\
\hline 18 & Base, 3rd from $\mathrm{E}$ & Picea abies \\
\hline 18 & Base, 4th from $\mathrm{E}$ & Pinus silvestris \\
\hline 18 & Base, 2nd from $\mathrm{E}$ & Picea abies \\
\hline 18 & Foot-board & Pinus silvestris \\
\hline 18 & Base, 6th from $\mathrm{E}$ & Pinus silvestris \\
\hline 22 & Not known & \\
\hline 24 & Not known & Pinus silvestris \\
\hline 24 & Not known & Pinus silvestris \\
\hline 24 & Nail wood & Pinus silvestris \\
\hline 24 & Nail wood & Pinus silvestris \\
\hline 24 & Nail wood & Pinus silvestris \\
\hline 24 & Nail wood & Pinus silvestris \\
\hline 24 & Nail wood & Pinus silvestris \\
\hline 24 & Nail wood & Pinus silvestris \\
\hline 24 & Nail wood & Pinus silvestris \\
\hline 24 & Nail wood & Pinus silvestris \\
\hline 28 & Not known & Pinus silvestris \\
\hline 28 & Not known & Picea abies \\
\hline 28 & Not known & Picea abies \\
\hline 31 & $\mathrm{~W}$ side at base & Pinus silvestris \\
\hline 31 & Base-board & Pinus silvestris \\
\hline 31 & Foot-board & Pinus silvestris \\
\hline 31 & Lid & Pinus silvestris \\
\hline 31 & Not known & Pinus silvestris \\
\hline 31 & Not known & Pinus silvestris \\
\hline 31 & Not known & Pinus silvestris \\
\hline 31 & Not known & Picea abies \\
\hline 31 & Not known & Picea abies \\
\hline 31 & Not known & Picea abies \\
\hline 31 & Not known & cf Picea abies bark \\
\hline 31 & Not known & Pinus silvestris \\
\hline 46 & Board 5 & Pinus silvestris \\
\hline 46 & Side of coffin & Pinus silvestris \\
\hline 46 & Board 4 & Pinus silvestris \\
\hline 46 & Lid & Pinus silvestris \\
\hline
\end{tabular}

of preserved wood were also identified. All the wood was Scots pine. The wood preserved by the iron salts appears to be wider than the dessicated wood but this presumably indicates some shrinkage in the latter type. It was hoped that the coffin could be reconstructed from the nail evidence. This was not possible because it was not possible to establish the alignment of the nails to the original alignment of the timber. In general, the curvature of the growth rings and the concentration of knot-holes indicates that wood used was of small diameter $(10-20 \mathrm{~cm}$ diameter).

Coffin 46, P3, BP4 (illus 25; illus 26) The sample of this coffin recovered was four heavily weathered fragments, representing part of the base, side and lid of the coffin. All the pieces were from Scots pine. 
Table 2 Identifiable elements of the coffins

\begin{tabular}{|c|c|c|c|c|c|c|}
\hline \multirow[t]{2}{*}{ Coffin } & \multicolumn{2}{|c|}{ Species } & \multirow{2}{*}{$\begin{array}{l}\text { Base-board } \\
\text { max width }(\mathrm{mm})\end{array}$} & \multirow[t]{2}{*}{ Other } & \multirow{2}{*}{$\begin{array}{l}\text { Nails } \\
\text { present }\end{array}$} & \multirow{2}{*}{$\begin{array}{l}\text { Worked } \\
\text { surfaces }\end{array}$} \\
\hline & Pine & Spruce & & & & \\
\hline 18 & 4 & 3 & 9.00 & Foot & None & Yes \\
\hline 24 & 9 & 0 & 12.00 & None & 7 & Yes \\
\hline 31 & 8 & 4 & 5.2 & Lid, foot & None & Yes \\
\hline 46 & 4 & 0 & 10.5 & Side & None & Yes \\
\hline
\end{tabular}

On one fragment, that from the base, soil and small stones adhered to the most weathered face, suggesting that, if truly a base fragment, the worst of the damage was done to the outer face. Again no reconstruction was feasible.

Coffin 18, P3b, BP5 (not illustrated) Seven samples were submitted, all from the base of the coffin, and these appear to be slats or battens arranged across the width of the coffin. Although generally in a poor state of preservation, the degree of decay differed between surfaces of three of the specimens. In two cases, the most weathered surface was impregnated with soil and small stones, one of which retained a resinous deposit on the smoother surface, while a third had small stones impressed into the smoother surface. It is reasonable to assume that the smoother surface represents the side best protected from the agents of weathering. Therefore, the third board mentioned above has suffered the least damage on the face in contact with the soil. This indicates some variation in the weathering regimen within the coffin as all three specimens were described as 'base-boards'. If, as an alternative, the position of this third board was a product of the collapse of the coffin within the grave, it is possible that the state of preservation records variation inside and outside the coffin. This may be a result of misidentification of the structural elements in the field and makes reconstruction of the form more problematical.

\subsubsection{The nails}

In coffin 24 , all the nails had been driven through two timbers set perpendicular to each other. While this may represent the attachment of the cross pieces in an openwork structure, the number of nails present is far less than would be necessary, so either some have been lost, or the coffin was not a complete structure, or the components were a few broad boards rather than narrow planks.

The lack of nails from the other graves is, perhaps, the product of small-scale variations in the soil chemistry within the vicinity of decaying corpses, but also may indicate a genuine lack of nailed structures. The use of pegs has been recognized on better-preserved sites (see below).

The form of the nails is best illustrated by the contents of the grave around SK24. All the nails survived as extensively corroded objects, and consequently the dimensions are somewhat distorted. The shafts ranged in length from $39 \mathrm{~mm}$ to $65 \mathrm{~mm}$, with an average of $56 \mathrm{~mm}$. The heads were all severely corroded and retained no intact metal. The heads appear to have been relatively thin and, in plan, were often oval. The shafts were square and rectangular in section, ranging in dimension from $5 \times 5 \mathrm{~mm}$ to $5 \times 7.5 \mathrm{~mm}$, and tapered down to a narrow, but in every case blunt, terminal. The actual points had presumably been lost as the wood decayed.

The nails were in most cases driven into the wood at right angles to the grain, but in several instances they had penetrated at a marked angle. This may be explained by the timber being cut or split at this angle, the nail thus penetrating at right angles to the prepared surface, or by the nail being driven into the wood at this angle. In one instance it was clear that the latter was the case.

Two of the eight nails examined in detail were buckled. It would appear that not only was the joiner content to misplace the nails but also that he was equipped with nails of variable quality.

The probable poor positioning of the nails and the lack of any joinery technique must indicate the resulting structure was poorly built. The over-use of nails in at least one case, while perhaps reflecting an occupant of great bulk, may again testify to a poverty of carpentry skills either used or available.

\subsubsection{The timber}

The timber had survived both as fossils within metallic corrosion products and as dessicated wood, and the wood was generally well preserved. In thin section it was clear that the some of the wood had shrunk to a considerable degree.

An average of $9.5 \mathrm{~mm}$ is given for the thickness of the preserved wood, while the fossilized wood has an average thickness of $19 \mathrm{~mm}$. Variation in the thickness along the length of any plank is likely to have been considerable but it would seem reasonable to infer that there has been shrinkage of the wood after the date of the corrosion of the nails.

The form of the decomposition of the wood is probably complex, and the coffin will have experienced major fluctuations in its environment after interment. Initially, some aerobic agents will have operated, but as the body degenerated 
the regimen would have become anaerobic, with a harsh environment based on the chemical status of the decomposed remains and a rich population of micro-organisms. As the degenerative processes progressed, a state of equilibrium would have pertained in which decay would have almost ceased until the grave was disturbed. In the case of an urban graveyard, one must assume that reuse of the plot would have caused frequent re-exposure of the grave contents. 


\section{The Human Bones by David Henderson}

\subsection{Materials and methods}

A total of 113 in situ inhumations were recovered from the 1981 excavations. A further considerable quantity of unarticulated bone was also excavated, but with the exception of a small number of fragments recovered from within recognized gravecuts (or immediately adjacent to the inhumations), this material was re-interred at the end of the excavation and was not available for study. During the excavation of the geotechnical trial-pits in 1977, the unarticulated bone was recovered and conserved, but it has proved impossible to relate the recorded stratigraphy of the test-pits to that of the 1981 excavation. Consequently, this earlier material has been treated as a single population.

The burials have been assigned, on the basis of site stratigraphy, into five clear phases of burial activity (described above). Due to the relatively small numbers of individuals recovered, and the uncertainty in assigning 21 skeletons securely to a single burial phase, it was decided that several burial phases would have to be amalgamated for the purposes of this report. The groupings used are Period 2a (Burial Phases 1 and 2, external cemetery, late 12th-13th centuries), Period 2b (Burial Phase 3 , external cemetery, 14th century) and Period 3 (Burial Phases 4 and 5, within the South Choir Aisle of the church, late 14th century to Reformation).

\subsubsection{Preservation}

Of the in situ material, the preservation varied considerably. Only six skeletons were recorded as being of'excellent' preservation (5.3\%), a further $30(26.5 \%)$ were 'good' and 11 (9.7\%) 'terrible'. These descriptions are necessarily subjective, and it is likely that, as more bones were examined, the criteria for 'good' and 'fair' preservation changed, with the benefit of the doubt being given to skeletons whose preservation was relatively better than the usual. Over the entire site it would appear that the best preserved skeletons were those which had been buried outside the church (during Burial Phases 1,2 and 3) and those with no evidence of a coffin, suggesting that the best conditions for bone preservation occurred when the products of decomposition were leached quickly away by rainwater draining through the soil of the graveyard.

There was a very low degree of completeness in the skeletons recovered. Apart from the different physical preservation conditions, the graveyard was used intensively between the 12th and 16th centuries, causing many graves to be intercut. In only two cases were bones missing from one skeleton recovered from the grave-fill of the inhumation which cut it, suggesting that no systematic attempt was made to preserve the integrity of disturbed skeletons. In addition to these factors, extensive building work on the kirk of St Giles' from the 14th century onwards caused further disturbance. In consequence, only 14 individuals (12\%) presented near-complete skeletons for study, and in no single case was a complete set of standard measurements obtained. Half the skeletons $(\mathrm{n}=56)$ lacked a skull.

\subsubsection{Reconstruction}

Each skeleton was laid out individually and the bones reconstructed to the greatest possible degree, although ribs were not reconstructed unless they displayed evidence of disease or trauma, and longbones were only repaired if the articular ends were sufficiently intact to allow measurement of the greatest length. Crania were usually reconstructed as far as possible, unless it became apparent that earth-pressure had rendered them too distorted for accurate measurement, or they were in such small pieces as to make the reconstruction of doubtful accuracy.

Measurements were then taken of the bones, following methods described previously (Cross \& Bruce $1989 \mathrm{mf}$ 1, F13) with the exception of FEM MAP, FEM AP(MAX), FEM ML(MAX), TIB NFL, TIB $\operatorname{AP}(1 / 3)$, TIB $M L(1 / 3)$ and, with the addition of Hum Bd (the bi-epicondylar width of the distal humerus, after Bass 1987), Rad MHD (the maximum diameter of the proximal radius), Rad DTD (the distal transverse diameter of the radius) and Tib $\mathrm{Bd}$ (the maximum breadth of the distal tibia). The cranial measurements were taken (following Brothwell 1981, 82-3), with the exception of DA, BQ' and C. Skeletal and cranial indices were calculated. A summary of all the metrical data is contained in the archive.

\subsubsection{Age estimation}

Where possible, age estimation was made using the teeth - the stage of eruption (after Schour \& Massler, quoted in Hillson 1986, 188-94) for immature individuals, and attrition for adults (after Brothwell 1986, 72). The pubic symphysis face was also examined where available (in 20 of 81 adult skeletons) for ageing criteria. In the case of sub-adults for whom the teeth were unavailable, the state of epiphyseal fusion was used to age 
Table 3 Sex distribution by period

\begin{tabular}{lrrrr}
\hline \multicolumn{1}{c}{ Period } & Male & Female & Unknown & \multicolumn{1}{c}{ Child } \\
\hline $2 \mathrm{a}$ & $23(51 \%)$ & $11(24 \%)$ & $1(2 \%)$ & $10(22 \%)$ \\
$2 \mathrm{~b}$ & $9(27 \%)$ & $8(24 \%)$ & & $16(49 \%)$ \\
3 & $11(31 \%)$ & $17(49 \%)$ & $1(3 \%)$ & $6(17 \%)$ \\
\hline
\end{tabular}

Table 4 Age distribution of the in situ inhumations by period.

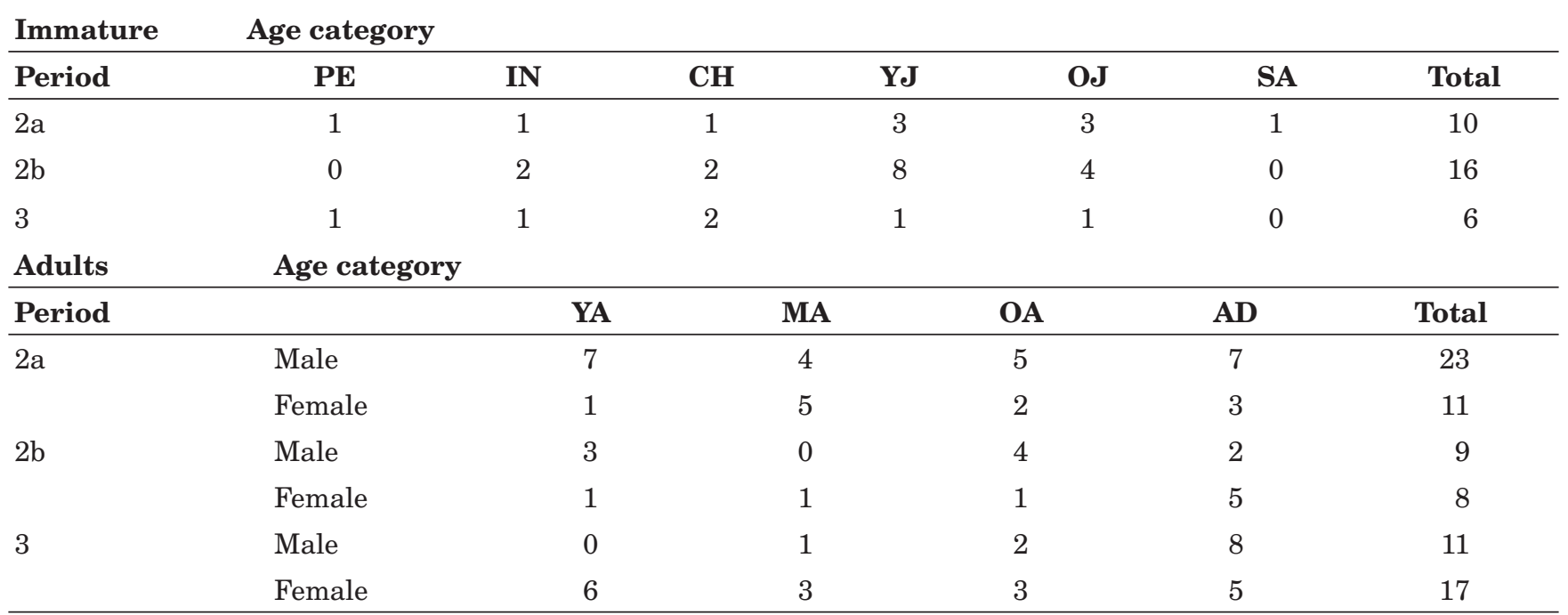

PE, perinatal; IN, infant; $\mathrm{CH}$, child; YJ, young juvenile; OJ, old juvenile; SA, sub-adult; YA, young adult; MA, middle-aged; OA, old-aged, $\mathrm{AD}$, adult.

the adolescents, and for the younger individuals age was estimated from the length of long-bone diaphyses. The data used for this estimate were a combination of figures used previously (Molleson \& Cox 1993, figs 10.3 and 10.4) and diaphyseal lengths derived from sub-adults from the St Giles' sample whose age had been estimated from their dental development. Of the 81 in situ adult individuals, $30(37 \%)$ could not be assigned to any age category. Although an attempt was made to place every adult into at least a 10-year age-band, for the purposes of this report only the categories YA (young adult), MA (middle-aged) and OA (old age) have been used. Sub-adult skeletons were placed in one of six categories: Perinatal (PE, birth +/- 2 months), Infant (IN, 2 months -2 years), Child ( $\mathrm{CH}$, 2-6 years), Young Juvenile (YJ, 6-12 years), Old Juvenile (OJ, 12-18 years) and Sub-adult (SA, 1825 years) (following Cross \& Bruce 1989, 121).

\subsubsection{Sex estimation}

Adult skeletons were sexed primarily on the basis of pelvic morphology. In two cases where the pelvis was lacking, skull morphology was used, and where neither skeletal area was present, an attempt was made to sex the skeleton using single-dimension measurements based on the securely sexed populations (see Stroud \& Kemp 1993, 166 for discussion). It would appear that this method yields reasonably accurate results, as less than $10 \%$ of the securely sexed individuals would have been misattributed on the basis of one of the single-dimension measurements. Ultimately, only two adult individuals remained unassigned as to sex.

\subsection{Demography}

\subsubsection{Number of individuals}

The excavations recovered a total of 113 in situ inhumations (one of which, SK70, was present as a shadow only, and subsequently not recovered). A summary of the findings from each inhumation is recorded in Appendix A. Of the charnel assemblage from 1977, bones were fully examined and measured only where it was felt the most useful information could be extracted: the femora, tibiae and cranial bones (with dentitions). All other charnel bones were examined for pathological and traumatic lesions (including the small quantity of charnel retained from the 1981 excavations). The most common skeletal element from the charnel was the humerus, which yielded a minimum number of 30 adult individuals. A minimum of a further 12 immature individuals was represented by left femora. Comparisons of measurements from the two assemblages showed no significant difference, it can be assumed that the charnel derived from the same population. 


\subsubsection{Age and sex}

Of the adult inhumations, 44 (55\%) were male, 36 (45\%) female and two could not be sexed. Thirty-one inhumations (27\% of the total) were immature, ie individuals under 18 years of age at death. The sex distribution varied considerably over time (illus 27).

The preponderance of males in Period 2a, of children in Period $2 \mathrm{~b}$ and of females in Period 3 (shown in Table 3 ) are statistically significant $\left(\chi^{2}=\right.$ $16.263,4 \mathrm{df}, \mathrm{p}<0.005$, discounting the unsexed individuals). It is particularly striking that nearly half of the inhumations during the 14th century were of children. This may reflect a change of status of the area to the south of the church in the 14th century. There is some evidence that children were buried preferentially at sites dedicated to certain saints (particularly the Magdalene) in medieval Scotland (Lindsay 1989, m.f.1, B12; Henderson, in prep). The preponderance of females among the interments of Period 3 is almost entirely derived from a single row of six individuals at the western limit of the adult burials in these burial phases. This row contained no males, and it is perhaps significant that a one-yearold infant and a child of five or six years were also buried in this area. There is a distinct preponderance of males in Period 2a, a large number of whom (seven of 23 , ie $30 \%$; Table 4 ) had either leprosy or an injury that may have caused restricted movement.

Low numbers in each age category and the high proportion of non-aged adults preclude any reconstruction of age-at-death profiles for this site. For the 1977 charnel, analysis of all the items of bone which allow an estimate of sex (innominates, mastoid processes, frontals, occipitals and metrical analysis of long-bones as described above) all yielded an approximately 1:1 ratio of sexes. Age estimates for adult dentitions in the charnel assemblage $(\mathrm{n}=38)$ showed $47.8 \%$ YA, $30.4 \% \mathrm{MA}$ and $21.8 \%$ OA.

\subsection{Population variability}

\subsubsection{Non-metric traits}

A summary of prevalence of various common skeletal anomalies (following Brothwell 1989, 91-100) is contained in the archive. Of the anomalies noted systematically there, the following were of particular note.

SK23 had no proximal tibio-fibular articulations (the fibulae were bowed). In SK58 the tubercles of the 5th metatarsals had failed to ossify, bilaterally (see burial 5502 in Stroud \& Kemp 1993, 195). SK107 had no articular surface on the pubic part of the right acetabulum (left; no data) but had a rough fossa instead. There is no effect on the femoral head, so the condition was probably asymptomatic. In SK115 the medial cuneiform was in two parts on the right (split transversely) and also in two parts, but incompletely separated, on the left (see burial 2175 in Stroud \& Kemp 1993, 195). The 1977 charnel yielded a rib with a bifurcated body and a left distal humerus fragment with a supracondyloid process.

\subsubsection{Body size and indices}

Stature was estimated from the long bones of the inhumations using Trotter's figures (quoted in Bass 1985). Because of the incomplete nature of the skeletons, and of the bones which comprised them, heights were estimated from any leg-bones recovered, and the results averaged for that individual. The results were as shown in Table 5, with external and internal burial phases separated.

Table 5 Average estimated height in metres (Periods 2a and 2b amalgamated because of low numbers of adults in Burial Phase 3)

\begin{tabular}{lcc}
\hline Period & Male & Female \\
\hline Whole site & 1.677 & 1.559 \\
Period 2 & 1.667 & 1.561 \\
Period 3 & 1.710 & 1.556 \\
\hline
\end{tabular}

Male height ranged from $1.80 \mathrm{~m}$ ( $c 5 \mathrm{ft} 11 \mathrm{in})$ to $1.55 \mathrm{~m}$ (c $5 \mathrm{ft} 6 \mathrm{in}$ ), with females ranging between $1.67 \mathrm{~m}(c 5 \mathrm{ft}$ 5.5in) and $1.49 \mathrm{~m}(c$ ft $10.5 \mathrm{in})$. The average heights of the sexes are very close to those derived from a small medieval sample excavated at Holyrood Abbey in the neighbouring burgh of Canongate (Hazel 1998) so that people from Edinburgh appear to be slightly smaller than their contemporaries in medieval Britain. The females, especially, were shorter than the women from the Carmelite friary site in Aberdeen, for example (Cross \& Bruce 1989, 126). The males are shorter than those from Linlithgow Friary (Cross \& Bruce 1989, 126), although the tallest individuals at St Giles' were taller. At all periods the Edinburgh citizens were shorter than their exact contemporaries from Fishergate, York (Stroud \& Kemp 1993), and other broadly contemporary sites in the north-east of England (Anderson 1994, 5).

The diaphyseal lengths of children's long-bones all indicated that they were shorter at a given age (where established by dental eruption stage) than the Maresh sample (quoted in Molleson \& Cox 1993, fig 10.4) but were of comparable height with the Spitalfields sample (Molleson \& Cox 1993).

Very few skulls from the in situ sample were complete enough to yield indices; however, with the addition of the cranial material from the 1977 charnel, sufficient indices could be calculated to show some differences between the sexes. It would appear that the males had a greater tendency to narrow foreheads and narrow nasal apertures, while the females had a slight bias towards skulls that were low compared to their breadth. Most males in the sample had narrow eyesockets, a trait also found in the sample from Holyrood (Hazel 1998), although there the small sample produced mostly 
broad noses. In general, the crania were distributed fairly evenly through the various categories of skull shapes. Any changes over time are unfortunately masked by the majority of measurable skulls coming from unstratified deposits.

Of the 96 individual femora recovered, 83.3\% were platymeric (80/96). This rate is comparable with the medieval sample from Whithorn (Cardy 1997, 523) but much greater than the rates in Aberdeen and Linlithgow, which are $64 \%$ and $69 \%$, respectively (Cross \& Bruce 1989, 127). The cnemic indices were obtained from 106 tibiae, of which 12 (11\%) were platycnemic or hyperplatycnemic, 27 (26\%) were mesocnemic and 67 (63\%) were eurycnemic. There was no significant difference between the rates of these indices either between males and females or between Periods 2 and 3. These figures are similar to those from Aberdeen and Linlithgow but a greater proportion of the Whithorn tibiae were mesocnemic (45\%). Platymeria and platycnemia (flattening of the bones of the leg) are more common among pre-industrial peoples than their present-day descendants, possibly as a result of a generally more vigorous lifestyle (Cross \& Bruce 1989,129).

SK43, a Burial Phase 3 male of over 50 years old, showed some indication of obesity. The position of the skeleton in his grave (the arms bowed out from the torso and pushed hard against the sides of the grave-cut) may have been a result of a large girth. The individual was suffering from a mild or incipient form of Diffuse Idiopathic Skeletal Hyperostosis (DISH, or Forestier's disease; see below for discussion) It has been shown that DISH is often associated with late-onset diabetes, a disease of the overweight elderly (Roberts \& Manchester 1995, 120).

\subsection{Pathology (illus 27)}

\subsubsection{Trauma}

Bones from 13 individuals from the inhumations (11.5\%) displayed signs of trauma in the form of healed or healing fractures (Table 6).

Table 6 Numbers of fractures recorded

\begin{tabular}{ll}
\hline Parietal & 3 \\
Hand & 3 \\
Clavicle & 1 \\
Ribs & 1 \\
Humerus & 1 \\
Tibia & 3 \\
Radius & 1 \\
Fibula & 4 \\
Ulna & 2 \\
Foot & 2 \\
\hline
\end{tabular}

One individual (SK104) displayed an unreduced fracture of the right clavicle, as well as a fractured skull which may have been sustained in the same episode. This skeleton also had a scoliosis of the spine, but it is not certain that this was caused by an injury as the aetiology is not clear.

One of the ulna fractures came from the 1977 charnel, a fragment of left mid-shaft with the signs of an un-united healing break. The distal end was not recovered. In SK34, the left metacarpals 3 and 4 had been fractured. Small marks of adhesions showed that the hand had been bound too tightly, immobilizing it during healing, causing the fusion of the two metacarpals in a 'squeezed-together' position. SK72 seemed to have had the left little finger amputated, from halfway along the proximal phalanx. In SK99 an unreduced right tibial fracture was associated with a fracture of the fibula. Both bones were broken about two-thirds of the way down the shaft and the subsequent shortening had pulled the right toes into plantar flexion. The right tibia was $33 \mathrm{~mm}$ shorter than the left and the incident had caused extensive arthritic changes to both legs, a consequence of the uneven gait which would have resulted. The broken feet were an unreduced fracture of a left 5th metatarsal (SK53) and a fracture of the distal end of a first proximal phalanx of the right foot from charnel.

\subsubsection{Arthropathies}

All joint surfaces were examined for signs of degeneration and disease; osteophytic lipping, sclerosis, porosity and eburnation were all noted where they occurred, but for the purposes of the following discussion, only those joints where the disease process was sufficiently advanced as to produce polishing (eburnation) of the sub-chondral bone are considered, in view of the generally poor bone preservation of the assemblage. A total of 36 individuals from the in situ inhumations displayed signs of arthritis in at least one joint (outwith the spine, which will be dealt with separately). Of these, 18 were male, 17 female and one unassigned to sex. The age distribution is shown in Table 7.

Primary osteoarthritis was never the cause of polished joint surfaces in the young adult individuals. In two cases (SK69, male; SK103, female) the lesions had probably been caused by the unusual stresses placed on the joints by a scoliosis of the spine. For SK81 the cartilage was probably destroyed by an infection secondary to leprosy. SK78 had ankylosing spondylitis. In the case of SK111, the individual had DISH, unusual in one so young, but both the dental and pubic symphysis indicators placed his age securely under 35 years. Almost every woman in the Old Age category had some evidence of osteoarthritis. There was one case each in the foot, the hand and the shoulder; two cases affecting the hips only; and in one case the hips, knees and the symphysial surface of the pubis were affected. 

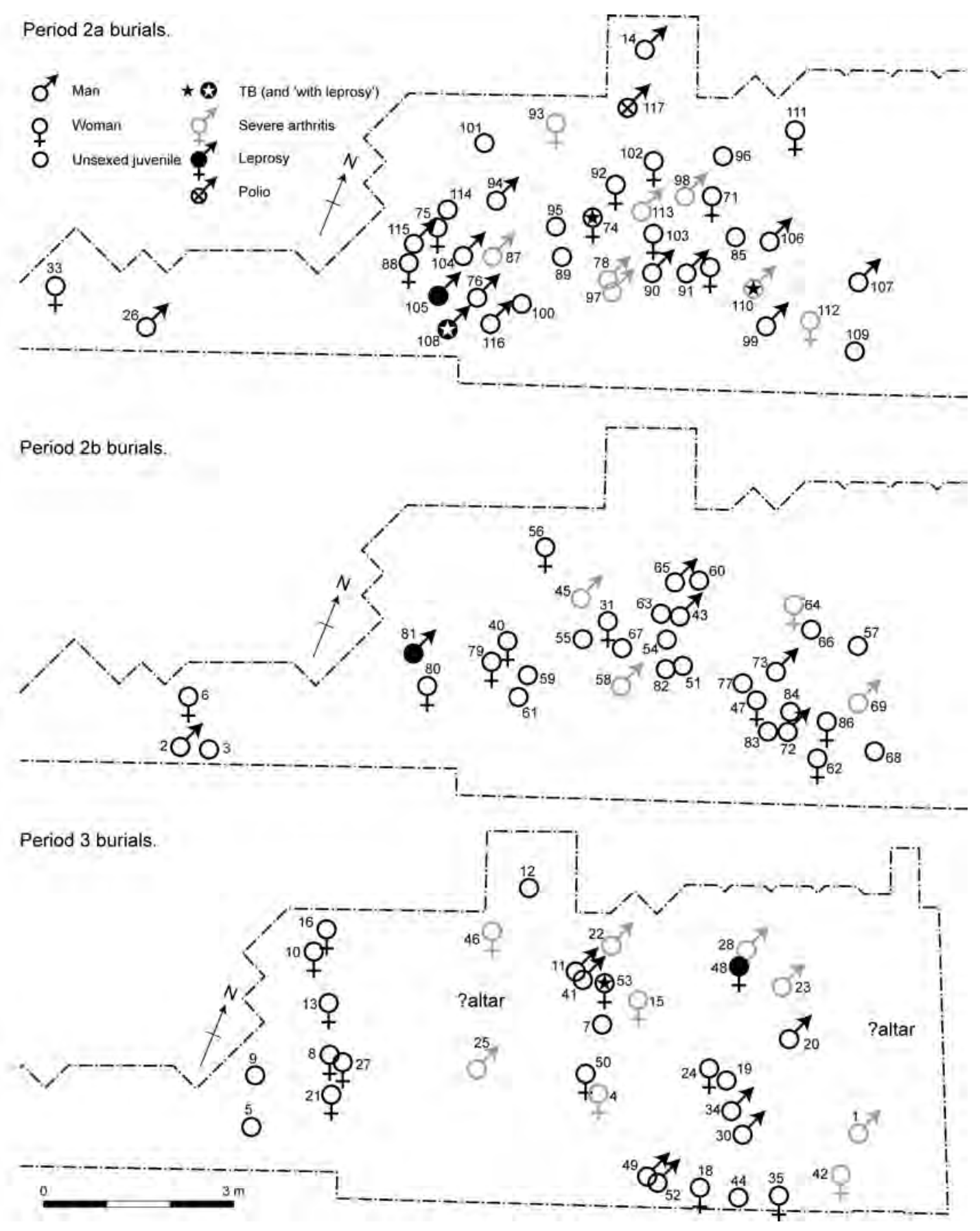

Illus 27 Plot of sex and pathology of excavated skeletons by period

No certain evidence of erosive arthropathies, such as rheumatoid arthritis or psoriatic arthritis, were observed but, in light of the generally poor state of preservation of many of the bones (especially the articular parts of the fingers and toes), post-mortem damage may perhaps have masked some cases. Table 8 shows the most frequently affected joints, expressed as a proportion of all joints of that type examined from the in situ inhumations. A joint was considered to be present if either of its surfaces was recovered; the knee was considered as two joints: the tibio-femoral and the patello-femoral.

All these figures are quite low compared to other medieval sites, even when less severe indications of joint degeneration are added into the figures. For example, where osteophytic lipping and pitting or sclerosis of the joint surface are added in the case of the knee joint, the percentage of affected knees rises to $7.02 \%$ on the left, which contrasts with between $9 \%$ and $16 \%$ of knees affected in the Fishergate sample (Stroud \& Kemp 1993, table 46). It should also be noted that there was only one example of a severe lesion, where the polishing effect of bone on bone had led to grooving of the joint surface. This was at the distal end of a 1st metatarsal, where a sesamoid bone was involved. 
Table 7 Individual skeletons with extra-spinal arthritis (percentage of total in age class in brackets)

\begin{tabular}{cllc}
\hline Age category & Male & Female & Unknown \\
\hline YA & $5(45 \%)$ & $1(12.5 \%)$ & 0 \\
MA & $3(60 \%)$ & $4(50 \%)$ & $1(100 \%)$ \\
OA & $4(36 \%)$ & $6(86 \%)$ & 0 \\
AD & $6(37 \%)$ & $6(43 \%)$ & 0 \\
\hline
\end{tabular}

Table 8 Joints most commonly affected by severe osteoarthritis (eburnation)

\begin{tabular}{lccc}
\hline \multicolumn{1}{c}{ Joint } & No. affected & Total examined & \% \\
\hline Hips (L + R) & 17 & 60 & 28.33 \\
Clavicle/acromion & 5 & 45 & 11.11 \\
Radius distal (R) & 4 & 39 & 10.25 \\
Ulna/Lunate (R) & 3 & 30 & 8.1 \\
Proximal humerus (L) & 3 & 37 & 7.69 \\
Clavicle/sternum & 4 & 52 & 7.14 \\
Lunate/triquetral (L) & 2 & 28 & 6.6 \\
Capitate/hamate (L) & 2 & 33 & 6.17 \\
Femur/patella (R) & 3 & 49 & 5.88 \\
Fibula/talus (R) & 3 & 51 & 5.7 \\
Proximal humerus (R) & 2 & 35 & 5.7 \\
Radius proximal (R) & 2 & 35 & 5.35 \\
Femur/patella (L) & 3 & 56 & 5.17 \\
Femur/tibia (R) & 3 & 58 & 5 \\
Radius distal (L) & 2 & 40 & 4.65 \\
MT 1/Sesamoid (R) & 2 & 43 & 4.35 \\
MT/ Ph1 (L) & 2 & 46 & 4.35 \\
MT 1 /Sesamoid (L) & 2 & 46 &
\end{tabular}

Overall, the most commonly affected joints were the hip, the acromio-clavicular and the wrist, which broadly reflects the pattern seen from the medieval period to the modern day (Roberts \& Manchester 1995, 114). The results for the hip joint were examined to test for differences in prevalence between male and female, but no significant difference was found.

\subsubsection{Spinal degeneration}

The gradual increase in the severity of degenerative changes displayed in the vertebral column appears to be an inevitable concomitant of increasing age in humans. A full analysis of degenerative changes to individual vertebrae is held in the site archive, showing percentage of joint surfaces examined which had degenerated to Sager's Grade 2 or 3 (Brothwell 1981, fig 6.9). The most commonly affected sites were the body surfaces between the 5th, 6th and 7 th cervical, and between the 10th, 11th and 12th thoracic and the 3rd and 4th lumbar vertebrae. On the articular joints, the $4 \mathrm{th} / 5$ th thoracic and $4 \mathrm{th} / 5$ th lumbar vertebrae were most often affected; with the cervical spine and the 6 th to 9 th thoracic vertebrae very rarely involved.

Schmörl's nodes were common in the load-bearing parts of the spine, with up to a quarter of examined body surfaces between the 9 th thoracic and the 2 nd lumbar vertebra displaying this lesion.

\subsubsection{DISH}

In addition to this normal degeneration, several spines displayed specific pathology. Six individuals had signs of Diffuse Idiopathic Skeletal Hypertrophy (DISH). The classic symptoms are large flowing osteophytes (bony outgrowths) on the front righthand side of the thoracic vertebrae fusing them together, and the ossification of muscle tendons where they are inserted into the bones. Although the disease is said to be present clinically only when four or more vertebrae are fused, the signs of 'incipient' DISH can often be recognized in archaeo- 
logical material (Stroud \& Kemp 1993, 213). One such example from St Giles' is SK34, an adult male, where enthesoses (tendon ossifications) were found at the calcaneus, patella, tibial tuberosity and sacroilliac joints and there were extensive ossifications of the costal cartilages as well as large (though as yet unfused) osteophytes on the anterior surfaces of the vertebrae from 5 th thoracic to 2 nd lumbar. A similar case was SK43 (an old male) whose body position in the grave suggested obesity (see Section 3.2, above). SK4 (old female), SK71 (adult?female), SK76 (old male) and SK111 (young male) all displayed the standard signs of DISH.

\subsubsection{Other spinal pathologies}

Several individuals had a scoliosis or lateral distortion of the spine. In the case of SK48, this may have been a result of osteomalacia (adult rickets), and in SK104 it may possibly be the result of severe trauma, such as a fall, but in SK10, SK34, SK69, SK103 and SK110 there was no clear aetiology. SK27 showed a kyphosis (the spine is bent forward) at the 11th thoracic vertebra, as a result of vertebral body collapse due to Paget's disease.

In SK22 the 10th and 11th thoracic vertebrae were fused, probably as the result of a prolapsed disc. SK78 and SK39 showed signs of ankylosing spondylitis, in neither case severe.

\section{Osteomyelitis}

Apart from the specific infections (discussed below) three bones showed signs of osteomyelitis, a pyogenic infection of the bone and periosteum. Two of these were from charnel, a left fibula (distal one-third) and a shaft fragment of a right radius. It is possible that the fibula may have derived from an individual with syphilis. The left tibia of SK28 had a large swelling on the posterior part of the shaft, below the soleal line, which appeared to be a result of osteomyelitis (the roughened cortex of the bone and the position of the lesion would seem to preclude an alternative diagnosis of osteochondroma, although the affected area had no visible drainage sinuses.)

\section{Syphilis}

Evidence of syphilis was recorded in several individuals, the only securely dated specimen was of 16 th century date. Bone changes associated with syphilis (usually manifest in the skull and the lower legs) occur in only about $10 \%$ of those infected (Roberts \& Manchester 1995, 153) so it is possible that one or two of the other Burial Phase $4 \& 5$ individuals may have suffered from the disease. SK32, the legs and feet of an adult male, had the tibiae and fibulae grossly malformed by infection with Treponema pallidum, the infectious agent of syphilis. The right leg was particularly badly affected, with osteomyelitis tracked up to the end of the femur and down to involve some talar bones in the ankle. Unfortunately, preservation of the knee joints was very poor, so it is unknown if these were affected; syphilis in its final stages sometimes attacks and destroys joints. Two syphilitic individuals were recovered from the charnel. A skull of a 30- to 40-year-old man (St G77 II.1) with five radial scars (typical of healed caries sicca lesions) and some palatal and alveolar destruction; it also had erosion of the nasal bones and nasal aperture. A matching pair of tibiae $(\mathrm{U}(\mathrm{co})$ and $\mathrm{U}(\mathrm{cp})$ ), probably from a woman, were also recovered, showing the 'sabre shin' deformity typical of the disease.

\section{Tuberculosis}

Several possible cases of tuberculosis were apparent in the population. The most certain in the very poorly preserved ribs and spine of an adult of unknown sex from Burial Phase 2 (SK74). The poor preservation, especially of the vertebral bodies, make this diagnosis tentative, but several features seem to favour a diagnosis of TB. There is a smooth-sided erosive lesion on the anterior aspect of the body of the 7th thoracic, and apparently on the 10th and 11th thoracic vertebrae also. While the bodies of the 12 th thoracic and 1st lumbar vertebrae are unrecovered, the arches of these vertebrae are fused in a kyphosis; the individual must have been bent forward at the waist at a sharp angle.

In SK53, from Burial Phase 4, the poor preservation again prevents any certain diagnosis, but certain features are suggestive. The arches of the 4 th and 5 th lumbar vertebrae (once again the bodies are missing) show severe eburnation and pitting of the articular processes, while all the other lumbar and thoracic vertebral arches are completely normal, suggesting a very localized lesion at a site typical of TB. There are also extensive cystic lesions around the rims of the acetabulae and the heads of the femurs, which may be indicative of early signs of the erosive destruction of the hip joints, a symptom of tubercular infection, although without the spinal lesion simple osteoarthritis would be a more likely explanation. One other possible case is in SK108, which presents even more problems of diagnosis than the above cases. According to Roberts \& Manchester, plaques of periosteal bone on the internal surfaces of the ribs may indicate pulmonary tuberculosis (Roberts \& Manchester 1995,139). These lesions were found on the internal surface of all the ribs on the left side of this skeleton (except the first); however, the rest of the skeleton displays clear signs of leprosy. It is very rare to find the two diseases in a single individual (Roberts \& Manchester 1995, 150) as the bacteria responsible for both diseases are very closely related, and a tubercular infection will confer a degree of immunity to leprosy. The converse is not true, however, and pulmonary 


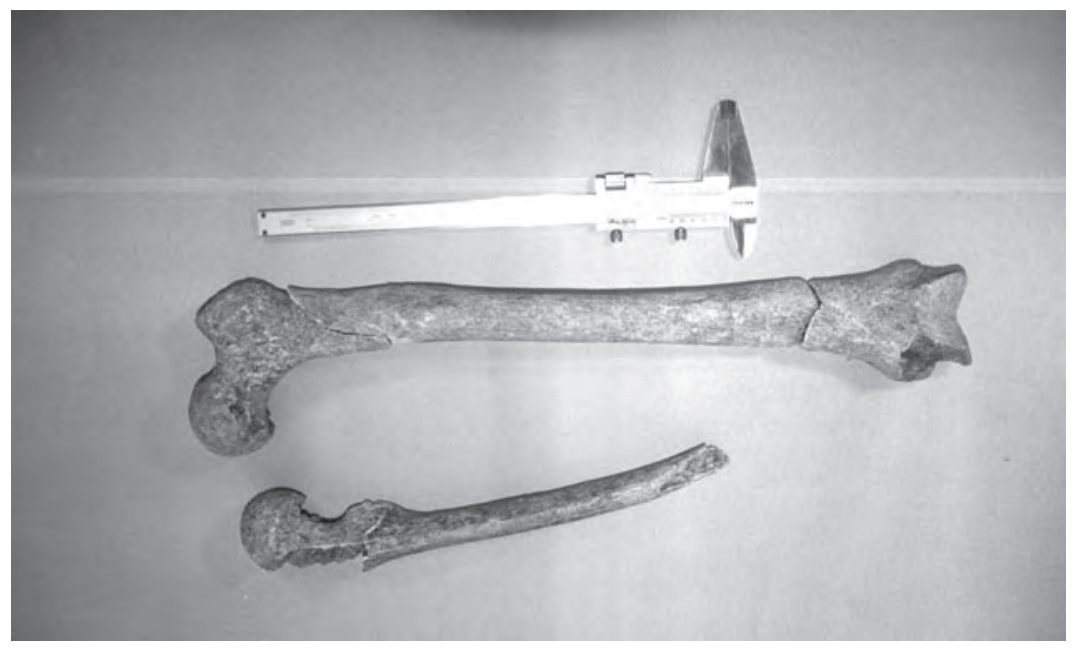

Illus 28 Evidence of poliomyelitis in SK117

TB was a common cause of death in 20th-century leper hospitals. None of the periosteal lesions on the ribs of SK108 displayed the oval foci described previously (Stroud \& Kemp 1993, 222) as typical of pulmonary tuberculosis, and it may be that there is another aetiology for this finding, such as pleurisy.

\section{Leprosy}

Five individuals exhibited the symptoms of lepromatous leprosy. Four of these individuals were buried, during Burial Phases $1 \& 2$, in close proximity to one another at the western end of the excavated area; the other individual is from BP5. SK48, a middle-aged female and the sole post15 th century leper, displayed symptoms of a whole slew of diseases, trauma and other conditions. Her lepromatous symptoms include enlarged nutrient foramina and periostitis on the shafts of the metacarpals and proximal phalanges of the hands, with wasting and periostitis of the intermediate and distal phalanges of the hands and feet, florid periostitis of the fibulae (especially the left) and erosive lesions on the maxillae and at the lateral wall of the right orbit. SK17 displayed some periostitis and wasting of the bones in the hands and feet, the palate was paper thin and the inferior border of the piriform aperture was eroded. The maxilla on the right was very eroded with the loss of the incisors, the alveolar crest being reduced in this area to a sharp edge. SK81 was a male young adult, of which only the legs, left radius and hands were recovered. Every bone displays some periostitis except for the bones of the fingers. These, however, have enlarged nutrient foramina. SK105, the poorly preserved skeleton of a middle-aged female, displayed periostitis on bones of hands, forearms, feet and distal ends of tibiae, with some vascular grooving. Her facial bones were not recovered. The hands, forearms and shins of SK108, an old male, with possible tubercular lesions on the internal rib surfaces all displayed periostitis; unfortunately, the feet and most of the facial bones were missing from this skeleton.

\section{Poliomyelitis(?)}

SK117 was an adult male with very poor preservation of the bone. The right femur and possibly the right humerus (only a small mid-shaft fragment was recovered) were considerably shorter and more gracile than their corresponding left-side bones (illus 28). Photographs of the burial in situ show the femora to be articulated. When reconstructed, the right femur head showed distortion. Although very similar in size to the left, the ball of the right femur pointed in a much more vertical and posterior direction (relative to the normal orientation of the shaft). The shaft itself was wasted, with a very slight linea aspera and other muscle scars. The presence of osteophytes round the head of the femur indicate that the limb must have borne some weight, even though an approximate calculation shows that the right leg was about $80 \mathrm{~mm}$ shorter than the left, without taking account of any further discrepancies there may have been in the tibia (the lower legs were missing.) Although present in a very fragmented and decayed state, the vertebrae did not reveal any signs of disc degeneration, or lateral spondylarthrosis (at least fragments typical of every spinal level were recovered) and the site photograph shows no scoliosis; this is a remarkable finding in view of the considerable stress which must have been placed on the spinal column with the very uneven gait of this individual (probably requiring crutches or a built-up shoe). The skeleton lacked any parts suitable for establishing age. There are several possible aetiologies of the restricted growth in the right side of the body. In light of the apparent involvement of upper and lower limbs, perhaps the most likely is polio. Other possibilities are defective growth subsequent to a traumatic 
birth or in utero trauma, or childhood spinal nerve trauma or disease.

\section{Periostitis}

Several of the skeletons were affected in one or more bones with periostitis, an inflammation of the periosteum (a fibrous membrane covering the surface of all bones, except at their articular surfaces). In 21 individuals there was no obvious cause for the periostitic reaction and, of these, 15 were affected in one or several of the bones of the lower leg. This is a common finding in medieval material, though no thoroughly convincing explanation has been put forward for its prevalence. Among the other cases noted were two women from BP4 with periostitis on the internal surface of the pelvis, which may have arisen from an adjacent gynaecological inflammation. A middleaged woman, also from BP4, showed porosity and periostitis on the occipital bone, posterior to the foramen magnum, which probably arose from an overlying tissue infection. Another BP4 middleaged woman had an area of periostitis on the right maxilla, secondary to periodontal disease at the roots of her incisors. It is possible that these lesions were a consequence of vitamin $\mathrm{C}$ deficiency (scurvy).

Where possible, the surface of the maxillary sinuses was inspected. In seven of the inhumations and in one of the maxillae from the charnel (out of 23 examined), changes were seen indicative of chronic sinusitis, probably related to pollution of the air by dust and smoke (Roberts $\&$ Lewis 1994). These figures are certainly a large underestimate of the incidence of sinusitis in the population, given that not all of the delicate sinus surfaces which did survive were available for examination.

\section{Metabolic diseases}

A number of skeletons and charnel bones showed evidence that the individual concerned had suffered from metabolic diseases or from vitamin deficiency. Ten individuals from the inhumations, and ten bones from the charnel, displayed bowing of the long bones of the limbs, typical of rickets (vitamin D deficiency). Two of these individuals were children (a five-year-old and a seven-yearold) who may well have been in the active phase of the disease when they died. The femora of the seven-year-old (SK57) were particularly distorted. Of the others, one individual, SK48, had a scoliosis of the spine at the 3rd and 4th lumbar vertebrae and a distorted pelvis, with the symphysial faces of the pubes being apparently a considerable distance apart. This suggests that this individual was suffering from osteomalacia, the adult form of rickets.

\section{Anaemia}

Childhood and adult anaemias can sometimes affect the skeleton as iron-deficiency anaemia and may cause the blood-forming cells of the marrow to proliferate, causing changes in the bones, most unmistakably in the skull. Eight of the skulls from the inhumations (of 38 orbits examined 21\%), displayed cribra orbitalia (porosity of the roof of the orbit associated with childhood anaemia). In one of these cases (SK114), the lesions were healing, even though the individual was around seven years old. Two further adult skulls, both male, had thickened frontal and parietal bones, with a porous surface texture. Both also had porosity of the palate, which may also be indicative of iron-deficiency anaemia occurring after maturity. Three bones from the charnel (one female, two male) also displayed cribra orbitalia (all inactive) and a further cranial fragment had a 'lumpy' and matted appearance over the parietal bones, possibly healed porotic hyperostosis. An alternative diagnosis would be an overlying scalp abscess.

\section{Paget's disease}

Four possible cases of Paget's disease were observed. Often the disease will cause no problems for the sufferer; in other cases, constant pain and spontaneous limb fractures occur. SK113 showed some symptoms, for example there was no medullary cavity at the midline of the jaw. SK14 may also have been in the early stages of the disease, he was of unknown age, but his femora and humeri were very heavy and slightly thickened and distorted. In SK27, an old female, the femora and the clavicle were thickened, and there was a kyphosis at the 11th lumbar vertebra, possibly as a consequence of the disease. SK56 was a young adult female, all the limb-bones recovered show thick, disorganized looking cortex but the diagnosis of Paget's disease is unlikely because of her age.

\section{Osteoporosis}

Osteoporosis is characterized by loss of bone volume, especially thinning of the bone cortex. It is a symptom of various conditions and can lead to fragile bones, prone to fracture. No fractures typical of the condition, such as of the wrist or the femur neck were found in the St Giles' assemblage and the microscopic structure of the trabecular bone of the limbs was not examined to search for microfractures. However, one right innominate from charnel showed extreme thinning of the ilium blade, with the loss of cancellous bone over a large area, leading to the bone being paper thin and in places actually perforated. This phenomenon was entirely erosive and showed no signs of inflammation. Osteoporosis seems the most likely cause. Several other 
skeletons had noticeably light bones, but the variable preservation over the site makes any diagnosis of osteoporosis prohibitively tentative.

\section{Neoplasms}

Evidence of cancers (both benign and possibly malignant) was recovered from both the in situ inhumations and the charnel. Because of the relative rarity of neoplasms in the archaeological record it is worthwhile to list them all separately.

a. SK110 osteosarcoma. This was a disorganized spherical mass of cancellous bone, about the size of a cherry-stone, investing the frontal process of the left maxilla, just superior to the nasallachrymal groove. This mass in the corner of the eye would inevitably have caused some visual disturbance. A small $(c 13 \times 10 \mathrm{~mm})$ plaque of disorganized bone was also noted on the inner table of the frontal bone, which may be a metastasis from the main sarcoma (illus 29).

b. Charnel skull U(c) had one lenticulate button osteoma just to the right of lambda.

c. SK108 revealed a small odontome in the mesial wall of the right maxillary first incisor alveolus, where the bone was broken. The small oval mass (maximum dimension $4.6 \mathrm{~mm}$ ) appeared to be made of dentine only.

\subsection{The teeth}

\subsubsection{Dental pathology}

Dentitions or partial dentitions were recovered from 46 of the in situ inhumations (29 adult), and a further 45 dentitions (39 adult) were recovered from charnel. From these, rotated teeth were noted (Table 9).

Of the nine in situ individuals with rotated teeth, it is striking that, with only two exceptions, the

Table 9 Position of rotated teeth. $L$, left side; $R$, right side

\begin{tabular}{ll}
\hline Tooth & SK no \\
\hline Lower I1 & $60(\mathrm{R}), 73$ \\
Lower I2 & $11(\mathrm{R}), 60(\mathrm{R}), 77(\mathrm{R})$ \\
Lower C & $48(\mathrm{R}), 60(\mathrm{R}), 73(\mathrm{R}), 109(\mathrm{R})$, Charnel \\
U(bp) and U(bu) \\
Lower P3 & $15(\mathrm{R})$, \\
Lower P4 & $15(\mathrm{R}), 66(\mathrm{~L}), 73$ \\
Upper I2 & $60(\mathrm{~L})$ \\
Upper C & $60(\mathrm{R})$ \\
Upper P3 & $15(\mathrm{~L}), 109(\mathrm{R})$ \\
Upper P4 & $48(\mathrm{~L})$ \\
Upper M2 & 115 \\
\hline
\end{tabular}

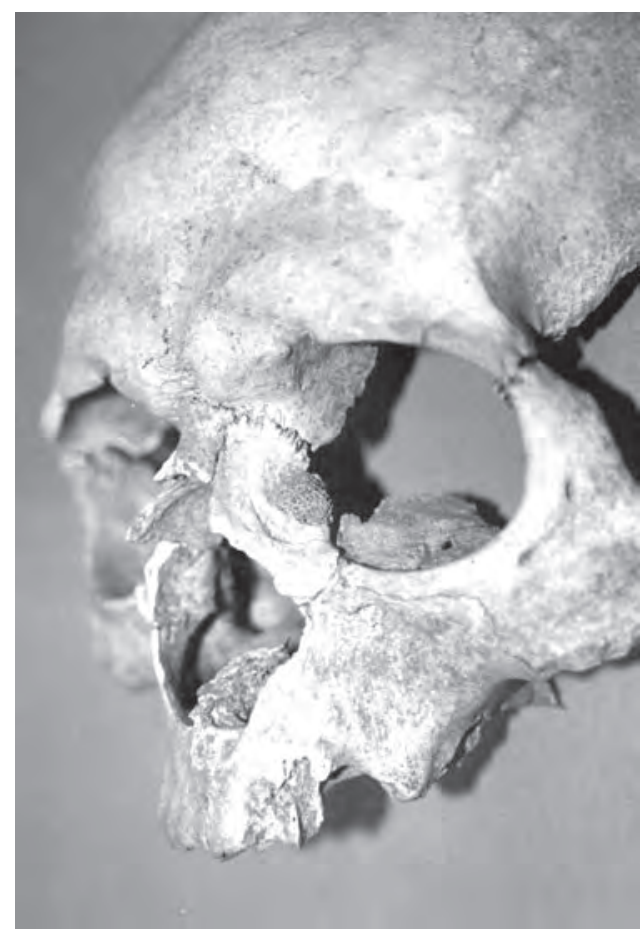

Illus 29 Evidence of osteosarcoma in SK110

individuals also displayed some sign of childhood stress or illness; four displayed symptoms of deficiency disease (rickets or cribra orbitalia), two showed multiple ossicles at the lambdoid suture (possibly linked to childhood stress; Cross \& Bruce 1989, 124) and three (SK15, SK66 and SK109) displayed hypoplastic lines in the tooth enamel (discussed further in Section 8.5.2 below), indicating physiological stress before five or six years of age. Of all individuals displaying rickets or cribra orbitalia from whom the jaws were recovered, four of $15(27 \%)$ had rotated teeth. Overall, nine of 46 dentitions (19\%) displayed this trait. Bearing in mind the low numbers of cases, the coincidence of rotated pre-molars and the evidence of stress at age five or six, when the permanent pre-molar roots are just starting to grow, it is tentatively suggested that this tooth rotation may be related to physiological insult in a similar manner to enamel hypoplasia.

One lower right canine from 1977 charnel was double-rooted. In SK116 the lower left deciduous canine had been retained onto adulthood (although it was lost post-mortem) in addition to the full complement of adult teeth.

The most common tooth to be congenitally lacking was the third molar (M3). If there was any doubt, for example if the second molar had been lost antemortem, then the third molar was not counted as congenitally absent. One individual lacked all four M3s, one lacked all M3s except for the lower right, which was reduced to a small 'peg', three lacked both the upper M3s, two lacked both lower M3s, one lacked lower right and upper left, and one lacked lower right only. Other congenitally lacking teeth were in SK48 (lower left I1), SK109 (upper right 
I2) and SK111 (upper left I2). In a charnel maxilla (Uae), the left second molar was of reduced, peg-like, size.

\subsubsection{Childhood morbidity}

If episodes of severe malnutrition or disease occur during childhood, the physiological insult may leave a permanent record on the teeth; any tooth developing at the time may show a hypoplastic line and the position of this line can be related to the known ages of tooth development (estimated from Massler's illustration, quoted in Hillson 1986, 135). For example, hypoplastic lines were evident in eight out of 11 dentitions from individuals with other skeletal evidence of childhood stress (cribra orbitalia or rickets). Within the in situ sample, severe hypoplastic lines were noted on 23 dentitions (of 46 recovered, 50\%) but it was striking that in many cases the affected individual was a young adult, or younger. Nine of 15 (60\%) young adult dentitions, and nine of 17 (53\%) sub-adult dentitions, were affected with at least one strong hypoplastic line. In contrast, among adults over about 35 years at death, five of $14(36 \%)$ were affected. It has been suggested (Stroud \& Kemp $1995,204)$ that the higher prevalence of dental hypoplasia in those who die younger is due to the long-term effects of the childhood stress, leading to 'sickly' individuals more likely to succumb to subsequent illness. It must be remembered, however, that abrasion and attrition of the teeth in older individuals may well remove the evidence of enamel hypoplasia, thereby skewing the apparent prevalence towards the younger individuals. In 13 cases the hypoplastic line suggests illness or malnutrition at about five or six years old, five other lines are at the 18- to 24-month age span and may be related to weaning. SK116 displayed three lines, corresponding to episodes of stress at six months, two years and ten years old (this individual died at between 25 and 35 years old). Ten other individuals showed at least two separate lines. Of the 23 individuals displaying enamel hypoplasia, four had suffered from rickets and six displayed cribra orbitalia, suggesting an episode of iron-deficiency anaemia. In SK82, a 12year-old girl from BP3, the canine and incisor teeth showed a particularly marked hypoplastic line, corresponding to bodily stress at about 3.5 years of age. In this case the stress was severe enough to delay the formation of the pre-molar teeth (the crowns of which are beginning to form between three and four years old). Although her adult incisors and canines were in wear and her permanent second molars were through, she had retained her deciduous molars, which normally begin to drop out by the age of ten.

\subsubsection{Dental disease}

The molars were by far the most commonly affected teeth for both ante-mortem loss and caries. Indeed most of the incisors lost ante-mortem were as a consequence of leprosy rather than dental disease. Overall, the most common site for caries was the lower first molar, with $23 \%$ of surviving teeth affected. Of these caries cavities, 39\% were at the distal side of the cervical/enamel junction. The incisors and canines were the teeth most often lost post-mortem (especially in the charnel sample, where by definition the bones had been moved around). This is the inevitable result of the single straight roots of these teeth making them easier to dislodge. A summary of the age-specific rates of ante-mortem loss and caries for the site is contained in the archive. The rate of caries increased between the external and internal burial phases. Taking the bias towards younger adults in the external cemetery into account, each tooth in BP4 and BP5 was nearly two-thirds more likely to develop a caries cavity. An analysis of the ratio of carious to sound teeth for only those individuals affected with caries shows that there was also a significant increase in severity of infection over the same time-span, ie if an individual in BP4 or BP5 had caries, they would be likely to be affected in a greater number of teeth. It is likely that the individuals buried underneath the kirk were of higher status than those buried outside and access to more refined food might account for the increase in caries. No significant difference was found between the caries rates for men and women and, as would be expected, there was a significant increase in caries rate and ante-mortem tooth loss with age. Nine individuals from the in situ collection and seven from the charnel had dental abscesses. Of particular note was SK106, where an apical abscess at the right upper M1 had peaked into the maxillary sinus and the subsequent sinus infection had peaked into the mouth. The skull of a very old woman recovered from 1977 charnel (Cranium 1) revealed a large abscess in the right maxilla, centred around the canine and pre-molars, which had peaked to the maxillary sinus and destroyed part of the palate. The missing area of bone was roughly ovoid and about $20 \mathrm{~mm}$ in diameter at the tooth-row. From the 1977 charnel, skull StG 77 II.18 had retained the broken stump of the left upper second molar, possibly the result of a poorly executed extraction. Calculus was common, and often considerable, on all adult teeth. Many jaws showed periodontitis, the loss of bone from around the tooth sockets, which can result in tooth loss over time. From the charnel recovered in 1977, a maxilla (U(ac)) exhibited generalized maxillary alveolar hyperostosis. This takes the form of eight 'mushroom-shaped' compact bony masses on the buccal surface of the maxilla. Each is associated with an individual alveolus (right I2 to M2 and left I2 and C), each arises on a short stalk from just above the alveolar crest and appears, from the lines of calculus on the teeth, to have been completely invested in the gum tissue. The largest lesion (at the right canine) was $9.5 \mathrm{~mm}$ long, the smallest 
(at the left canine) was $3 \mathrm{~mm}$. This condition is a response of the body to the bone loss of periodontitis, an attempt to preserve the teeth.

\subsubsection{Sub-adult dentitions}

Of the 285 erupted teeth recovered from individuals under the age of 15 years, only seven were found to be carious (2.5\%). In only one case did the lesion appear to be of normal aetiology (a distal interproximal caries cavity on the lower right M1 of a 14-year-old). SK57, seven years old, displayed gross caries of the occlusal surfaces of the lower left and right first permanent molars and interproximally at the right second deciduous molar. These lesions were secondary to severe enamel hypoplasia, from a disease episode at 18 to 20 months old. In SK68, two years old, caries lesions were observed at the lingual surfaces of the upper deciduous incisors, it is suggested that these may have been caused by the use of a dummy-tit (see Watson 1995, 244).

Other dental anomalies displayed in sub-adult skeletons include SK85, 15 years old, where all four permanent canines were deviated and unerupted, and SK114, seven years old, where the lower deciduous first molars had been lost and the alveoli remodelled, but there is no sign of the underlying permanent teeth. The delayed eruption of the pre-molars of SK82 is discussed in Section 8.5.2 (above).

\subsection{Summary}

The site at St Giles' yielded an absolute minimum of 155 individuals, 113 represented by in situ inhumations, and the rest by unarticulated charnel (Table 10). Over the entire period of the use of the site as a burial ground, the ratio of sexes was around 1:1, but women predominated in Period 3, men predominated in Period 2a and children predominated in Period 2b. It is speculated that the reasons for these inequalities relate to the religious dedication of this area of St Giles' in Periods 2b and 3, and to a designated area for marginal members of society in Period 2a. The individuals represented are on average quite short compared to their contemporaries in Scotland and north-east England but in other respects appear to be a typical medieval population, although with a low prevalence of osteoarthritis. Apart from a group of individuals buried in the western end of the site during the first two burial phases, who were distinguished by the severity of their pathological conditions, the population seems quite healthy. Three individuals were syphilitic (5\% of Period 3 inhumations plus charnel), three may have been tubercular (2.6\% of all inhumations) and five exhibited symptoms of leprosy (4\%). A Period 2a adult male appeared to have contracted poliomyelitis, although poor preservation leaves the possibility of other diagnoses. Episodes of malnutrition were apparent in a number of individuals. Nine of the inhumations had suffered rickets in childhood, one individual had osteomalacia, a symptom of vitamin $\mathrm{D}$ deficiency in adulthood. Examination of the eyesockets revealed that $21 \%$ of the population had suffered childhood anaemia. Other episodes of stress in childhood were revealed in hypoplastic lines in the tooth enamel, with $50 \%$ of the dentitions from in situ inhumations displaying this trait. Dental disease, especially caries cavities and lost teeth, became more common and more severe in Period 3, possibly reflecting a higher social status (and access to more refined food) in those individuals buried under the floor of the kirk, as opposed to the surrounding graveyard in earlier burial phases.

One individual, in particular, had suffered extreme and continuous bad luck. SK48, a middle-aged female from BP5, suffered childhood anaemia, followed by osteomalacia leading to a deformed spine, pelvis and legs, the stress of which occasioned osteoarthritis of the knees. Also, in adulthood, she contracted leprosy (a lesion from which in her left orbit may have led to loss of sight in that eye) and her teeth were badly affected with cavities and abcesses. At some point she sustained fractures to her sixth to ninth ribs on the left side, which were still in the process of healing when she finally died. 
Table 10 Catalogue of recovered skeletons, giving estimated age, sex, estimated height and major pathology (for age categories, see Section 8.1.3). R, right; $L$, left

\begin{tabular}{|c|c|c|c|c|c|c|}
\hline Skeleton no & Sex & Age & Height (m) & Pathology & Trauma & Other \\
\hline 1 & $\mathrm{M}$ & $\mathrm{OA}$ & 1.70 & & & \\
\hline 2 & M & $\mathrm{OA}$ & 1.62 & & & \\
\hline 3 & & $\mathrm{CH}$ & & & & \\
\hline 4 & $\mathrm{~F}$ & $\begin{array}{l}\mathrm{MA} / \\
\mathrm{OA}\end{array}$ & 1.58 & $\begin{array}{l}\text { Periostitis on } \\
\text { basioccipital }\end{array}$ & ?Fracture of $(\mathrm{R})$ parietal & \\
\hline 5 & & IN & & & & \\
\hline 6 & $? \mathrm{~F}$ & $\mathrm{AD}$ & & & & \\
\hline 7 & & $\mathrm{PE}$ & & & & \\
\hline 8 & $\mathrm{~F}$ & MA & 1.54 & Rickets & & \\
\hline 9 & & $\mathrm{CH}$ & & & & \\
\hline 10 & $? \mathrm{~F}$ & YA & & & & Slight scoliosis \\
\hline 11 & $\mathrm{~F}$ & YA & 1.54 & Periostitis at pubis & & \\
\hline 12 & & OJ & & & & \\
\hline 13 & $\mathrm{~F}$ & $\mathrm{AD}$ & 1.60 & & $\begin{array}{l}\text { Rotator cuff } \\
\text { ensethopathy }\end{array}$ & \\
\hline 14 & M & $\mathrm{AD}$ & & ?Early Paget's disease & & \\
\hline 15 & $\mathrm{~F}$ & $\mathrm{OA}$ & 1.62 & Rickets & & \\
\hline 16 & $\mathrm{~F}$ & YA & 1.53 & & & \\
\hline 17 & $\mathrm{~F}$ & MA & 1.55 & Leprosy & & \\
\hline 18 & $\mathrm{~F}$ & YA & 1.64 & & & \\
\hline 19 & & OJ & & & & \\
\hline 20 & M & $\mathrm{AD}$ & 1.69 & & & \\
\hline 21 & $\mathrm{~F}$ & YA & 1.50 & Rickets & & \\
\hline 22 & $?$ & MA & & $\begin{array}{l}\mathrm{T} 10 \text { and } \mathrm{T} 11 \text { fused } \\
\text { (secondary to } \\
\text { spondylolysis) }\end{array}$ & & \\
\hline 23 & M & $\mathrm{AD}$ & 1.80 & & & $\begin{array}{l}\text { Proximal tibio-fibular } \\
\text { joint absent }\end{array}$ \\
\hline 24 & $\mathrm{~F}$ & YA & 1.57 & & & \\
\hline 25 & M & $\mathrm{AD}$ & 1.64 & & & \\
\hline 26 & M & YA & & Cribra orbitalia & & \\
\hline 27 & $\mathrm{~F}$ & $\mathrm{OA}$ & 1.58 & & $\begin{array}{l}\text { Rotator cuff } \\
\text { ensethopathy }\end{array}$ & Kyphosis at T11 \\
\hline 28 & M & $\mathrm{AD}$ & 1.66 & Osteomyelitis $(\mathrm{L})$ tibia & & \\
\hline 29 & & OJ & & & & \\
\hline 30 & M & MA & 1.73 & & & $\begin{array}{l}\text { (L) Femur } \\
\text { hyperplatymeric }\end{array}$ \\
\hline 31 & M & $\mathrm{AD}$ & 1.61 & Rickets & & \\
\hline 32 & M & $\mathrm{AD}$ & & Syphilis & & \\
\hline 33 & $\mathrm{~F}$ & $\mathrm{AD}$ & & & & \\
\hline 34 & M & $\mathrm{AD}$ & 1.67 & DISH & $\begin{array}{l}\text { Fracture, (L) metacar- } \\
\text { pals } 3 \& 4\end{array}$ & \\
\hline 35 & $\mathrm{~F}$ & ?YA & 1.50 & & & \\
\hline 39 & $\mathrm{~F}$ & $\mathrm{AD}$ & & & $\begin{array}{l}\text { Trimaleolar fracture (L) } \\
\text { tibia }\end{array}$ & \\
\hline 40 & $\mathrm{~F}$ & $\mathrm{AD}$ & 1.51 & & & \\
\hline 41 & $\mathrm{M}$ & $\mathrm{OA}$ & 1.77 & & & \\
\hline 42 & $? \mathrm{~F}$ & $\mathrm{AD}$ & 1.60 & & & ? Hammer toes \\
\hline 43 & $\mathrm{M}$ & $\mathrm{OA}$ & 1.69 & Incipient DISH & & \\
\hline
\end{tabular}


Table 10 (cont.) Catalogue of recovered skeletons, giving estimated age, sex, estimated height and major pathology (for age categories, see Section 8.1.3). R, right; $L$, left

\begin{tabular}{|c|c|c|c|c|c|c|}
\hline Skeleton no & Sex & Age & Height (m) & Pathology & Trauma & Other \\
\hline 44 & & $\mathrm{CH}$ & & Rickets & & \\
\hline 45 & $\mathrm{M}$ & YA & 1.55 & & & Chronic sinusitis \\
\hline 46 & $\mathrm{~F}$ & $\mathrm{OA}$ & & Rickets & & \\
\hline 47 & $\mathrm{~F}$ & $\mathrm{AD}$ & 1.49 & & & \\
\hline 48 & $\mathrm{~F}$ & MA & 1.55 & $\begin{array}{l}\text { Leprosy, osteomalaccia, } \\
\text { cribra orbitalia }\end{array}$ & Fractured (L) ribs 6-9 & $\begin{array}{l}\text { Scoliosis (secondary to } \\
\text { bowed tibia) }\end{array}$ \\
\hline 49 & M & $\mathrm{AD}$ & 1.75 & & & \\
\hline 50 & $\mathrm{~F}$ & $\mathrm{AD}$ & 1.57 & Rickets & & \\
\hline 51 & & IN & & & & \\
\hline 52 & M & $\mathrm{AD}$ & & & & \\
\hline 53 & $\mathrm{~F}$ & $\mathrm{AD}$ & 1.52 & Possible TB & Fractured (L) MT V & \\
\hline 54 & & YJ & & & & \\
\hline 55 & & YJ & & Cribra orbitalia & & \\
\hline 56 & $\mathrm{~F}$ & YA & & Paget's disease & & \\
\hline 57 & & YJ & & Rickets & & \\
\hline 58 & M & $\mathrm{AD}$ & 1.59 & & & $\begin{array}{l}\text { MT V tuberosities } \\
\text { unfused }\end{array}$ \\
\hline 59 & & $\mathrm{CH}$ & & & & \\
\hline 60 & & OJ & & & & \\
\hline 61 & & YJ & & & & \\
\hline 62 & $\mathrm{~F}$ & $\mathrm{OA}$ & 1.54 & & & \\
\hline 63 & & OJ & & & & \\
\hline 64 & $\mathrm{~F}$ & $\mathrm{AD}$ & 1.55 & & & \\
\hline 65 & M & $\mathrm{OA}$ & 1.61 & & & \\
\hline 66 & & OJ & & & & \\
\hline 67 & & IN & & & & \\
\hline 68 & & IN & & & & \\
\hline 69 & M & YA & 1.64 & & & $\begin{array}{l}\text { Scoliosis at lumbar } \\
\text { spine }\end{array}$ \\
\hline 71 & $\mathrm{~F}$ & $\mathrm{OA}$ & 1.67 & DISH & $\begin{array}{l}\text { Fractured (L) index } \\
\text { finger }\end{array}$ & \\
\hline 72 & M & $\mathrm{OA}$ & 1.71 & & $\begin{array}{l}\text { Rotator cuff ensetho- } \\
\text { pathy, (R) little finger } \\
\text { amputated }\end{array}$ & \\
\hline 73 & M & YA & $\sim 1.65$ & & $\begin{array}{l}\text { Rotator cuff } \\
\text { ensethopathy }\end{array}$ & \\
\hline 74 & $?$ & $\mathrm{AD}$ & & Probable TB & & $\begin{array}{l}\text { Kyphosis at T12/L1 } \\
\text { (?Sequelae of TB) }\end{array}$ \\
\hline 75 & $\mathrm{~F}$ & $\mathrm{AD}$ & 1.61 & & & L5 sacralised \\
\hline 76 & M & $\mathrm{OA}$ & 1.65 & DISH & & \\
\hline 77 & & YJ & & $\begin{array}{l}\text { Cribra orbitalia and } \\
\text { frontal porosity }\end{array}$ & & \\
\hline 78 & M & YA & 1.65 & Ankylosing spondylitis & $\begin{array}{l}\text { ? Healed fracture }(\mathrm{R}) \\
\text { parietal }\end{array}$ & \\
\hline 79 & $\mathrm{~F}$ & $\mathrm{AD}$ & 1.56 & & $\begin{array}{l}\text { Healed fractures }(\mathrm{L}) \\
\text { radius, }(\mathrm{L}) \text { fibula }\end{array}$ & \\
\hline 80 & $\mathrm{~F}$ & $\mathrm{AD}$ & 1.58 & & & \\
\hline 81 & $\mathrm{M}$ & YA & 1.71 & Leprosy & & \\
\hline 82 & & OJ & & Cribra orbitalia & & $\begin{array}{l}\text { Anomalous tooth } \\
\text { eruption }\end{array}$ \\
\hline
\end{tabular}


Table 10 (cont.) Catalogue of recovered skeletons, giving estimated age, sex, estimated height and major pathology (for age categories, see Section 8.1.3). R, right; $L$, left

\begin{tabular}{|c|c|c|c|c|c|c|}
\hline Skeleton no & Sex & Age & Height (m) & Pathology & Trauma & Other \\
\hline 83 & & YJ & & & & \\
\hline 84 & & YJ & & & & \\
\hline 85 & & OJ & 1.67 & Spina bifida occulta & & $\begin{array}{l}\text { Canines deviated, } \\
\text { unerupted }\end{array}$ \\
\hline 86 & $\mathrm{~F}$ & MA & 1.53 & & & \\
\hline 87 & M & $\mathrm{AD}$ & 1.72 & & & $(\mathrm{R})$ leg shorter than $(\mathrm{L})$ \\
\hline 88 & $\mathrm{M}$ & $\mathrm{AD}$ & 1.71 & & & Little toes ankylosed \\
\hline 89 & & YJ & & & & \\
\hline 90 & $\mathrm{M}$ & SA & 1.72 & & & \\
\hline 91 & M & $\mathrm{AD}$ & 1.65 & & & \\
\hline 92 & $\mathrm{~F}$ & MA & 1.61 & & & \\
\hline 93 & $\mathrm{~F}$ & MA & & & & \\
\hline 94 & M & $\mathrm{OA}$ & 1.68 & Porosity of frontal & Healed fracture (L) ulna & \\
\hline 95 & & $\mathrm{PE}$ & & & & \\
\hline 96 & & $\mathrm{CH}$ & & & & \\
\hline 97 & M & $\mathrm{OA}$ & 1.68 & ?Rickets & & \\
\hline 98 & M & MA & 1.71 & & & \\
\hline 99 & M & $\mathrm{AD}$ & 1.64 & & $\begin{array}{l}\text { Unreduced fracture }(\mathrm{R}) \\
\text { tibia and fibula }\end{array}$ & $\begin{array}{l}\text { (R) foot fixed in plantar } \\
\text { flexion }\end{array}$ \\
\hline 100 & & YJ & & & & \\
\hline 101 & & YJ & & & & \\
\hline 102 & $\mathrm{~F}$ & MA & 1.61 & & & \\
\hline 103 & $\mathrm{~F}$ & YA & 1.54 & & & $\begin{array}{l}\text { Scoliosis and fusion at } \\
\mathrm{T} 4 / 5\end{array}$ \\
\hline 104 & M & YA & 1.64 & Cribra orbitalia & $\begin{array}{l}\text { Fractures }(R) \text { parietal } \\
\text { and clavicle }\end{array}$ & Severe scoliosis \\
\hline 105 & $\mathrm{~F}$ & MA & 1.55 & Leprosy & & \\
\hline 106 & M & MA & 1.72 & & & $\begin{array}{l}\text { Dental abscess infecting } \\
\text { (R) maxillary sinus, } \\
\text { peaking to buccal }\end{array}$ \\
\hline 107 & M & $\mathrm{AD}$ & 1.74 & & & $\begin{array}{l}\text { No articular surfaces } \\
\text { on pubic part of } \\
\text { acetabulum }\end{array}$ \\
\hline 108 & M & $\mathrm{OA}$ & 1.71 & Leprosy and TB & & Odontome \\
\hline 109 & & OJ & & Cribra orbitalia & & \\
\hline 110 & M & MA & 1.62 & $\begin{array}{l}\text { Osteosarcoma, corner of } \\
\text { (R) eye }\end{array}$ & & Scoliosis \\
\hline 111 & M & YA & 1.59 & DISH & & \\
\hline 112 & $\mathrm{~F}$ & $\mathrm{OA}$ & 1.56 & & & \\
\hline 113 & M & MA & 1.64 & & Sternum deviated & \\
\hline 114 & & YJ & & $\begin{array}{l}\text { Cribra orbitalia, } \\
\text { sinusitis }\end{array}$ & & $\begin{array}{l}\text { Lower deciduous m1s } \\
\text { shed, no permament } \\
\text { replacements }\end{array}$ \\
\hline 115 & M & $\mathrm{OA}$ & 1.80 & & & $\begin{array}{l}\text { Medial cuneiforms in } \\
\text { two parts }\end{array}$ \\
\hline 116 & M & YA & & & & \\
\hline 117 & M & $\mathrm{AD}$ & $\sim 1.66$ & Probable poliomyelitis & & \\
\hline
\end{tabular}




\section{$9 \quad$ Other Excavations}

Small-scale archaeological investigations have been carried out within the South Transept, in 1981 in the Choir Vestry and, during installation of a new organ in 1990-1, during reflooring of the Choir in 1993, and around the North Transept in 1992.

\subsection{Choir Vestry excavations}

Subsequent to the 1981 excavations in the South Choir Aisle, limited excavation was carried out later in the same year by Peter Raisen and Derek Hall below the floor of the Choir Vestry which lay in the crypt area below the southernmost bay of the South Transept (illus 6; illus 30; illus 31). The floor level in the Vestry (at $c 87.40 \mathrm{~m}$ AOD) was $2.30 \mathrm{~m}$ below the main church floor above; excavation was limited to a depth of $0.90 \mathrm{~m}$ below this.

The original site records were not available at the time of the compilation of this report but an interim report and a summary description of the stratigraphy encountered had been prepared immediately after the excavation, and this has been used as the basis of this account (Raisen \& Hall, undated). The finds from these excavations were deposited at the time with Edinburgh City Museums and Galleries and they are included in the relevant sections below, especially within the medieval pottery report, as a good assemblage of East Coast White Gritty Ware was recovered.

The earliest deposit was a substantial layer of firm yellow-brown clay (ECV C120) extending over the whole of the exposed area, with its upper surface at $c 86.70$ AOD. A single burial was found cut into the upper surface of this clay.

Above the clay, and sealing the burial, were two distinct sequential deposits, ECV C118, a mixture of disturbed clay and brown loam with much shattered stone (identified by the excavators as possible waste from stone dressing), and a midden deposit (ECV C114) containing deposits of ash, pottery and animal bone, with a suggested 13th-century date for the pottery. Two burials had been made through this midden deposit prior to the deposition of a firm clay loam (ECV C101), which had several burials cut into it.

Along the south edge of the excavated area, the foundations of a stone wall, running east to west were exposed, almost certainly the footings of the original wall of the Transept when it was extended $c$ 1500. The extant south wall of the Choir Vestry (and the Transept above) lay a small distance to the south of these footings, apparently constructed during Burn's reworking of this area in the 1820s.

In the upper level of clay (ECV C101), part of the stone foundation for a pier was exposed, and this may have formed part of the original superstructure of the crypt area formed below the South Transept at the time of its extension $c 1500$.

On the east side of the Vestry a blocked arch was uncovered within the original fabric of the Transept. It may originally have housed a tomb or effigy but subsequently it had been partially walled up to form a narrow rectangular space, heavily blackened with soot, with a flue leading out from it up the east side of the wall. A reference to the use of the adjacent Montrose vault as a coal-cellar immediately prior to the restoration of the South Transept in 1879-80 is relevant in this regard (article in The Architect, 21 August 1880, 125, quoted in Addyman \& Kay 2001, 105).

Along the west side of the Vestry, post-dating the construction of the Transept, was a tomb, seen to contain three lead coffins and fragments of a wooden one. The place has long been associated with the tomb of the Regent Moray who died in 1570 but no evidence was found to confirm this was his tomb. There was a plaque beside one of the coffins bearing the inscription: 'Francis Steuart Esq. Died at Rheims 7th October 1768. Aged 22'. The coffins were left undisturbed and the tomb was resealed.

\subsection{Installation of the new organ, 1990-1}

The installation of a new organ within the South Transept required excavation for concrete footings, including two deep pits (illus 30, A and B) which had to be taken down to solid deposits at depth. The initial excavation of these foundations was carried out by building contractors but, following the discovery of in situ stone walls and articulated human skeletons, the remainder of the excavation was carried out by staff from the City of Edinburgh District Council Archaeology Service. The pits were very limited in plan (a maximum of $1.1 \mathrm{~m}$ by $0.70 \mathrm{~m}$ ) and datable finds were absent. However, the stratigraphic sequence, which was identical in both foundation pits, is of value in considering the development of the south side of the church, and is described here and shown in section (illus 31 ).

At the base of the pits, a deep deposit of firm clay (ESG91 C21), with its upper surface at $c 87.35 \mathrm{~m}$ AOD, was encountered. Excavation to a depth of more than $1 \mathrm{~m}$ into the deposit showed that it was clearly redeposited with a sequence of layers of differing clays, some with a high fraction of sand, and at the base a deposit of clean yellow sand.

Above this, two distinct sequential deposits, both compact dark loams (ESG91 C20 \& C17), had been 


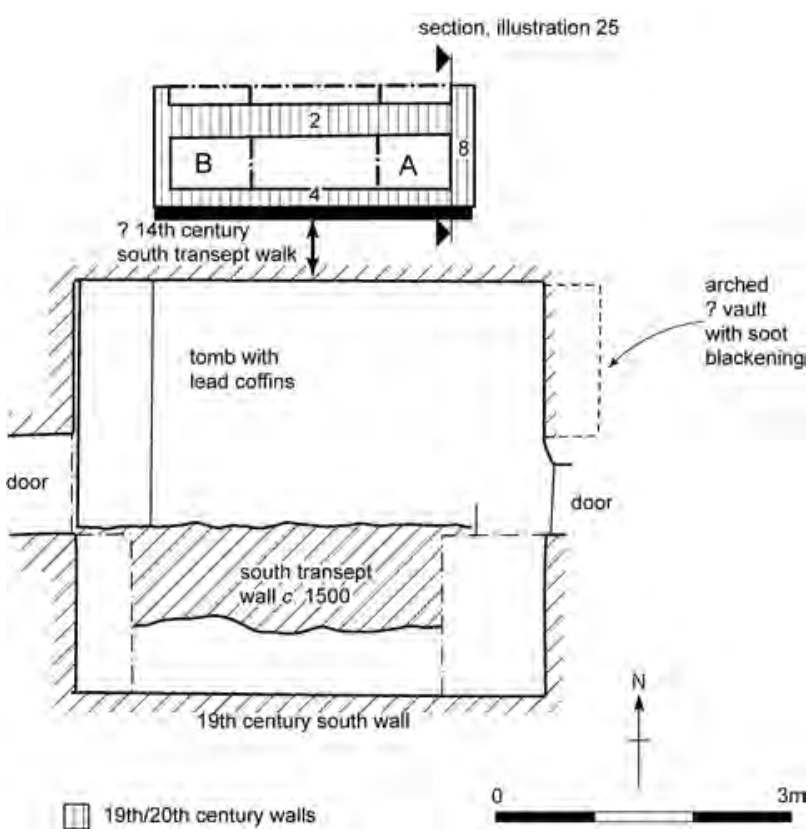

Illus 30 Plan of South Transept showing features recorded in 1981 (Choir Vestry excavations) and 1990-1 (organ foundation excavations)

deposited and/or accumulated to depth of almost $1 \mathrm{~m}$, with the upper surface of C17 lying at $c 88.20 \mathrm{~m}$ AOD. Both deposits were the matrix for a number of in situ burials, none showing any signs of an associated coffin, although copper-alloy pins, presumably used as shroud fastenings, were found. C17 was then clearly cut by the construction trench for a coursed rubble wall (ESG91 C5), the upper level of which lay just beneath the modern floor of the South Transept. The south face of this wall was also exposed within the Choir Vestry excavations. Against its north face, and over the fill of the construction trench, a deposit of mortar (ESG91 C9) was probably the bedding for paving of the floor contemporary with the wall. It can be presumed that the wall (ESG91 C5) was the external south wall of the Transept prior to its expansion by the addition of St Anthony's Aisle to the south in $c 1500$.

Above the mortar surface was a sequence of sleeper walls (ESG91 C4, C8 \& C22) and ducts for the sub-floor heating system, all associated with the 19th-century building works in this area, and with the foundations of the original organ.

\subsection{Reflooring of the Choir, 1993}

In January 1993, monitoring of the installation of underfloor heating within the central area of the Choir (illus 6) required the removal of loose rubble and overburden to a depth of $0.25 \mathrm{~m}$. The discovery, in the early stages of the work in the second bay of the Choir, of wall remains and clear evidence for graves led to a revised methodology for the works in the rest of the Choir, with excavation subsequently confined within the 19th-century rubble to protect the

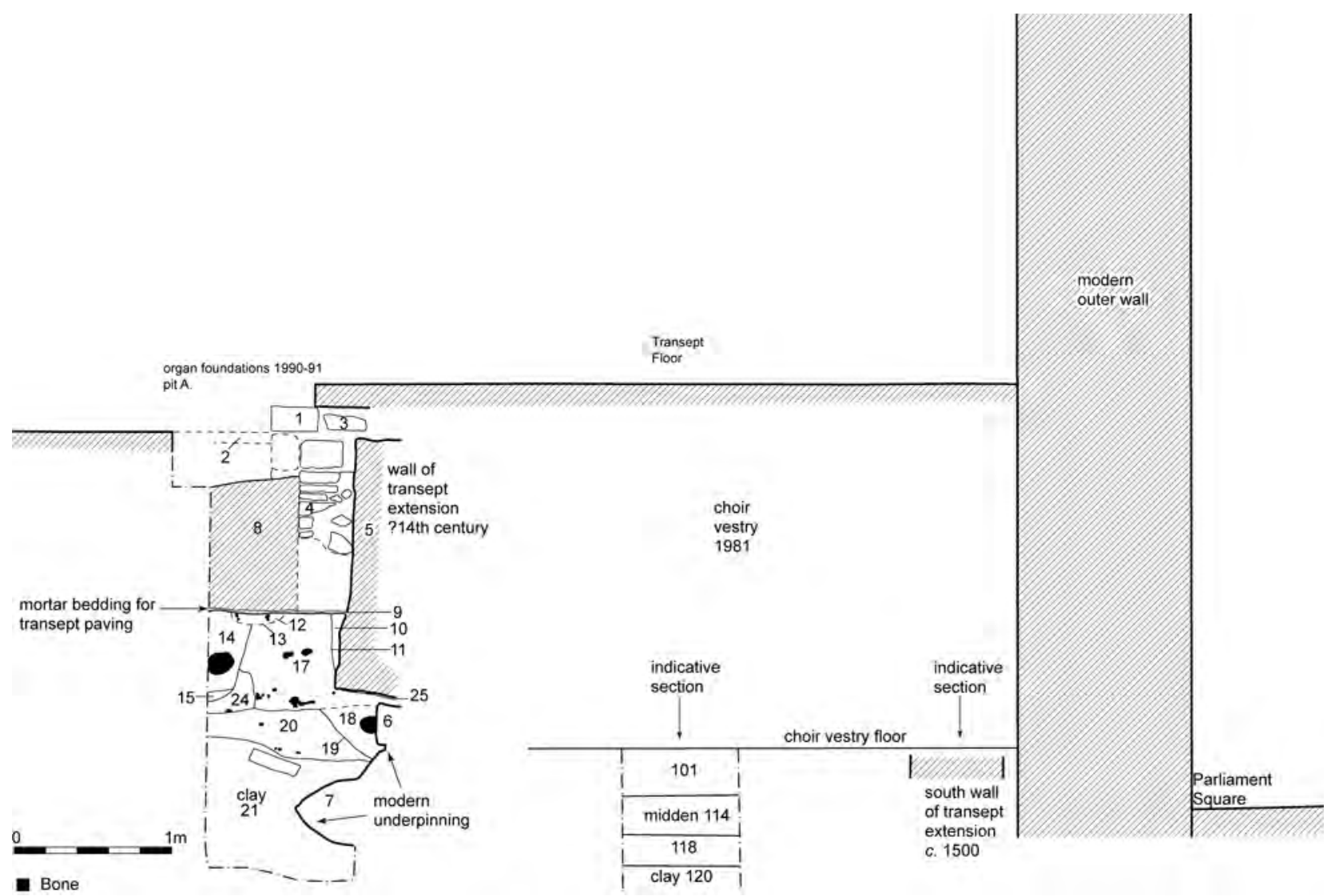

Illus 31 Section across South Transept, information from 1981 Choir Vestry excavations and 1990-1 organ foundation excavations 


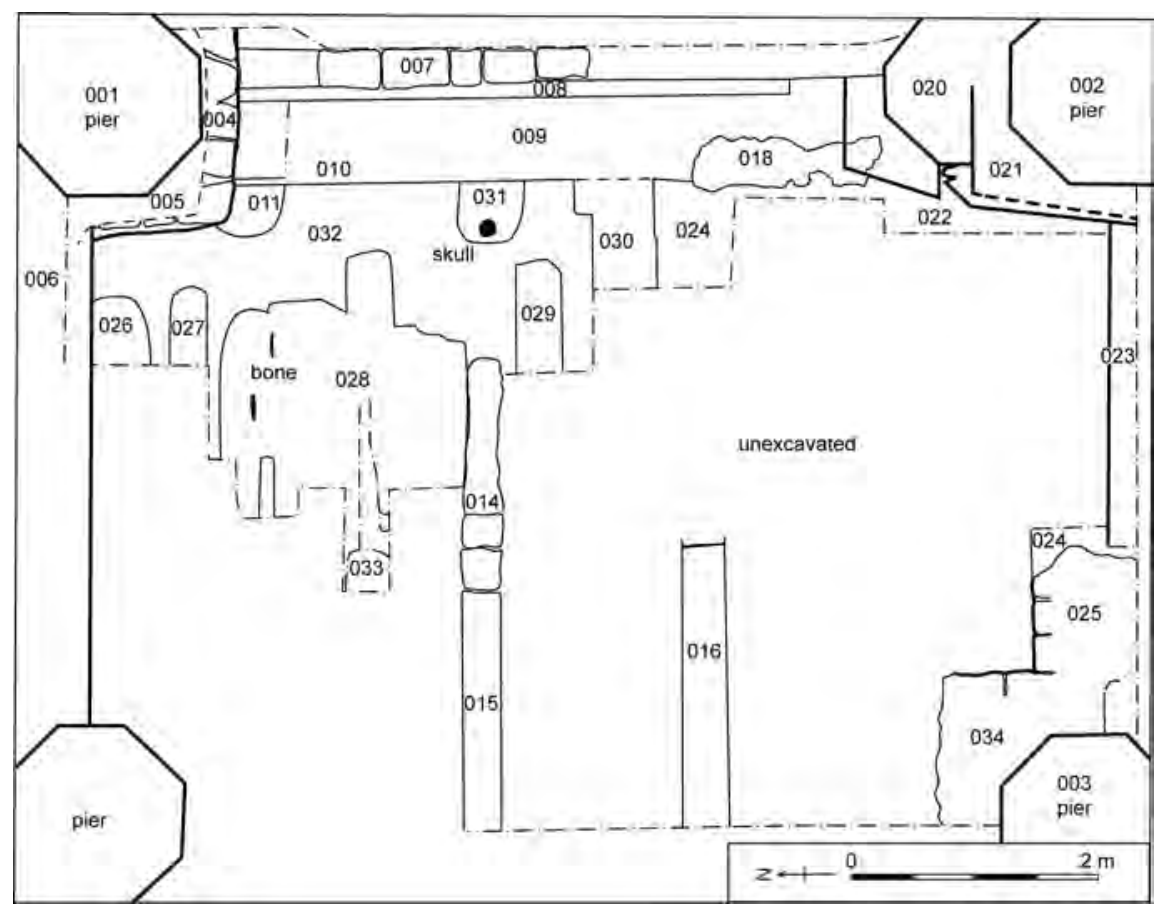

Illus 32 The Choir 1992: plan of recorded features

archaeological remains. Within the area of original ground reduction, the archaeological features, where exposed, were recorded in plan (illus 32) but no further investigation was carried out.

Removal of the 19th-century floor and rubble make-up revealed an extensive spread of pinkishbrown clay (ESG93 C32) across the width of the Choir, into which a series of clearly distinguishable graves had been cut; these were clearly truncated, as in situ human bone could be seen in the surface of the fills. Its upper surface lay at $c 89.05 \mathrm{~m}$ AOD. Although no dating evidence was recovered, the area of investigation was the site of the high altar in the later medieval church, and it is notable that at least some of the graves lay directly beneath where the altar must have stood.

The conclusion that the burials are likely to predate the extension of the earlier medieval church is reinforced by the fact that the sub-base foundation (ESG93 C4) of the northern pier (ESG93 C1) at the junction of the first and second bay, sat directly on top of the boulder clay and clearly overlay a grave (ESG93 C11) on its south side. The carved heraldic shields displayed on the pier above are dated by heraldry to $c 1453$ (RCAHMS 32), giving at least a terminus ante quem for both the clay and grave, although by analogy with similar deposits described elsewhere in this report, it is likely that both the clay, and the graves cutting it, date from several centuries earlier. The footing was only two courses in depth, and the floor level of the later medieval church in this area must have been almost identical to that of the modern church, as demonstrated by the top of the footings (ESG93 C21) of the corresponding southern pier (ESG93 C2) which lay only $0.07 \mathrm{~m}$ below the present floor level. The footings of the southern pier extended deeper than those of the northern, and the surface of the clay was not seen in this area as it sloped away to the south.

Between the footings of the eastern piers of the bay, across the full width of the central Choir, ran a shallow robber trench (ESG93 C10), broad but shallow, with sharp vertical edges. Filled with a loose rubbly deposit (ESG93 C9), which contained fragments of tile or brick, its eastern edge was not seen as it lay beneath a later sleeper wall (ESG93 C8), but its western edge was coincidental with the western face of the columns between which it ran. This robber trench, and also presumably the structure which was removed by the robbing, cut through graves in this area. It is suggested that this structure may have been part of the high altar in the mid-15th-century and later medieval church, and may perhaps be seen as the footing for the reredos. At the southern end, adjacent to the pier (ESG93 C2), was a polygonal plinth (ESG93 20) of mortared ashlar blocks, supported on a massive single stone foundation block. The relationship with the column was obscured by mortar but the plinth seems to be contemporary with the pier. The plinth seems likely to have formed part of the structure of the high altar.

Two rubble wall foundations (ESG93 C25 \& C34) were partially exposed, running between the piers of the bay. Although their relationship with the pier footings here was not clear, these walls were similar in form and function to those recorded in the excavations in the South Choir Aisle which had been constructed in Period 3b, either as below-ground buttressing between piers during the alterations in the Choir and its southern aisle of the $1450 \mathrm{~s}$, or simply as sleeper walls. 
All other features recorded were post-medieval in date.

\subsection{North Transept, 1992}

In 1992, two watching briefs were carried during the excavation of service trenches inside and outside the door of the North Transept (Johnston 1992a; Johnston 1992b) (illus 6). Inside the northern doorway, sandstone bedrock was observed immediately below the floor at $87.87 \mathrm{~m}$ AOD, while monitoring of a service trench along the northern side of the church showed that bedrock in this area lay at $c 86.93 \mathrm{~m} \mathrm{AOD}$, again immediately below the modern ground level. 


\section{The Finds}

\subsection{The pottery by Derek Hall \& George Haggarty}

This report considers the medieval and later pottery from the sites excavated at the east end of the Cathedral and in the Choir Vestry in 1981, as well as medieval material recovered from the 1977 geotechnical trial pit excavations.

The medieval assemblage consists, in the main, of material of Scottish manufacture. In total, 866 sherds from both sites are represented. All the sherds were examined by microscope at a $\times 20$ magnification in an attempt to define separate fabric types. In the fabric descriptions an attempt has been made to convey the hardness of the fabric and the frequency and size of the inclusions present. No petrological analysis was carried out.

\subsubsection{South Choir Aisle, 1981}

Scottish White Gritty Ware (SWGW) Ninetyfour per cent of the medieval pottery from the South Choir Aisle excavations consists of variations of this ceramic type (illus 33). Recent work would seem to indicate that the three main production centres for this pottery were the Lothians, Borders and Fife, and these may show both regional characteristics and trade (Haggarty 1984; Hall 1997). The results of the recent pilot ICP-MS chemical sourcing project have for the first time suggested that the SWGW industry is more complicated and widespread than previously assumed (Chenery et al. 2004). This ceramic type has now been recovered from a number of east coast Scottish burghs such as Leith in association with 12th-century imported pottery
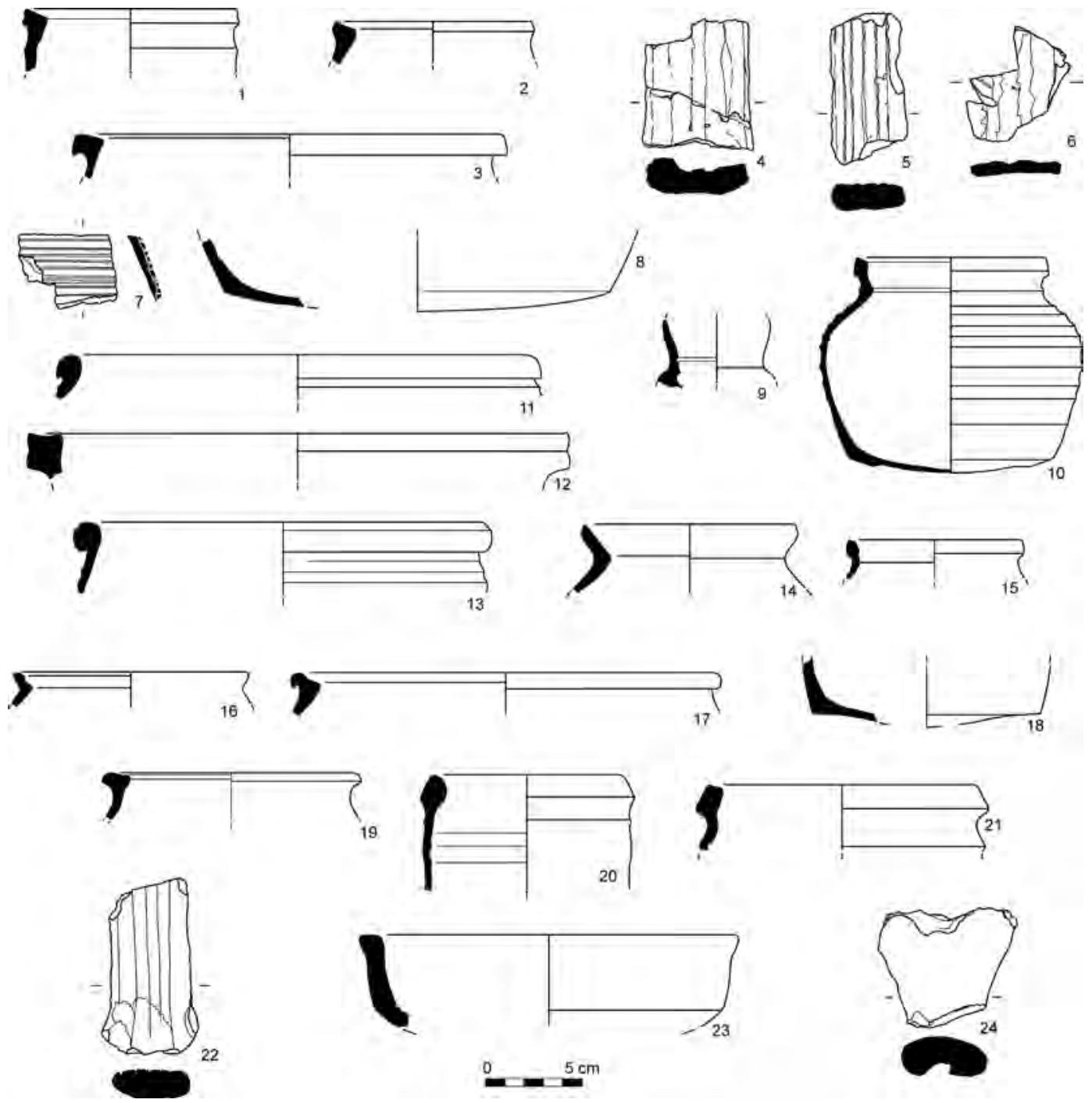

Illus 33 Pottery: East Coast White Gritty Ware; South Choir Aisle, 1981 


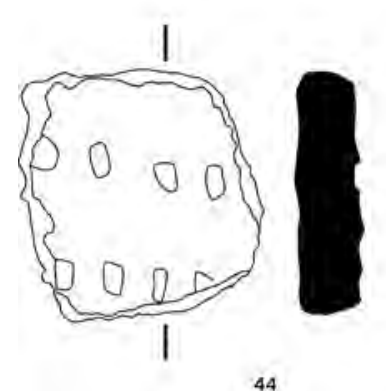

44

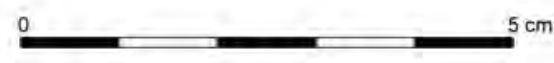

Illus 34 Pottery and cannel coal counters
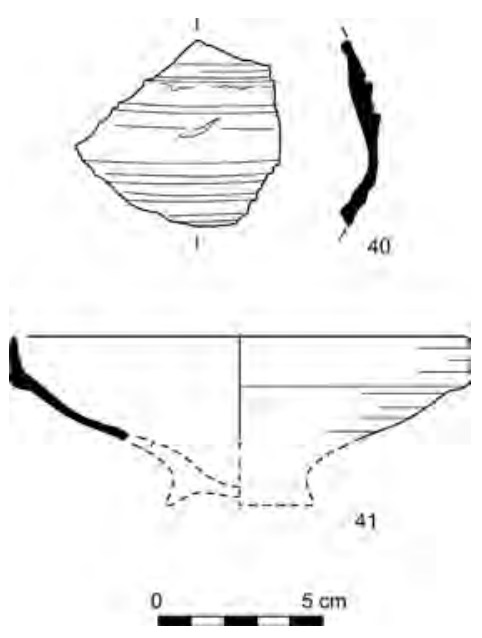

Illus 35 Pottery: stoneware

including Developed Stamford Ware (John Lawson, pers comm).

The White Gritty Wares from the excavations exhibit variations in colour, probably indicating different firing conditions within the kiln or usage. The most common variation in this pottery is reduced grey in colour, containing abundant quartz grits and occasional red sandstone fragments. Some sherds possess an external pink slip and are smokeblackened, while another common group is pink in colour with a white core (P2a).

Jugs are the most common vessel type in this assemblage and outnumber cooking pots by at least three to one. There are two sherds from a dripping pan from C246 in P3, a local copy of a Low Countries Redware vessel type (Verhaege 1983). A bodysherd from C84 (P2b) has been reused as a counter (see illus 34,45$)$.

East Coast Redwares More than 20 years of archaeological excavations along the Scottish east coast, in
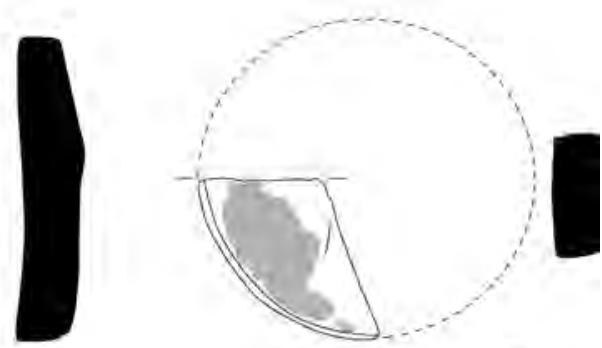

45

46

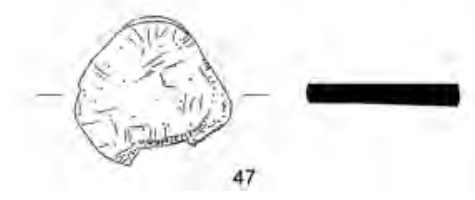

particular Perth and burghs north of the River Tay, have identified this widespread industry as forming a tradition of native pottery production, apparently dating from the 13th to the 15th centuries (Hall 1996, 126). Archaeological evidence also suggests that in the Lothian area, where white firing pottery (SWGW) was the norm during this period (Brooks 1981), material was liable to be imported in only very limited quantities from the Redware production sites to the north of the Tay (Hall 1998, 170). There are eight Redware sherds present in the assemblage from the 1981 South Choir Aisle excavations in St Giles', from Periods 3 and 4.

\section{English Imported Wares}

Yorkshire-type wares Vessels in these often distinctively glazed fabrics are generally the most common imports in the Scottish east coast burghs in the 13th and 14th centuries (McCarthy \& Brooks 1988, 227-52). There are six sherds from a minimum of three jugs from C84 (P2b).

\section{Continental Imported Wares}

Beauvais or Siegburg stonewares A small unglazed bodysherd $(\mathrm{C} 9, \mathrm{P} 4)$ and a rim sherd from a drinking bowl in a beige/mushroom colour fabric (C25, P4; illus 35, 41) could either be from Siegburg in the Rhineland or Beauvais in France. These vessels are generally believed to have been produced in the 15th and early 16th centuries at both Siegburg in the Rhineland (Beckmann 1974, 161-4; Gaimster 1997, 168-9) and in France in the area of Beauvais (Hurst et al. 1986, 105). As the fabrics are visually similar, without analysis it is impossible to be sure of the source for the numerous Scottish finds. However, in many instances, unlike this example from St Giles', the Scottish examples have been recovered in asso- 

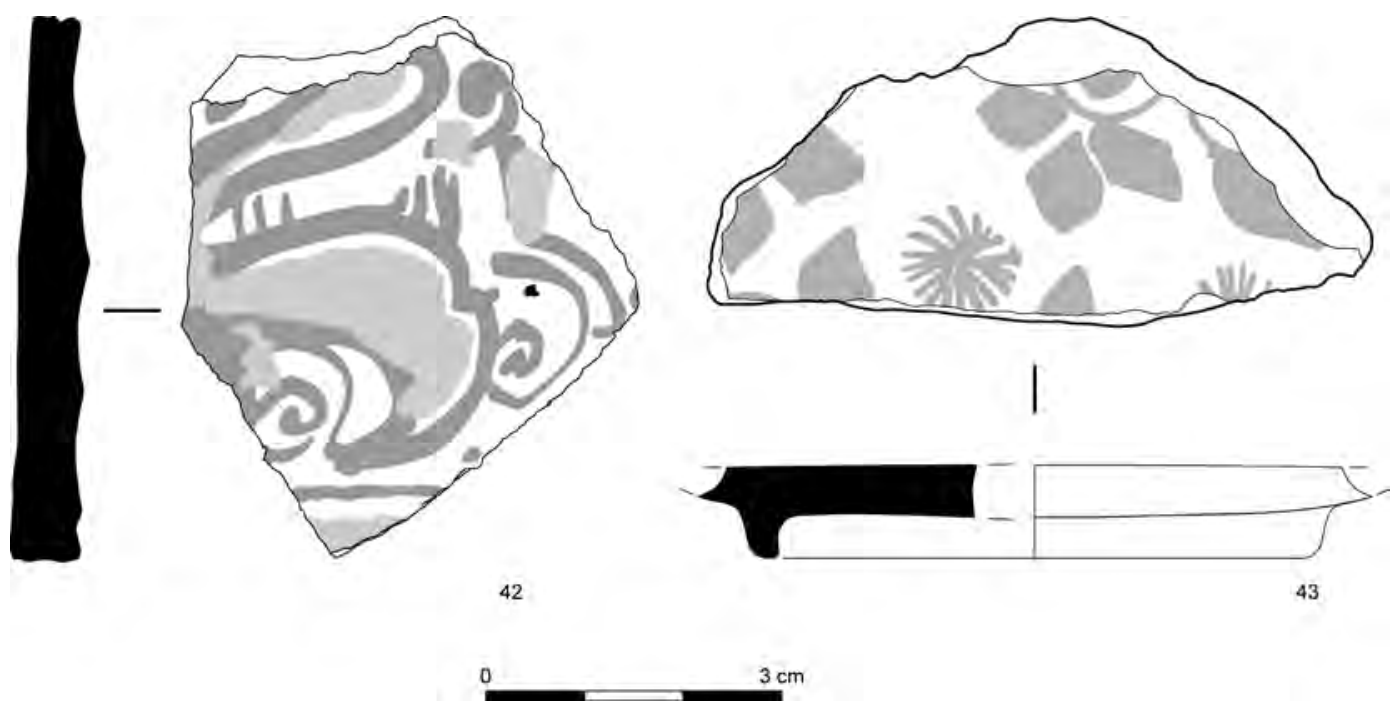

Illus 36 Pottery: Anglo-Dutch wares
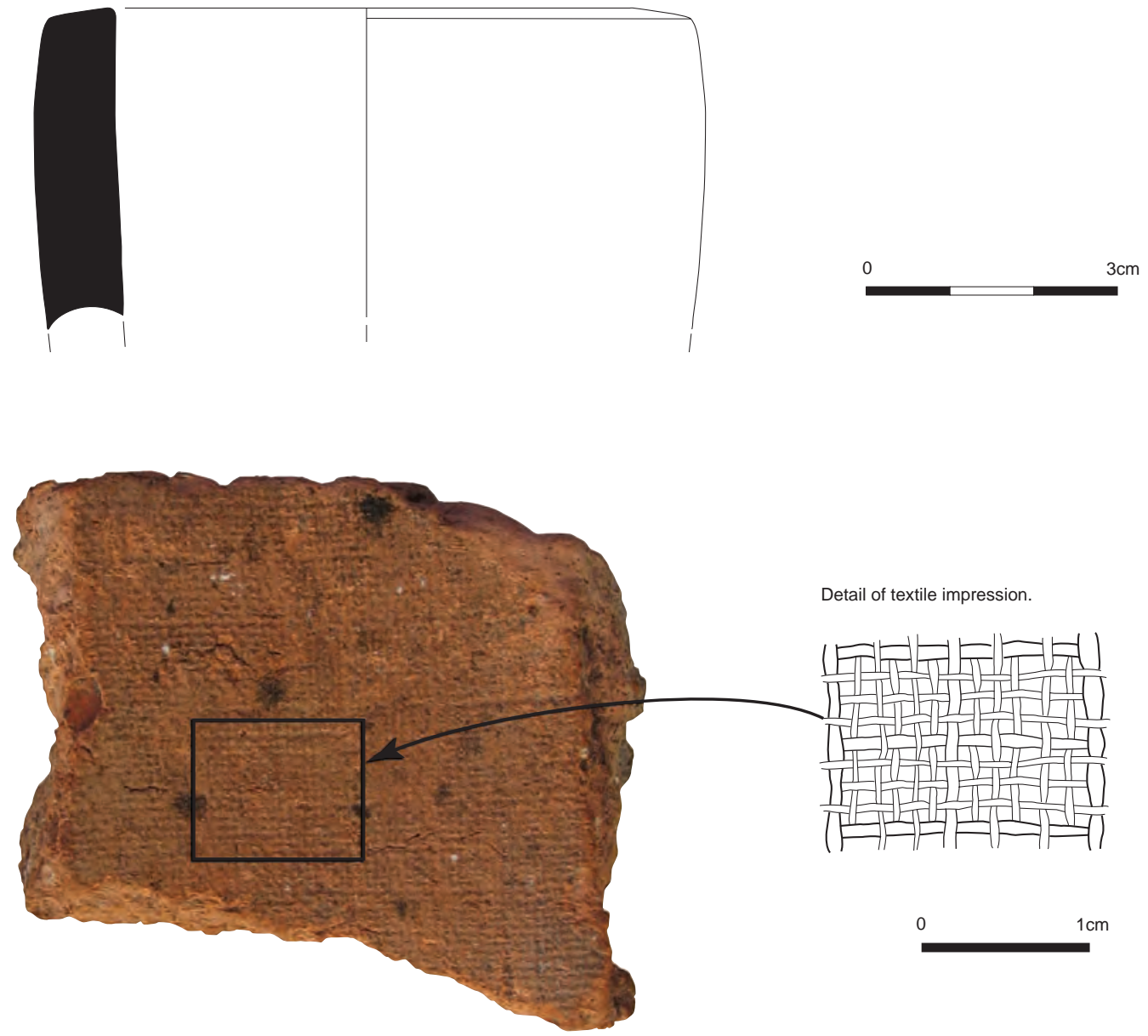

Illus 37 Pottery: 14th/15th-century crucible sherd with cloth impression on interior surface

ciation with Beauvais earthenware, which suggests that most of the examples recovered in Scotland may be French (Haggarty, forthcoming b).

Raeren stoneware There are six sherds of Raeren stoneware, probably all from the ubiquitous 16 th- century drinking mugs, from contexts 84 (P2b, where it is probably intrusive) 22,53 and 151 (all P3). There is also a further bodysherd (C53, P3; illus $34,46)$ which has been reused as a counter; this sherd also shows signs of wear and survives only as a quarter of the original circumference. 


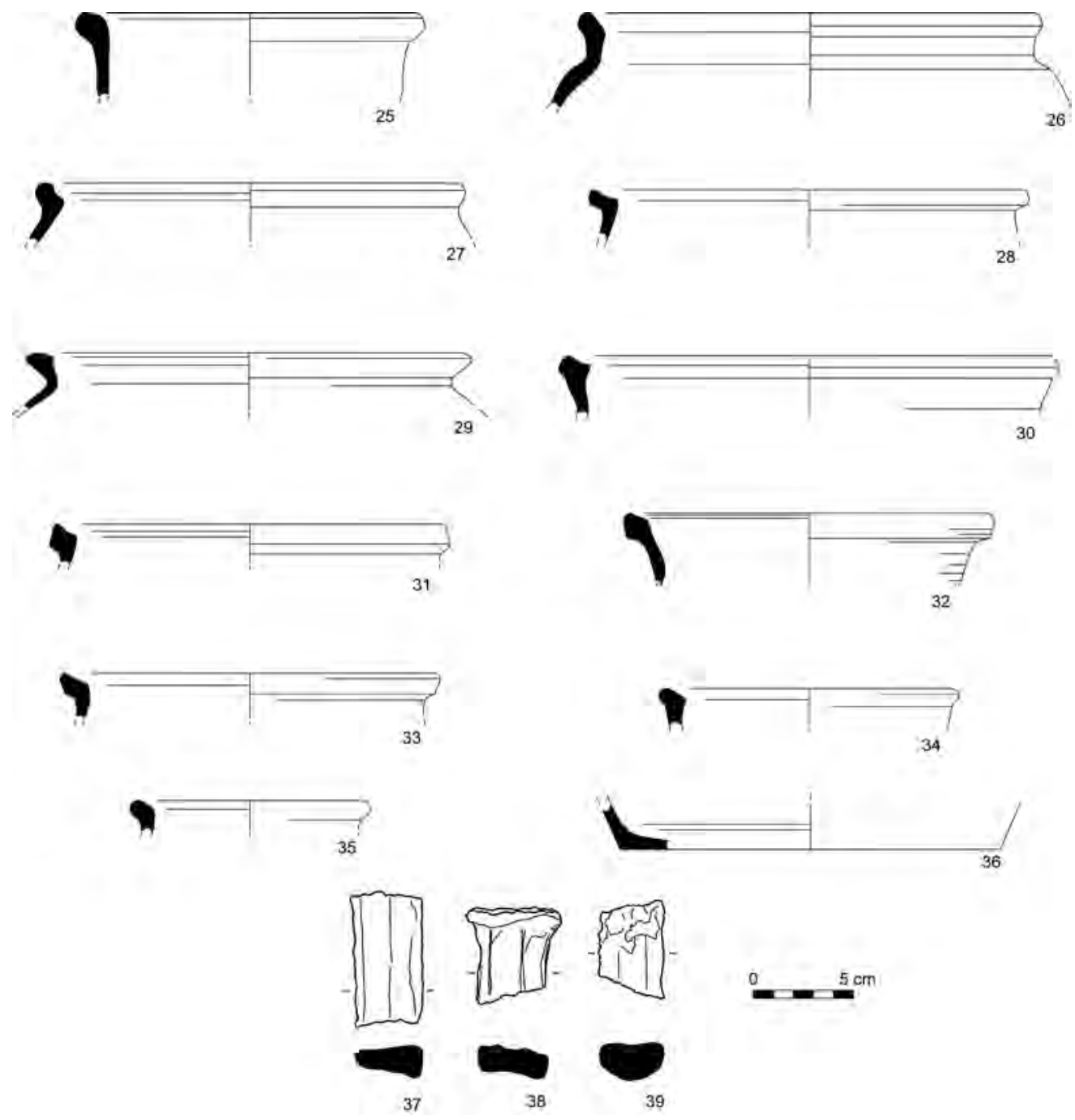

Illus 38 Pottery: East Coast White Gritty Ware; Choir Vestry, 1981

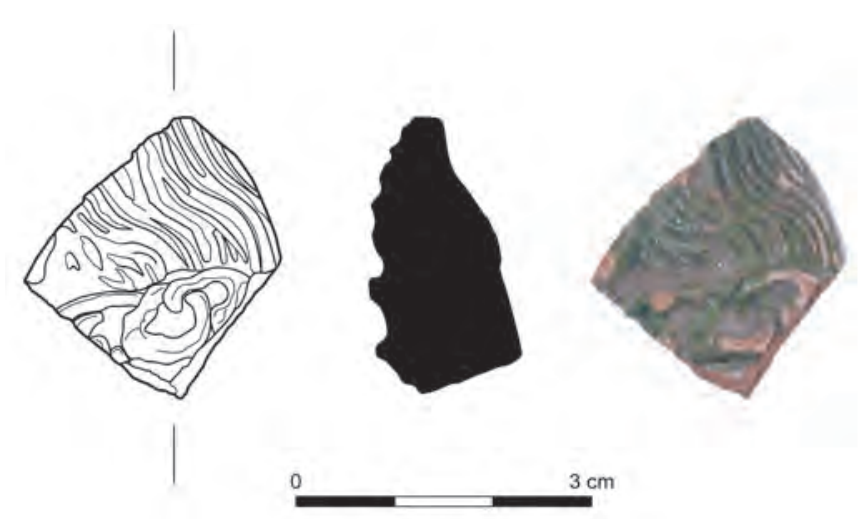

Illus 39 Ceramic building material: stove tile 15th-17th century; C25

Unprovenanced stoneware There is one heavily rilled bodysherd from C25 (P4; illus 35, 40). This is from the shoulder and belly of a small globular stoneware jug covered on the exterior with a thick coating of glossy light grey glaze which is in turn covered with spots of dark brown. The sherd is also decorated with a pair of prominent incised lines, which have formed horizontal cordons. These can be paralleled on some Raeren vessels (Hurst et al. 1986, 197). The fabric, however, for this vessel is sandy in texture, reddish in colour with small black inclusions, and its provenance is unknown.

Tin-glazed earthenwares Three sherds of tinglazed earthenware were recovered from all the excavations. Two bodysherds from albarellos (drug jars) were found in C11 (P4). The bodysherd illustrated is from an albarello in a buff fabric, decorated in a brown and blue abstract design (illus 36,42 ). The third sherd (from C25, P4; illus 36, 43) is a flat basesherd with a small foot-rim from either a small plate or shallow dish. All three sherds probably date to the 17 th or 18 th centuries.

French wares Three small bodysherds were recovered which are likely to be French in origin, possibly Saintonge, though this is far from certain as they are difficult to identify accurately given their size. The sherd from C87 (P3) is unglazed, thin and well-potted in a buff/pink fabric, and may be early 
Saintonge. Two sherds from C6 (P3) and C101 (P2b) were also unglazed but thicker, and may possibly be Saintonge but dating to the 15 th century.

Low Countries highly decorated ware There is one sherd, apparently from a green-glazed jug (Verhaege 1983), in this fabric from C84 (P2).

Other ceramics Two ceramic pieces from contexts C84 (P2b) and C81 (P3b) were identified, apparently in the same red earthenware fabric as the floor tiles, but with a reduced grey core. Much thinner than the floor tiles, these would seem more likely to have come from some sort of vessel. The piece from C84 is glazed yellow-green and is slightly curved.

A single piece of fired clay from a crucible or mould with internal textile impressions was found, dating to the late 14th to mid-15th century (C22, P3; illus 37). It is difficult to assign a function to this object; bell moulds normally have traces of textile impressions on the outside surface not the inside (Cox 1997, 92-4).

\subsubsection{Choir Vestry excavation (1981) and geotechnical trial pits (1977)}

The 1981 Choir Vestry excavation produced an interesting group of jars in SWGW apparently used for cooking and as jugs (illus 38). These include a straight-sided vessel from context ECV C118 (Cat 34 ), probably of 12 th-century date, and a mixture of rim forms from context ECV C114 that resemble vessels from excavations in Edinburgh, Leith and Coulston dating to the late 12th to early 14th centuries. The jug forms include three green-glazed strap handles from context ECV C114 (illus 38, 379) which have a flat edge, indicating that they had been cut off the wheel rather than pulled.

Twenty-seven sherds of pottery were found in a trial pit excavated in 1977. Nineteen of these join to form an almost complete jar in SWGW (illus 33, 10). The remaining eight sherds are all bodysherds from jugs.

\subsubsection{Conclusions}

Using native Scottish fabrics to date archaeological deposits is fraught with difficulties given the absence of reliable chronologies (Hall 1996). At St Giles' it may be reasonable to suggest that the earliest phases (P2a) are later 12th century in date. Sherds of Yorkshire-type wares do not occur until Period 2b, whilst the appearance of Rhenish stonewares in P2b would date this activity to the mid-14th century.

\section{Illustration catalogue}

\section{White Gritty Ware (illus 33)}

1 Rimsherd from jug glazed green brown. C196, P2a

2 Rimsherd from jug glazed green. C196, P2a
3 Rimsherd from jug glazed yellow. C30, P3

4 Strap handle with applied vertical strip glazed brown on green background. C84, P2b

5 Strap handle fragment glazed green with vertical incised lines. C22, P3

6 Bodysherds from jug glazed yellow with applied vertical brown-glazed strips. C84, P2b

7 Bodysherds decorated with horizontal incised lines glazed green-brown. C130, P3b

8 Basesherds from unglazed jug. C175, P2a

9 Pedestal basesherd from small vessel glazed green. C77, P2a

10 Virtually complete globular storage jar or drinking vessel. 1977 geotechnical trial pit

11 Rimsherd from unglazed storage vessel. C175, P2a

12 Rimsherd from unglazed storage vessel. C175, P2a

13 Rimsherd from storage vessel. C130, P3b

14 Rimsherd from jar internally glazed green-brown. C20, P4

15 Rimsherd from heavily reduced cooking pot. C223, P2a

16 Rimsherd from cooking pot. C197, P2

17 Rimsherd from cooking pot with slight traces of external smoke blackening. C134, P3

18 Basesherd from heavily reduced cooking pot. C175, P2a

19 Rimsherd from?straight-sided cooking pot. C185, P2b East Coast Redware (illus 33)

20 Rimsherd from jug glazed green-brown. C84, P2b

21 Rimsherd from jug with splashes of green glaze. C84, $\mathrm{P} 2 \mathrm{~b}$

22 Strap handle decorated with vertical incised lines glazed green. C130, P3b

23 Rim and base profile from small open vessel with spout glazed green internally with traces of external purple wash. C9, P3

24 Fragment of unglazed skillet handle with traces of external smoke blackening. C22, P4

Scottish White Gritty Ware, Choir Vestry excavation, 1981 (illus 38)

25 Rimsherd from straight-sided cooking jar. C118

26 Rimsherd from cooking jar. C114

27 Rimsherd from cooking jar. C114

28 Rimsherd from cooking jar. C114

29 Rimsherd from cooking jar. C114

30 Rimsherd from cooking jar. C114

31 Rimsherd from cooking jar. C114

32 Rimsherd from cooking jar. C114

33 Rimsherd from cooking jar. C114

34 Rimsherd from cooking jar. C114

35 Rimsherd from cooking jar. C114

36 Basesherd from cooking pot. C114/118

37 Green-glazed strap handle. C114

38 Green-glazed strap handle. C114

39 Green-glazed strap handle. C114

Imported stonewares (illus 35)

40 Heavily rilled sherd from the shoulder and belly of a small globular stoneware jug. C25, P4

41 Rimsherd from a well-potted, typical smooth stoneware drinking bowl of Beauvais or Siegburg stoneware. C25, P4

\section{Tin-glazed earthenwares (illus 36)}

42 Albarello bodysherd, decorated in a brown and blue abstract design. C11, P4

43 Basesherd from a small plate or shallow dish. Probably Dutch, late 17 th or early 18 th century. C25, P4

Pottery and Shale counters (illus 34)

44 Scottish White Gritty Ware counter. ECV C114

45 Scottish White Gritty Ware counter. C84, P2b 
46 Raeren stoneware, quarter fragment. C53, P3

47 Cannel-coal counter. C84, P2b

\subsection{The ceramic building material by Derek Hall}

Forty-nine fragments of ceramic building material were recovered from the 1981 excavation in the South Choir Aisle, 44 of which are of medieval date.

\subsubsection{Floor tile}

Forty fragments of floor tile were recovered, all of which were manufactured in a red-brown earthenware fabric. The majority of the tile fragments were recovered from Period 3 contexts, although three were found in Period 2a (C182, C196 and C229). Other fragments also occurred in other Period 2 (C55, C84, C101, C175). Very few of these pieces have any surviving traces of glaze but the presence of spots of yellow and green colour on some fragments suggest that that was the colour of these tiles. There are also traces of a white slip below the glaze on some of the tiles. The closest parallel for these tiles would seem to be those recovered from the excavations of the Trinitarian Friary in Dunbar (Eames 1983, 485). At Dunbar, the tiles were dated to the 15 th or early 16 th centuries and given a Low Countries provenance. There is nothing present in the St Giles' assemblage to suggest the presence of highly decorated floor tiles such as those that have been recovered from Newbattle and Melrose Abbeys or the Cistercian nunnery at North Berwick (Richardson 1929, 28497). Recent chemical sourcing of Scottish redware tiles from several abbeys and castles is suggesting that many of these were locally produced rather than imported (Chenery et al. 2005). With this in mind, it is intriguing that the presence of a waster at St Giles' from context 022/040 (P3) may suggest that tiles were being made in the vicinity.

\subsubsection{Stove tile}

Of most interest in this assemblage is the glazed decorative fragment from a ceramic stove tile from C25 (P4; illus 39). The fragment has the remains of the depiction of the hair and clothing of a human figure. St Giles' is only the fourth site in Scotland to produce a piece from one of these ornately decorated medieval central heating systems which are dated to the 15 th to 17 th centuries (Gaimster 1990, 4). The other pieces were found in excavations at St Nicholas Leper Hospital, St Andrews (Haggarty 1995), Calton Road, Edinburgh by AOC Archaeology Ltd (Haggarty, forthcoming a) and excavations in advance of the construction of the new Scottish Parliament building at Holyrood, Edinburgh (Hall, forthcoming). The fabric of the piece from St Giles' is very dark red, and appears to be North German in style. It has been dated to the late 15 th century and may belong to one of the well-known North German pre-Reformation devotional niche-tiles types (D Gaimster, pers comm). The hair may belong to a bearded saint (Gaimster 2001, 51-66, fig 14). This is an important find, being the first in Scotland.

\subsection{Coins and jetons by Nicholas Holmes}

The 15 numismatic finds comprise ten Scottish base metal coins from the reigns of the first four Jameses (1424-1513), one 17th-century French copper piece and four brass jetons made in Nuremberg between about 1480 and 1560 .

The earliest coin, a very worn billon penny of James I or II (1424-1460) (Cat No 1) was found in the backfill of the robber trench (C9, P3) of the original east wall of the late medieval church and it is unfortunate that it has not been possible to date this item more accurately.

The billon and copper coins from the reigns of James II-IV (1460-1513) all belong to Period 3, during which the burials were inserted beneath the floor of the South Choir Aisle, and indeed five of them were recovered from the fill of graves. Only one jeton came from an undisturbed context (Cat No 13, P3).

Only the French double tournois of Louis XIII (Cat No 11) dates demonstrably later than the final phase of burials. Its recovery from the fill of a pit (C13, P4) confirms that the latter must have been associated with some fairly late (P4, mid-17th century or later) construction or repair to the church. The presence of this coin also demonstrates that the two other coins (Cat Nos $3 \&$ 9) and possibly also the jeton (Cat No 15), which were also found in the same context, must have been redeposited in the backfill of the pit.

\section{Catalogue}

\section{Scotland}

1 James I or II billon penny, otherwise unidentified (14241460), very worn and mostly illegible. C9, P3b, SF231: from fill of robber trench of original east wall of church 2 James II-III copper 'Crux Pellit' issue, type IIIb ( $c$ 14511482 ?); diameter $21 \mathrm{~mm}$, weight $1.82 \mathrm{~g}$; die axis 1.0 ; uneven striking; slight surface accretion; moderate wear. Obv.: + [IACOB] VS * DEI * GRA * REX *; closed Old English Es; star stops; orb tilted upwards and to right, with rosette on centre. Rev.: + CRVX: PELLIT: OIE: CRIM; closed Old English Cs and Es; double annulet stops; pellets on cusps; nothing in spandels. C15, P4, SF14; redeposited in construction trench for modern heating duct

3 James III billon penny, class Cv (a or b) (c 1475-1482); diameter $13.0 \times 12.5 \mathrm{~mm}$; weight $0.40 \mathrm{~g}$; die axis 6.0 ; slight bent; worn. C13, P4, SF16; from fill of pit

4 James III copper farthing, first issue (c 1465/6): diameter $12.5 \mathrm{~mm}$; weight $0.25 \mathrm{~g}$; die axis uncertain; much edge damage; very worn and corroded. C65, P3b, BP5, SF121: from fill of grave containing SK18

5 James III copper farthing, second issue (c 1466); diameter $14.0 \times 14.5 \mathrm{mmm}$; weight $0.67 \mathrm{~g}$; die axis 9.0 ; 
uneven striking; obverse slightly off-centre; fairly worn. Obv.: [+I] ACOB [ ] DEI [ ]; closed Old English C and E; saltire stops. Rev.: +IACOBVS DEI GR [ ]; closed Old English C and E; saltire stops. C22, P3, SF94: from soil deposit cut by latest burials

6 James III copper farthing, 'ecclesiastical' type 1 ( $c$ 146582 ); diameter $15 \times 14 \mathrm{~mm}$; weight $0.61 \mathrm{~g}$; die axis uncertain; irregular angular flan; uneven striking; moderate wear. C78, P3, BP4, SF152: from fill of grave containing SK22

7 James III copper farthing, 'ecclesiastical' type 1 (c 1465-82); diameter $12 \times 11.5 \mathrm{~mm}$; weight $0.28 \mathrm{~g}$; die axis uncertain; irregular angular flan; uneven striking; moderate wear. C78, P3, BP4, SF153: from fill of grave containing SK22

8 James IV billon penny, second issue, type IVa ( $c$ 15001510 ); diameter $15 \times 14.5 \mathrm{~mm}$; weight $0.46 \mathrm{~g}$; die axis 2.0 ; some edge damage and surface corrosion; fairly worn Obv.: [ ] BVS DE [ ] REX SCO [ ]; closed Old English C and Es; pellet stops. Rev.: +VIL / [ ] DE / ED [ ] / BVR; closed Old English E; lis in first and third angles of cross. C41, P3, BP4, SF68: from fill of grave containing SK8

9 James IV billon penny, second issue, type III or IV (c $1500-1510$ ); diameter $16 \times 14 \mathrm{~mm}$; weight $0.47 \mathrm{~g}$; die axis 6.0 ; broken and repaired; much flattening and surface corrosion on obverse and some on reverse; moderate wear. Obv.: [] COTO [ ]; closed Old English C. Rev.: +VILL / [ ] / EDIn / BVRG; closed Old English E; lis in first and third angles of cross. C13, P4, SF35: from fill of pit

10 James III, IV or V billon plack (fragmented) (14671526); weight $0.48 \mathrm{~g} ; c$ one third of coin; bent; much flattening and surface corrosion. C67, P3b, BP5, SF123: from fill of grave containing SK19

\section{France}

11 Louis XIII copper double tournois (1639?), probably Duplessey (1989) type 1372; Diameter $19 \mathrm{~mm}$; weight $2 \mathrm{~g}$ die axis 6.0; obverse very worn; reverse fairly worn with some flattening. C13, P4, SF7; from fill of pit.

\section{Nuremberg Jetons}

12 Anonymous 'Dauphine'-type (c 1480-1500?), cf Mitchener (1988) 1043-1044a; diameter 32mm; weight 3.35g; die axis 9.0; some edge corrosion; gouge-mark through middle; mostly worn. Obv.: crown VIVAnV: EnV [ ] VnmOIDEVnE: unbarred A; closed Old English Es; quartered field, with dolphins in first and third angles, three lis in second and fourth. Rev.: crown AVBOnEmn EnVOLABOn [ ]; unbarred A; closed Old English Es; field of France. C25, P4, SF42: from redeposited material in upper layers

13 Anonymous 'ship penny' type (c 1490-1550?); diameter $27.5 \mathrm{~mm}$; weight $2.24 \mathrm{~g}$; die axis 11.5 ; chipped at $9.5-11.5$ on obverse; pierced and peck marked; moderate wear. Obv.: crown AVREON: VIANVRVEO; V [ ] R; Ns reversed; first A barred, second unbarred; ship sailing to left. Rev.: crown AV[] VIRVNV: ERIGVR: VOEVN'.; Ns reversed; four lis within a lozenge; ornament by each side of lozenge. C22, P3, SF83: from soil deposit cut by latest burials

14 Rose/orb type, almost certainly by Iorg Schultes (master 1515-1559) although unsigned; diameter 24.5 $24 \mathrm{~mm}$; weight $1.28 \mathrm{~g}$; die axis 8.0 ; some surface corrosion and accretion; moderate wear. Obv.: crown IESVS trefoil KRISTVS; three crowns and three lis arranged alternatively around a six-petalled rosette. Rev.: crown IESV [ ] RISTVS G trefoil; imperial orb surmounted by cross pattee, within tressure of three simple arches; trefoils in spandrels. The crown initial mark, three curved tressure and trefoil ornaments all indicate Iorg Schultes as the manufacturer (Mitchiner 1989, 394-5). The jeton probably dates from before 1550. Context AA, P4; SF275 from 19thcentury rubble cleared from contractor's excavations

15 Rose/orb type of Iorg Schultes (master 1515-1559) ISOV group, Mitchener (1988) 1315-1316b ( probably $1550 \mathrm{~s}$ ); diameter $25 \mathrm{~mm}$; weight $1.16 \mathrm{~g}$; die axis 11.0 ; slight edge buckling; some flattening; moderate wear. Obv.: [ ] ISOVBTG [ ]; three crowns and three lis arranged alternatively around a six-petalled rosette. Rev.: crown IOVBAGnDI [ ] BAGn small crown; unbarred As; D reversed; imperial orb surmounted by cross pattee, within simple three-arc tressure: trefoil between two pellets in each spandrel. C13, P4, SF24: from fill of pit

\subsection{Other finds by Julie Franklin and Mark Collard}

Most of the finds from the excavations in the South Choir Aisle were recovered either in direct association with the excavated burials or from the soil matrix around the burials. Consequently, the assemblage of finds is dominated by coffin nails and shroud fastenings such as pins and lace tags. It was clear from the excavation that almost all the accumulated deposits investigated had been introduced from elsewhere in the medieval burgh, with a range of midden material included within them. It is most likely therefore that most of the objects not directly related to the practice of burial had derived originally from outwith the site. The nature of the objects recovered reflects that environment of redeposition, with many of the pieces, particularly the metal finds, being fragmentary or unidentifiable. Their value lies, therefore, with the information they provide about the context of medieval life in the wider burgh beyond the kirk and its cemetery.

A small group of material, including the window glass, architectural fragments and some of the ceramic building materials, was deposited during periods of construction and demolition within the church. Although small in absolute quantity, they can provide glimpses of elements of the structural history and medieval decoration of the medieval and post-medieval kirk of St Giles'.

Catalogue entries are provided only for the illustrated pieces and include the context, period, site small find number and illustration number and, where appropriate, the burial with which it was associated and where in relation to the body it was found. A full catalogue of all finds is deposited with the archive.

\subsubsection{Copper alloy}

Lace tags, used to neaten the end of laces made of leather or fibre, are a common find on sites of late medieval and early post-medieval age. The 53 examples found at St Giles' have been divided into three types based on the typology devised for Linlithgow Priory (Lindsay 1989, fiche 12:F14). Most 


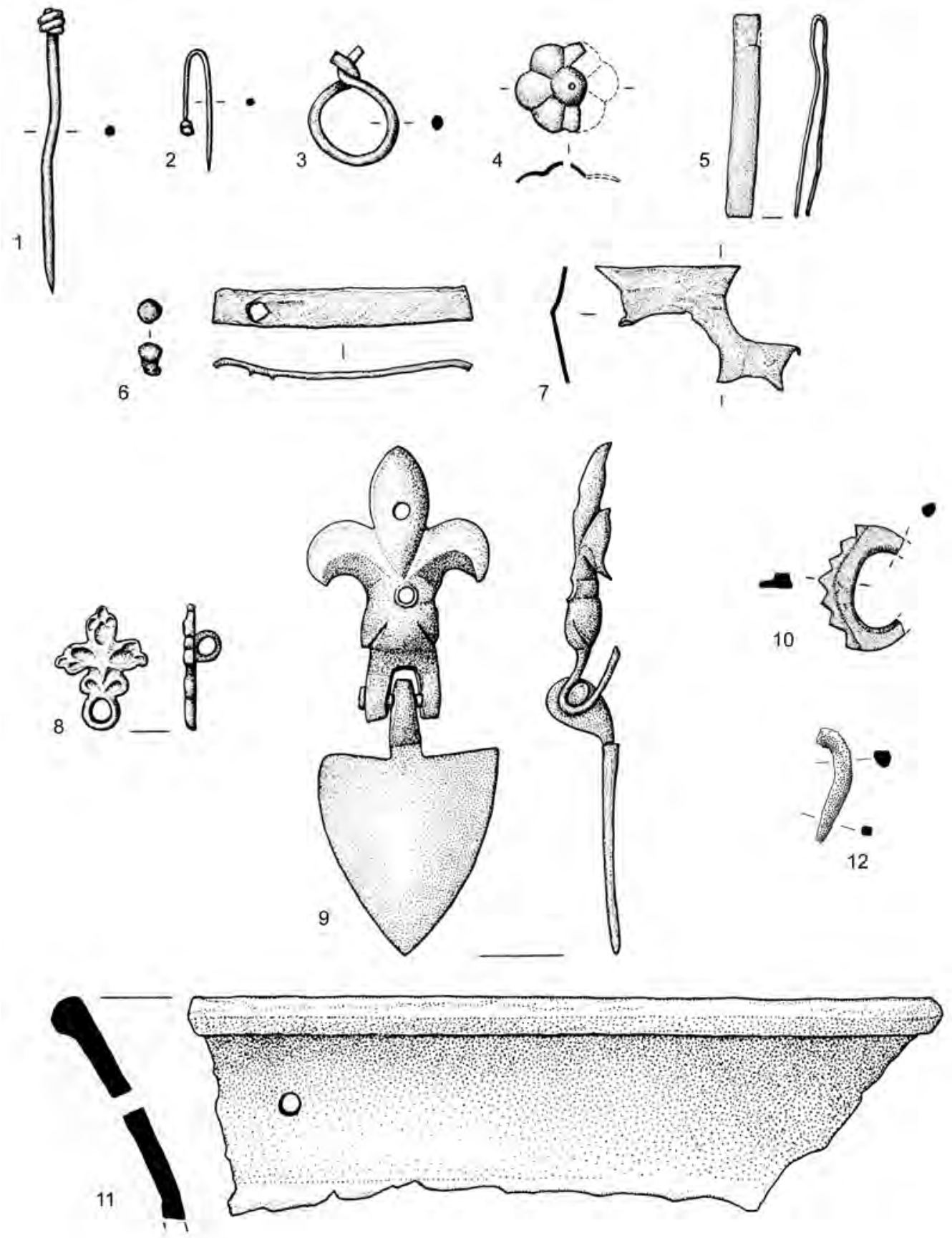

Illus 40 Metalwork: Copper alloy and silver

were of very simple construction, a small piece of sheet metal rolled into a cylinder, with both ends left open (Type 1, 41 tags), ranging in size from $13 \mathrm{~mm}$ to $25 \mathrm{~mm}$, with most in the range $15-22 \mathrm{~mm}$. Eight tags narrowed towards a finished free end (Type 2, 18-27mm long) and four had evidence they were fixed with rivets (Type $3,21-27 \mathrm{~mm}$ ). None were decorated. Two contained remains of the original laces, but no further analysis was undertaken on these. There is no chronological pattern to the use of the different types and all seem to have been in use together. At St Giles', although a single example was found in a Period 2a (BP2) context and seven from Period 2b (BP3), the majority (85\% of the total) are from Period 3 (BP4 and later). At Linlithgow Friary the tags came mostly from 15th- and 16th-century domestic areas, but there was a concentration associated with graveyard soils and grave fills (Stones 1989a). Excavations at Whithorn produced 144 tags, mostly associated with the later medieval burials up to the early 16th century (Nicholson 1997, 375). At St Giles', 20 of the examples are directly associated with burials.

The 77 wire pins fall into three head types, based on Caple's classification (Caple 1983, 273). The most numerous are made of small coils of wire soldered onto the top of the shaft, either a double coil, with the wire wound twice round the shaft (Type A, 22 
pins; illus 40,1-2) or a single coiled ring (Type B, 19 pins). There are also a few pin heads, made of coiled wire, but fixed to the shaft by stamping, giving them a characteristic spherical shape (Type C, 9 pins).

Shaft lengths varied according to the different head types. Type B pins were the longest and most uniform in length, between 27 and $38 \mathrm{~mm}$, averaging $31 \mathrm{~mm}$. Types $\mathrm{A}$ and $\mathrm{C}$ varied by $20 \mathrm{~mm}$ or more but Type A pins averaged $30 \mathrm{~mm}$ long, and Type C $24 \mathrm{~mm}$. The width of the wire was approximately the same $(0.9 \mathrm{~mm})$ for all the pins. Type $\mathrm{C}$ were generally more finely made, with a higher proportion showing evidence of tinning.

The majority (86\% of the total) of the pins of all types, as with the lace tags, are from Period 3 (BP4) or later. None came from Period 2a (BP1/2) burials or deposits.

Four wire loops were recovered, all from contexts dating to the 15th century or later, and all formed by simply twisting together the ends of a length of wire, varying in diameter between $0.8 \mathrm{~mm}$ and $1.6 \mathrm{~mm}$. The illustrated example was typical, with a loop diameter of $12 \mathrm{~mm}$, made of wire $1.6 \mathrm{~mm}$ thick. C95, P3b, SF97; illus 40, 3.

Similar items are a common find in medieval and early post-medieval contexts. At Coventry Free Grammar School, they were associated with the fastening of clothing (Woodfield 1981, 98). The excavations of the Carmelite Friary at Linlithgow produced 27 examples, mostly from graveyard soils and, on the evidence of fragments of leather and wood preserved with them, they appear to have been used as eyes to fasten leather shrouds, with thongs or wooden toggles (Stones 1989a). At Whithorn, 17 such rings were found, also from 15th- and 16thcentury deposits, from graveyard and midden deposits, and were probably used for both clothing and shrouds (Nicholson 1997, 384).

A number of small items of personal accessories were recovered. A small leaf-shaped pendant with a loop at the top and another projecting at the back was similar in form to examples found in London, including an almost complete necklace with seven surviving leaves and two rumbler bells spaced on loops around the chain. The pendants from datable contexts in London were both from the first half of the 15th century (Egan \& Pritchard 1991, 321). Two leaf pendants or mounts came from Threave Castle in Galloway, one of silver gilt and one of copper alloy; these were of comparable date, being from the Douglas era of the castle, between 1370 and 1455 (Good \& Tabraham 1981, 106-8). Length $18 \mathrm{~mm}$, width $13 \mathrm{~mm}$. C67, SK19 (by right side), P3b, BP5, SF104; illus 40, 8.

Only four buckles or parts of buckles were found, and only one was substantially complete, part of a single D-framed buckle, cast with a decorative sawtoothed front edge. The bar and pin are missing. Length $11 \mathrm{~mm}$, width $17 \mathrm{~mm}$. C22, P3, SF238; illus 40,10 . An identical buckle was found during excavations at Linlithgow Carmelite Friary, complete with bar and pin (Stones 1989a, 158) though this was unfortunately unstratified.
The other three partial buckles included a small oval or D-framed buckle (C084, P2, SF258) and a double oval-framed buckle (C95, P3b, SF96). A strap end made of a strip of metal was recovered from the earliest burial phase, broken across one end, with a rivet hole with loose rivet associated. Length $37 \mathrm{~mm}$, width 5mm. C175, P2a, SF257; illus 40, 6.

A strip of metal bent double across middle may be pair of tweezers or a further strap end (though no rivet hole was present), and came from an early burial phase context. Length $29 \mathrm{~mm}$, width $3 \mathrm{~mm}$. C175, P2a, SF256; illus 40, 5.

A number of decorative mounts were recovered, including a two-piece mount, the size of which suggests it was meant to decorate a relatively large object, possibly a box or door. The fleur-de-lis-shaped upper part has two large rivet holes for fixing. The lower part is shield-shaped and attached by a hinge and was presumably meant to be free-hanging. Length $72 \mathrm{~mm}$, width $26 \mathrm{~mm}$. C013, P4, SF010; illus 40,9 .

In the post-Reformation, Period 4, rubble deposits were three studs, with round-domed heads, $10 \mathrm{~mm}$ in diameter, set on square shafts $15 \mathrm{~mm}$ long (not illustrated). They match exactly examples recorded on fragments of wooden furniture (or coffins?) found in the excavations in the Choir Vestry (ECV C81, context 103), where they were hammered closely together in tight rows for decoration.

Other mounts found are more ambiguous in their original use. Flower-shaped and bar mounts were sometimes used on belts and straps (Egan \& Pritchard 1991). However, it was suggested that the several similar objects found in the excavations of the Carmelite Friary in Aberdeen had been used to decorate books (Stones 1989b, 155). A sexfoil, flowershaped mount with central rivet hole was of this type. Diameter 13mm. C22, P3/4, SF219; illus 40, 4. In addition to the illustrated example, also found were a decorated sheet with part of a stamped design of a cross with club-ended arms within a circle, and a bar mount formed of a small rectangular piece of sheet metal with a central rivet hole (both from $\mathrm{C} 22$, P3, SF226 and SF175).

Other miscellaneous objects included: a small fragment of the everted rim of a skillet, with a small hole drilled $16 \mathrm{~mm}$ down from rim, for hanging or attachment of handle (rim diameter $195 \mathrm{~mm}$, hole diameter 2.5mm. C9, P3b, SF271; illus 40, 11); a ferrule in the form of a cone made of sheet metal with a rounded tip with possible vertical millings and a hole in the side for attaching it (length $25 \mathrm{~mm}$, width $12 \mathrm{~mm}$, diameter 9mm. C173, SK68, around pelvis?, P2b, SF250, not illus); and part of a needle shaft, broken at both ends but with some of the eye still visible (length $15 \mathrm{~mm}$, width $2.4 \mathrm{~mm}$. C025, P4, SF604, not illus).

A total of 36 small pieces of offcut copper alloy sheet were found, the majority (two-thirds) from Period 3, particularly the deep levelling deposit (C22). Two offcuts had a number of circular holes cut or punched through. The illustrated example 

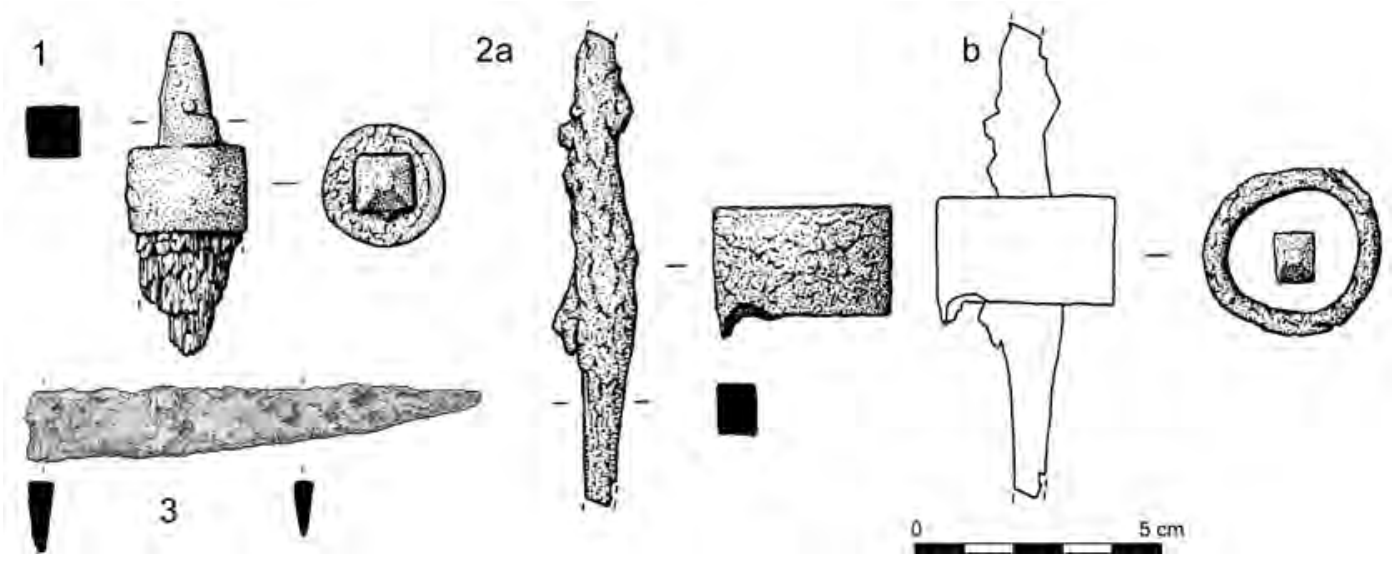

Illus 41 Metalwork:Iron

(C6, P3b, SF161; illus 40, 7) had a range of hole sizes from $10 \mathrm{~mm}$ to $20 \mathrm{~mm}$, while the other example (C98, P3b, SF244, not illus) was fragmentary but had evidence for the removal of circles of metal all $c 15 \mathrm{~mm}$ in diameter. These are presumed to be for the removal of blanks for the manufacture of decorative mounts or studs. Similar pieces were found at 80-86 High Street, Perth in 13th/14th-century contexts (Cox 1997, 745).

\subsubsection{Iron}

The two most interesting items were found in association with two of the Period 2b, BP3 skeletons, and appear to have been deliberately placed in the coffins at the time of interment (illus $14 \&$ illus 15 , depicted as 'batons'). Both objects were of identical form, though different dimensions. That from SK31 consisted of a short, tapering square-sectioned iron shaft, $12 \mathrm{~mm}$ square by $64 \mathrm{~mm}$ long, set into a surviving round-sectioned piece of wood, bounded by a circular iron collar $24 \mathrm{~mm}$ in diameter externally, $18 \mathrm{~mm}$ internally. The wood protruded from one side of the collar around the shaft; on the other side, the shaft projected with no wood visible. The iron shaft tapered at both ends. C101, SK31, in hand, P2b, BP3, SF203; illus 14 \& illus 41, 1.

The object from SK43 had no wood surviving within it but was larger. The length of the shaft was $94 \mathrm{~mm}$, the section of the shaft was again $12 \mathrm{~mm}$ and the external diameter of the collar was $36 \mathrm{~mm}$, the internal 26mm. C121, on feet, P2b, BP3, SF218; illus 15 \& illus $41,2 \mathrm{a} \&$ b.

Despite the differences in scale, the identical form and the proximity of the burials to each other point to them being objects of the same original type. However, despite seeking parallels for the objects, none has so far been found. The closest association so far identified is from the excavation of the Augustinian Friary in Hull by Humber Archaeology Unit, in which 12 burials had wooden rods of various types. Of these, two had two rods; five burials were in coffins, of which four were male, one female and one was a juvenile burial. The rods themselves seem to be of two different 'types' - that is short and long but no apparent fixtures or fittings, apart from a small amount of iron staining on a couple of them. Thus far, suggestions have been plentiful as to role, function, meaning, from pilgrim staffs to self-flagellation sticks or badges of office, but no clear use has been identified. They are dated to around 1343-1353 by dendrochronology of the associated coffins (John Buglass, pers comm).

A possible identification for the objects may be as the ferrules from the base of staffs commonly carried by pilgrims, which often had an iron hook for carrying bundles of possessions over the shoulder, with an iron tip on the end to prevent wear. The arrangement of the surviving wood in the example from SK31 would fit with this explanation as the wood does not project beyond the collar on one side.

Almost all the other iron finds were with a few unidentifiable pieces of structural ironwork or pieces of blade. The majority of nails (663 in total) seem to be mostly coffin nails and were recovered from Period $2 \mathrm{~b}$ and later contexts. They varied in length between 43 and $58 \mathrm{~mm}$. All had small, flat, round heads, between $c 10 \mathrm{~mm}$ and $17 \mathrm{~mm}$ in diameter. Wood was often found adhering to the shafts of these nails (see Section 7 - The coffin wood above).

Four knife blades were excavated from medieval contexts in Periods 2 and 3, of variable blade lengths of $93 \mathrm{~mm}, 104 \mathrm{~mm}$ (2) and $115 \mathrm{~mm}$. Two had scale tang handles. One is illustrated (C58, SK15, above pelvis, P3, BP4, SF102; illus 41, 3). A further 13 iron objects were recovered; the only objects identifiable to function were from P4 contexts and included part of a strap hinge and a T-bracket.

\subsubsection{Stone (see Section 10.4.7 below for architectural stone)}

Only three small stone objects objects were recovered. These were a barrel-shaped bead of quartzite, diameter $10 \mathrm{~mm}$, length $9 \mathrm{~mm}(\mathrm{C} 14, \mathrm{P} 4$, SF18; illus 42,5 ), a counter made of cannel coal, 
diameter 16mm, thickness 2mm (C84, P2, SF242; illus 34,47$)$ and a small possible whetstone of west Highland-type slate (C13, P4; not illus).

\subsubsection{Bone objects (with bone identifications by David Henderson)}

All three items made using animal bone were found in Period 2 contexts and included a barrel-shaped bead of polished bone, length $7 \mathrm{~mm}$, diameter $7 \mathrm{~mm}$ (C28, SK6, between knees, P2b, BP3, SF52; illus 42, $4)$.

An implement handle of square-sectioned handle, broken at one end and hollow in the middle, sanded and polished into a square section. Decorated with a row of drilled dots, it was made from an Ovis metatarsal. Handles made from ovid metatarsal are relatively common on medieval sites. Two examples were found during excavations at Burgess Street in Leith (Henderson in prep, LBS94 SF2790 \& SF3691), one of which was also decorated with dots, though in a random pattern. From Perth there is an example decorated with rows of drilled dots along two of its faces (Ford 1987, 151). The Perth example is from a 14th-century context, the two from Leith are possibly a century or two earlier. Length $62 \mathrm{~mm}$, width $11 \mathrm{~mm}$, breadth $9 \mathrm{~mm}$. C201, SK88, on pelvis, P2a, BP2, SF468; illus 42, 2.

A single pin, broken at its top end, had possibly been manufactured from a Bos long bone? Length $82 \mathrm{~mm}$, width $6 \mathrm{~mm}$. C115, SK115, above right shoulder, P2a, BP1, SF469; illus 42, 1.

\subsubsection{Vessel glass by Robin Murdoch}

A very small assemblage of vessel glass and a single glass bead were recovered from the excavations in 1981 of the South Choir Aisle. A small number of wine and beer bottle sherds were also recovered from the 19th-century rubble and debris $(\mathrm{C} 13, \mathrm{P} 4)$.

\section{Catalogue}

1 A small sherd in clear, thin-blown, colourless glass with heavy patchy silver-coloured denaturing, originally in one piece, $27 \mathrm{~mm} \times 17 \mathrm{~mm} \times 0.8 \mathrm{~mm}$ thick, which came from a prunted beaker. Two of the prunts survive, each $6.5 \mathrm{~mm}$ in diameter and projecting 5.2 and $3.2 \mathrm{~mm}$, respectively, from the vessel's surface. The prunts are drawn up and finished with a swirl imparting a profile similar to a small snail shell. The surviving curvature indicates an approximate vessel diameter of $60-70 \mathrm{~mm}$ and the sherd almost certainly comes from a prunted beaker, a relatively common vessel form around Europe from the 13th to 16 th centuries (Tyson 2000, 76). They were made in both potash and soda glass in southern France, Germany, Italy and Corinth (Tyson 2000, 87).

The lack of any rim or base detail makes dating slightly more difficult but the small size of the prunts is commensurate with a late 13 th- to mid-14th-century date, as prunts become considerably bigger on later examples. Parallels

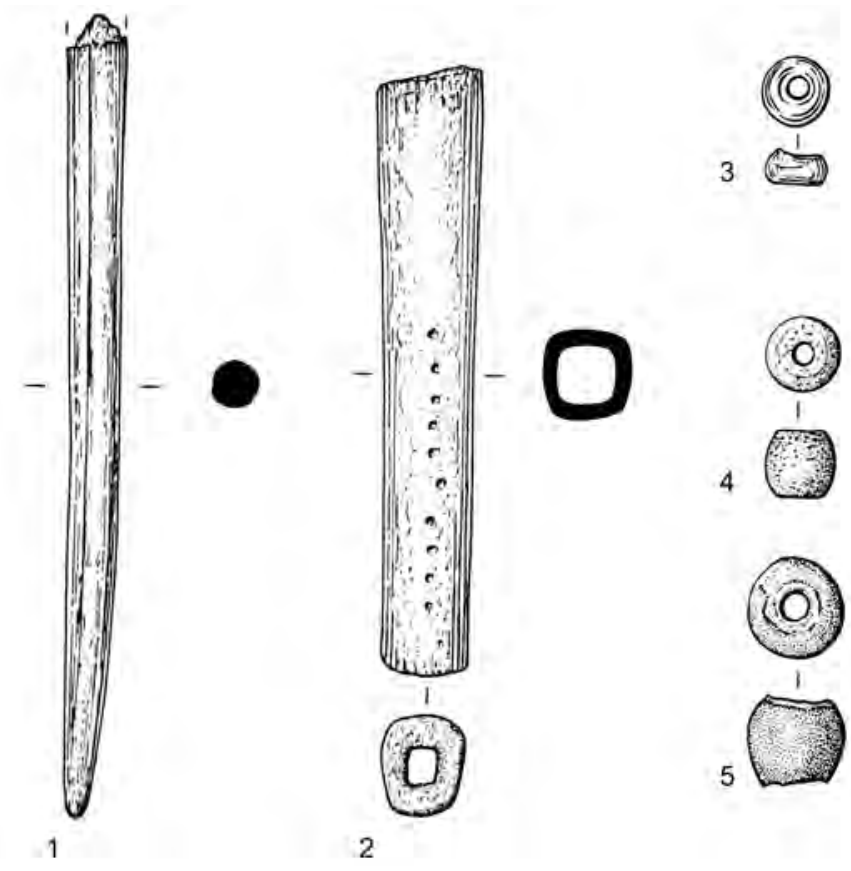

Illus 42 Bone objects $(1 \& 2)$ and beads (3-5: bone, glass and stone)

have been found in Britain, mainly in southern England, but Tyson remarks that they are not as common here as might have been expected (Tyson 2000, 76). This appears to be the first early example recovered in Scotland. Among half a dozen sherds of a similar item (noppenbeker) from Holland, two carry prunts finished in a similar swirling fashion to the St Giles' example and this Dutch example are dated to around 1300 (Henkes 1994, 28, fig 3.3).

Late 13th to mid-4th century. C073, P2b, SF124; illus 43. 2 Two small sherds in heavily denatured glass with dark brown corrosion products indicating potash glass; the original colour was not discernible. One is $27 \mathrm{~mm} \times 19 \mathrm{~mm}$ $\times 1.6-2 \mathrm{~mm}$ thick and appears to be either from a small, flattish dish or is possibly part of the rim from a widemouthed vessel, possibly a flask or urinal. The second sherd is $18 \mathrm{~mm} \times 11 \mathrm{~mm}$, with thickness varying between 2 and $3 \mathrm{~mm}$. Localized thickening may result from optic blowing to create a surface decorative feature, perhaps of small lozenges. If these two sherds are from the same vessel then it is not a urinal, as this type of vessel was not decorated.

Dating difficult but unlikely to be later than $c 1500$. C22, P3, SF306; not illustrated.

3 Small bead in very dark glass, some abrasion, rounded oval section, diameter $6.5-6.6 \mathrm{~mm}$, width $3.4 \mathrm{~mm}$, aperture $2.6 \mathrm{~mm}$ diameter. Marks from moulding are visible either side of the entry to the aperture.

C101, P2b, SF276; illus 42, 2.

4 Part base in clear, colourless glass with patches of moderate buff-coloured denaturing, with a rather small diameter of $31 \mathrm{~mm}$, with a pontil scar in the indented base. The apparent base of the bowl is only $8 \mathrm{~mm}$ above the base ring of the vessel, therefore either the item has not had a stem or the stem had at least one hollow knop (not enough left to ascertain which). The piece seems rather small for a drinking vessel base (although but this cannot be entirely ruled out) and other possible forms include a candlestick holder or small flask.

Colour and condition of glass would suggest no earlier than late 17th century. From contractor's excavations, P4, SF304; not illustrated. 


\subsubsection{Window glass and lead}

by Pamela Graves

\section{Background and documentary evidence}

Graves wrote a review of known documentary evidence relating to the production of window glass in medieval and Renaissance Scotland, the painting of window glass and its installation (Graves 1994, 124-6). The majority of the information relating either to Edinburgh or the immediate environs of the capital occurs in the later Middle Ages, and the most detailed accounts occur in the early 16th century. The only direct reference to glass in $\mathrm{St}$ Giles' was a note pointing out heraldic work in the eastern chapel of the western aisle of the North Transept: an elephant, 'very well executed', and a crown and hammers, within a wreath, which were probably the armorial bearings of the Incorporation of Hammermen (Wilson 1891, II, 228). The chapel had been dedicated to St Eloi, the patron saint of metalsmiths and goldsmiths. This was the only coloured glass that had survived into the $1820 \mathrm{~s}$, and must have disappeared sometime between the 1820s and 1848 (Wilson 1848, II, 180; Gray 1891-2, 37-8; Wilson 1891, II, 235; McRoberts unpublished). The reference to a painted wreath containing the Hammermen's arms suggests an early 16 th century date, akin to the compositional formula of surviving armorial roundels in the Magdalen Chapel in the Cowgate.

The Exchequer Rolls of Scotland imply that glass was imported from the Continent through the ports of Blackness, Leith and Dundee from the 14th century onwards (Exchequer Rolls III, 222; Exchequer Rolls IV, 533 and 619). Customs were raised on glass in Edinburgh in the 1520s and 1530s (Exchequer Rolls XV, 515; Exchequer Rolls XVI, 35, $65,229,360,374)$.

In 1504, a particular glasswright, Thomas Peebles, was granted lands to serve as the source of an annual pension for maintaining the windows in the royal palaces at Falkland and Linlithgow, the palace and abbey at Holyrood, and the castle at Stirling, and in 1506 he was paid for 60 feet of 'payntit glas in divers places' (Treasurer's Accounts III, 297; Apted \& Hannabuss 1978, 136-7). The relative quantities of white (colourless) glass and 'payntit roundis with chaiplitis' ordered for the Queen's oratory at Holyrood in 1512 (100ft and seven roundels, respectively) suggest that, here at least, the fashion was for minimum painted decoration, probably heraldic roundels similar to those of the mid-16th century surviving in the Magdalen Chapel, Cowgate, Edinburgh (Treasurer's Accounts IV, 375; cf Seton 1886-7). The 'kingis armis' are specified for other chambers in Holyrood between 1531 and 1532 (Works Accounts I, 93-5). However, 'ymagis ... of paynttit werk' are prescribed for the chapel of Linlithgow Palace in 1534-5 (Works Accounts I, 128). In 1535-6, 'Flanderis roundis and squair antik peces' together with 'paintit glas in bordouris and antik

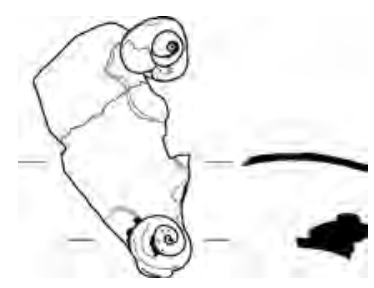

Illus 43 Vessel glass

faces' were placed in the 'new chapell' and elsewhere at Holyrood Palace (Works Accounts I, 190). 'Antik faces' may refer to Renaissance grotesques and masques.

The most complete remains of pre-modern painted glass relating to Edinburgh are all heraldic. These are the four roundels, referred to above, in the Magdalen Chapel in the Cowgate, dating to the mid-16th century; and a roundel from Woodhouselee, near Penicuik, outside Edinburgh, dating to 1600 (now housed in the Royal Scottish Museum, Chambers Street) (Seton 1886-7; Gray 1891-2). Glass of older date was found at Holyrood Abbey in 1909 (Eeles 1914-15), and represents the greatest range of painted motifs known from any site in Scotland, albeit that the date range is restricted to the13th/14th centuries (Graves 1994, 132-3). The Holyrood assemblage has been supplemented by a small amount of material excavated in 1995 (Bain \& Clark 1998). All other comparative material from Scotland may be found in various excavation reports (Graves 1985; Stones 1989b; Graves 1995; Graves 1996; Graves 2000a; Graves 2002).

There are three general categories of glass within the material recovered from the excavations (a full descriptive catalogue of all the window glass recovered has been deposited with the site archive). The first is undoubtedly medieval, with corrosion patterns characteristic of potash (ie wood ash-derived alkali) glass (c 440 sq cm). The second group is a finer, more durable glass, with opalescent surface corrosion, and characteristically less than $2 \mathrm{~mm}$ thick (c 325 sq cm). This is likely to be late medieval/early modern glass, possibly of the 16 th $/ 17$ th centuries. The third category is modern glass, and will not be discussed here.

\section{Medieval glass}

By far the majority of the medieval potash window glass is uncoloured with no painted decoration. There are four examples $(13 \mathrm{sq} \mathrm{cm})$ of fire-rounded edges from the cylinder method of manufacture, used throughout the medieval period. Whilst great quantities of fire-rounded edges in a single deposit may indicate the debris from installation of glass at a particular time (being effectively 'off-cuts' from the main sheets), there is no doubt that fire-rounded edges with a comparatively slight thickening at the edge could be, and were, used as quarries. The small number of such edges at St Giles' is consistent with 

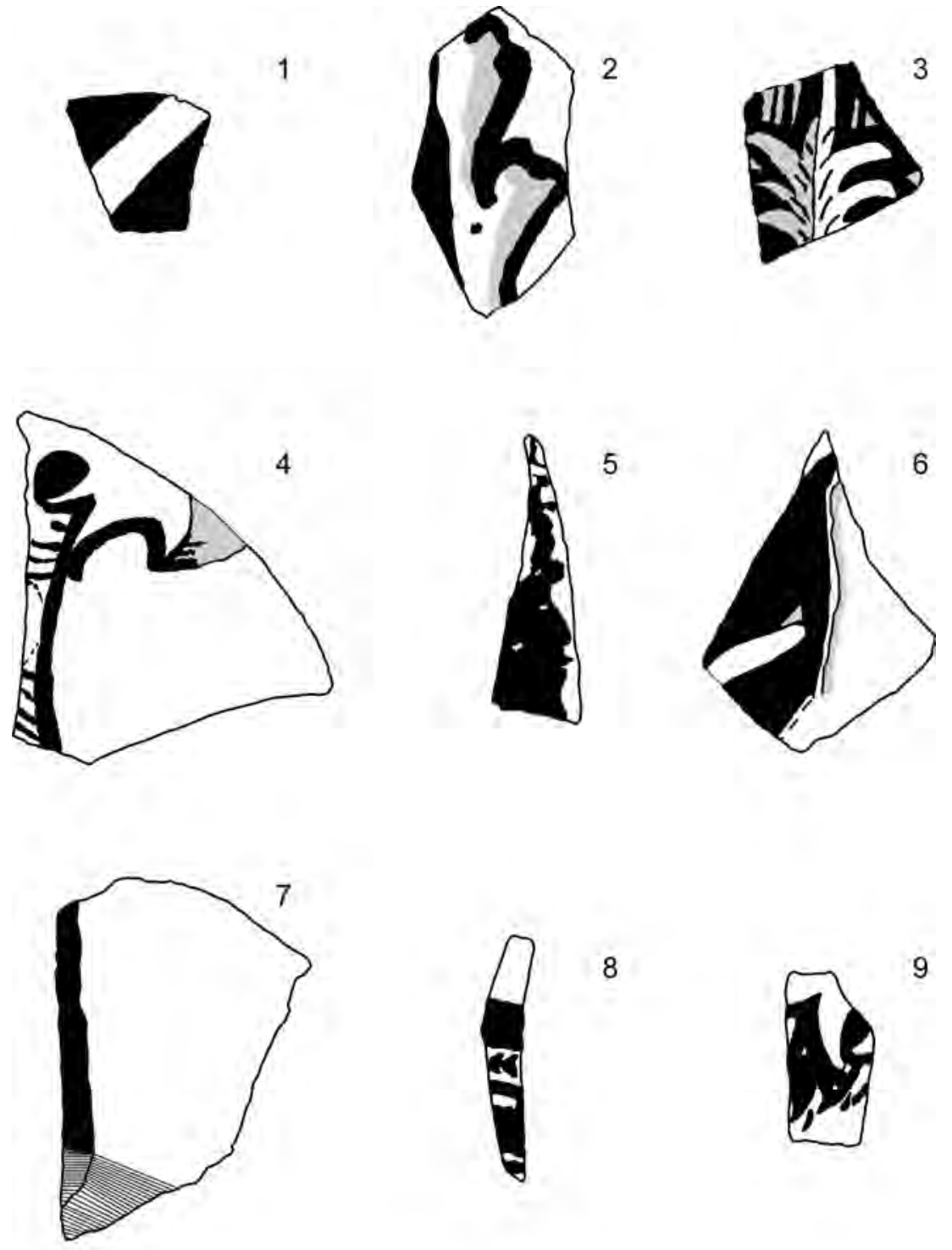

8
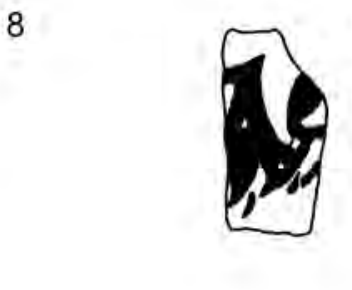

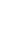


C25 (P4) may have part of an oak leaf painted in outline with slight shading following the line, and highlighted in yellow stain ( $c 4 \mathrm{sq} \mathrm{cm}$, SF342; illus 44,2 ). Because yellow staining in the British Isles dates to $c 1310$ onwards, but was more common from the 1320s and 1330s (French \& O'Connor 1987, 13), the St Giles' fragment would be consistent with mid-late 14th-century grisaille or simply an oak leaf motif used in some other compositional context. The enigmatic fragments from $\mathrm{C} 43$ (P3b, SF112A; illus 44, 4-6) have closely-spaced lines at one edge which resemble cross-hatching. Similarly, the rounded and curling terminals of paintwork may be consistent with trefoil grisaille, particularly that with tight heads found, eg at Jedburgh and dating to the early to mid-13th century (Graves 1995). However, the paintwork in other places on these fragments is more akin to the fine washes and stickwork which characterize early 14th-century rinceaux and diapers (cf French \& O'Connor 1987, plate 19). The condition of the surface has deteriorated too far to be able to be more precise, but the thickness of the glass and its general condition suggest a date in the 14 th century onwards rather than earlier.

C25 (P4) also contained a possible piece of black letter script (SF339). This form of inscription tended to replace Lombardic script from the mid-14th century onwards. The design on a piece from C43 (P3b, SF165B; illus 44, 9) is by no means certain, but could be the jagged edges of fur, as seen on heraldic animals, particularly their limbs, from the 13th century onwards. Again, the glass itself suggests a date in the $14 \mathrm{th} / 15$ th century. Fragments C and D (illus 44, 7 and 8 ) from the same context are equally likely to date to the 14 th- 15 th centuries, although their paintwork is not diagnostic. A tiny leaf $(3.5 \mathrm{sq} \mathrm{cm})$ in reserve from C25 (P4, SF47; illus 44,3) is the most complete design from the whole assemblage, and the use of dilute wash compares with that of the oak leaf (above) from the same context. Small leaves like this were common in background diapers of the 14th and early 15 th centuries in particular.

A possible 13th-century date for the fragment from C22 (P3, SF336) is plausible; it is clear from extant glass windows and from excavated assemblages that older glass would be kept and reused often. Contexts 73 (P2b, SF350) and 89 (P2, SF302) contained glass without diagnostic paintwork but it was medieval potash glass, consistent with a late 13th- to mid-14th century date, and 12th- to mid14 th century date, respectively.

\section{Post-medieval/early modern glass}

The first patent granted for the production of glass in Scotland dates to 1610, and Scotland was thought to be self-sufficient in the supply of glass by 1622 (Turnbull 2001, 1). Glass works were located at Leith, three locations to the immediate east of
Edinburgh, and at Kirkcaldy and Wemyss in Fife, and broad window glass seems to have been manufactured from the first (Turnbull 2001, passim). Venetian expertise was brought in between 1622 and $c$ 1646, but a skilled workforce from England was also employed (Turnbull 2001, 28, 87-8).

The assemblage of more durably transparent glass, with weathering mainly visible as an opalescent sheen on the surface, was almost consistently of $2 \mathrm{~mm}$ thickness or less. There were $c$ $33 \mathrm{sq} \mathrm{cm}$ of fire-rounded edges indicating cylinder or broad glass, the most common form of glass found in Britain in the 17th century (Turnbull 2001, 22). It is thought that traditional cylinder glass manufacture (as opposed to improved or drawn cylinder methods) became almost obsolete by 1700 (Burgoyne \& Scoble 1989, 4). Such thin glass was not unknown in the 14th century, at least in York (cf Graves 2000b; and with reference to York Minster, David O'Connor, pers comm). Thin glass of the early modern period (16th-17th centuries) has also been observed from other excavations in the north of England. In this respect it is perhaps significant that, in the $1620 \mathrm{~s}$ :

There was controversy about the thickness, and therefore strength, of glass, especially that from Scotland, and the frequent repairs listed in accounts bear witness to its fragility (Godfrey 1975, 206; Turnbull 2001, 54).

As the only example of lead came can be dated to the 16th-17th centuries by the marks left by the characteristic, close spacing of the teeth of the hand mill through which it was turned (see Section 2.2 below), it seems most likely that the cames, similarly marked lead strips, and this assemblage of thin glass, all relate to the same episode of glazing sometime between the late 16th and late 17th centuries at St Giles'.

\section{The window lead}

Fifteen lead window cames, with a characteristic $\mathrm{H}-$ shaped profile and seven flat lead strips were also recovered, all from contexts dated to P3 and P4.

There was only one wholly recognizable piece of lead came (C1, P4, SF196, illus 45). This had the regular dimensions and ridges consistent with

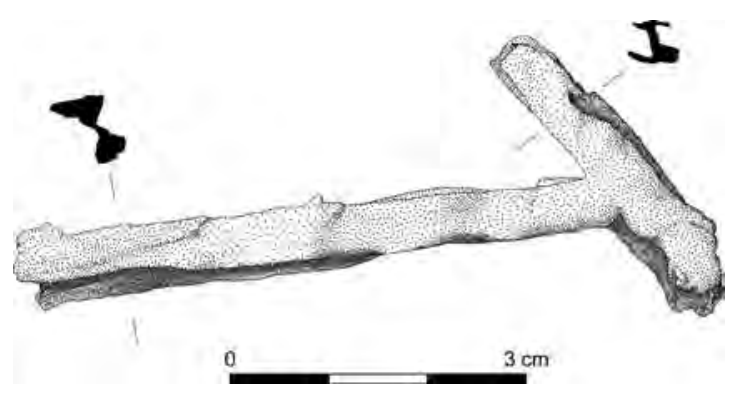

Illus 45 Metalwork: Lead came 


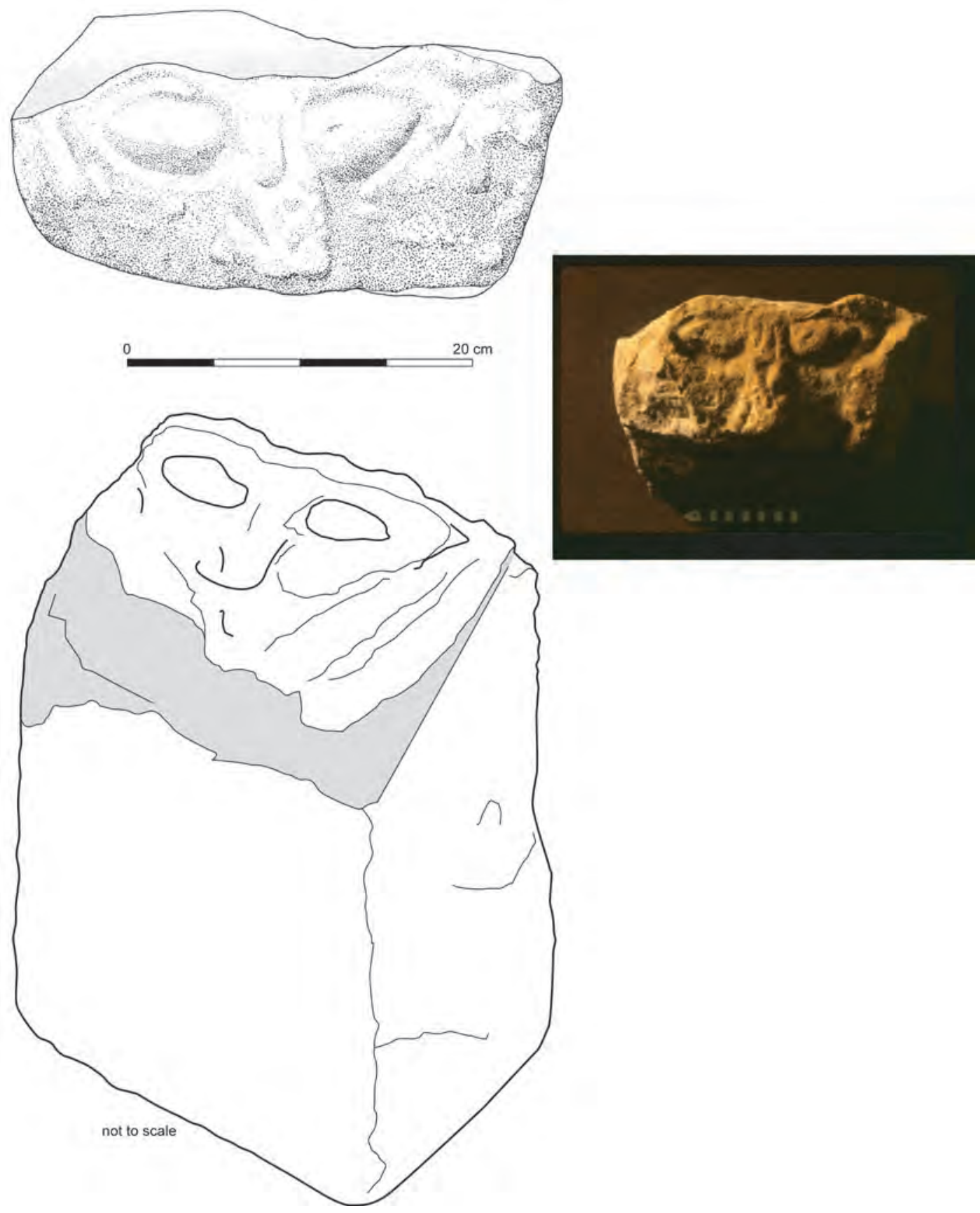

Illus 46 Architectural fragment: 12th-century Romanesque grotesque corbel or beakhead, reused in foundation (C256) of east wall of South Aisle

post-medieval milled cames rather than cast and hand-cut medieval cames. On the inner surfaces of the leaves, and on the web, closely-spaced grooves are indicative of the mill having been toothed. The close spacing suggests a date in the 16 th or 17 th century (Knight 1986, 31). Those strips of lead which have knife facets were probably cut from Hsectioned cames, and one (C13, P4, SF23) was almost certainly of $16 \mathrm{th} / 17 \mathrm{th}$-century date, having the same toothed mill features as the came from $\mathrm{C} 1$ described above. The implication is that most of the cames and lead strips relate to the same episode of glazing as the assemblage of very thin, Early Modern window glass above.

\section{Discussion}

The assemblage of medieval glass is disappointing in its lack of diagnostic decorative detail. There are some hints at 13th-century grisaille which may have entered the archaeological record as breakage during replacement by later glass (if for no other reason than that the lead would probably have had 

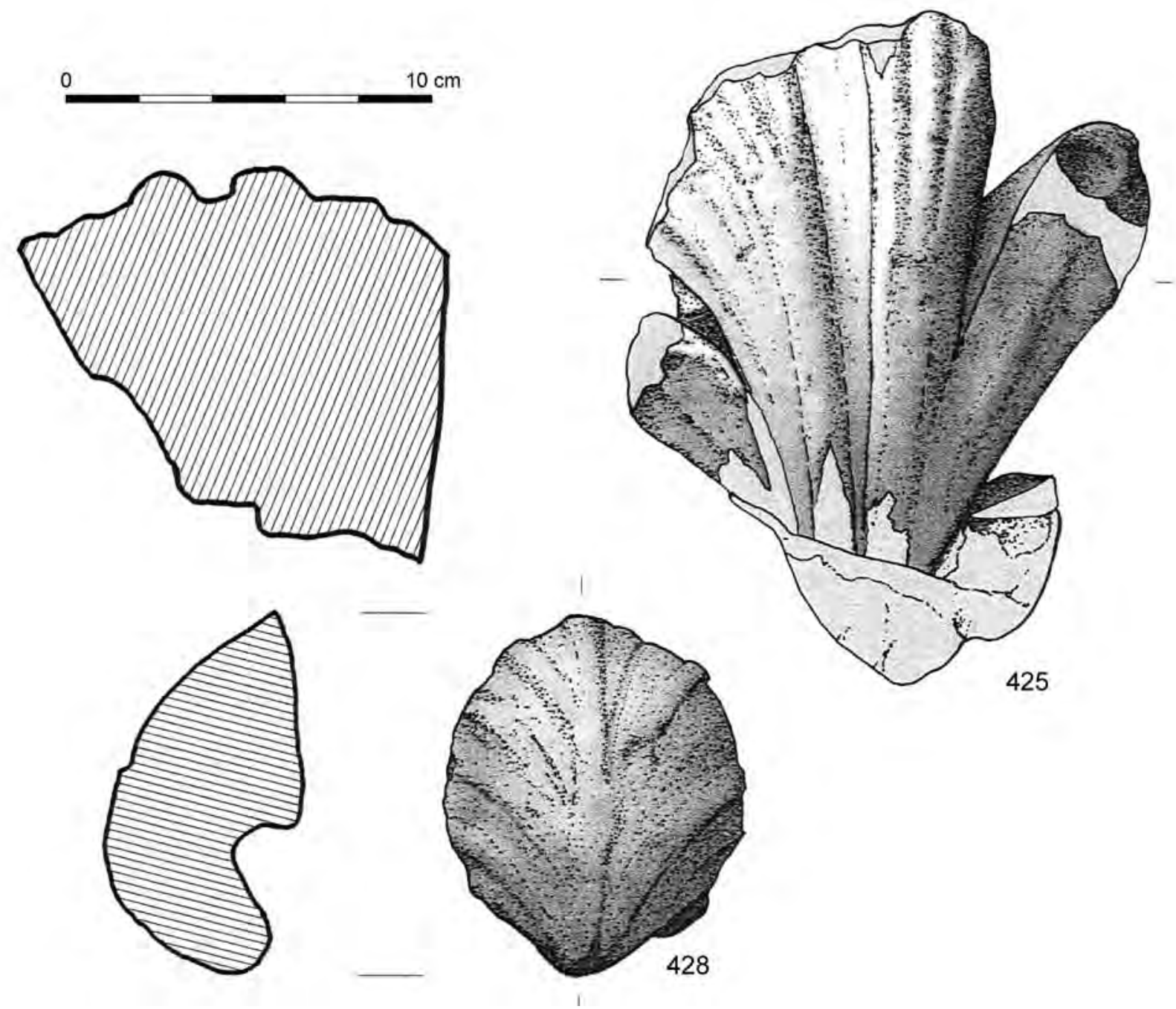

425

Illus 47 Architectural fragments: 19th-century foliate cast-plaster ornamental fragments

to be replaced during the course of the Middle Ages). On the other hand, residual fragments of older glass are a common feature of in situ glass that has been repeatedly releaded up until the present day. The majority of the decorated pieces, taking into consideration the relative homogeneity of the metal and execution of paintwork, the existence of yellowstained and ruby-flashed examples, would seem to be mid-late 14 th or 15 th century in date.

With regards to the assemblage of early modern glass, it is tempting to associate this with a period of deliberate, post-Reformation fenestration, replacing formerly coloured and historiated glass with plain glass. If medieval glass images had been destroyed in iconoclastic 'purgings', at St Giles', as in 1559 and early 1560 , this would provide a reason to reglaze windows for both practical and theological reasons. However, the iconoclasm at St Giles', at least such attacks as were recorded, seems to have fallen short of breaking the windows (Spicer 2003, 34). Indeed, The First Book of Discipline expressly required kirks to have 'close windowes of glasse, thack able to withold raine' (quoted in Howard 1995, 175; Spicer 2003, 34). It is quite likely that an amount of medieval glazing had to be replaced from this practical imperative alone. Because St Giles' was subdivided rather 'hastily' into four parish churches in 1562-3 (Howard 1995, 177), and galleries had to be inserted (Spicer 2003, 34), some accidental damage may have occurred in the process, necessitating the replacement of windows or panels. Similarly, the attempts to reinstate the building as a cathedral in 1633 , and the repartitioning of the interior following the signing of the National Covenant (Howard 1995, 192), may have induced further accidental damage and/or repair to the windows at any time along the way. The fragility of contemporary window glass, particularly in the early 17 th century, has been noted above and may have created a pattern of frequent glazing repairs and consequent deposits finding their way into the archaeological record. Contemporary contracts demonstrate that wealthy landowners, at least, expected to have to retain the services of local glaziers for repairs on a regular basis (Turnbull 2001, 54), thus underlining that late 16th/early 17th-century reglazing at St Giles' need not have been the consequence of dramatic events. 


\subsubsection{Worked stone and building materials by Thomas Addyman}

Avery small assemblage of worked stone and building materials was recovered from the excavations in the South Choir Aisle. Within this group were few pieces of recognizable architectural mouldings or other stone. The most important of these was a characteristically 12 th-century Romanesque grotesque corbel or beakhead (C246, P3a; illus 46), probably from a door-arch similar in style to that which survived as the entrance to the north side of the nave until 1797-8 (Chambers 1888, XIII).

Other pieces from medieval contexts included a carved fragment of a moulded detail including a $55 \mathrm{~mm}$-wide roll, quirked on one side hard, fine/ medium-grained, light pinkish tan sandstone probably part of a window or entrance surround, probably of late medieval date (C97, P3; not illus) and a fragment of rounded sandstone moulding extending into a flat surface (60mm-thick), perhaps the edge of a table tomb slab or the nosing of a stair (C101, P2b; not illus). A fragment of very hard, fine-grained though apparently friable limestone (possibly?magnesian limestone) was part of the edge and upper surface of a larger stone, most likely a funerary monument. The upper surface has a high polish and there is a suggestion of diagonal tooling along the remaining part of the side (C128, P3; not illus). A large funerary slab of probable late medieval date of very similar stone can be seen within the ruined church of Old St Andrew's, North Berwick.

From the 19th-century debris beneath the aisle floor came two cast plaster gypsum plaster ornamental fragments consisting of parts of foliate sculptural elements in full relief, perhaps crockets, of 14th-century 'Decorated' style though probably of 19th-century origin were, perhaps, part of an ornamental surround of a wall monument $(\mathrm{u} / \mathrm{s}, \mathrm{P} 4$, SF425, SF428; illus 47).

Pieces of 11 sandstone roofing tiles in ?Carmyllie stone were recovered, mostly from P4 contexts, although one was found in C137 (P3; not illus). Other building materials recovered included fragments of wall plaster and lime mortar, again mostly from P4 disturbed contexts. 


\section{The Faunal Remains by David Henderson}

A small quantity of animal, fish and bird bones was recovered by hand picking during the course of the 1981 South Choir Aisle excavations. In all, 818 elements were identified to species, $659(80.6 \%)$ of which derived from contexts assigned to Period 3. Most of these bones were recovered from C9, the mid-15th-century backfill of the construction trench of the present east wall, but the preservation of the bone and the nature of the fragmentation of the skeletal elements suggest that the bones are derived from primary deposition rather than redeposited and residual material.

\subsection{Methods}

The bones were identified to species and to skeletal element for mammal bones, to species for fish and to species for chicken and goose bones; other birds (a total of ten bones, mostly from small passerine species) were not differentiated. An attempt was made to distinguish between sheep and goat on the basis of horncores, teeth and metacarpals, but no element was judged to be from goat. All bones from this taxon were catalogued as 'sheep' therefore, though it should be remembered that these figures may contain some goat bones. Minimum numbers of individuals (MNI) were calculated for each species, primarily on the basis of paired elements, although epiphyseal fusion and tooth wear were also taken into account where relevant. The MNI was calculated for phases because of the small assemblage available from individual contexts. For the purposes of this report, the phases of activity on site are separated into three groups: Periods $2 \mathrm{a}, 2 \mathrm{~b}$ and 3 . The skeletal element frequency (SEF) was calculated on the basis of articular ends of longbones, jaws with teeth in situ, rib heads and vertebral bodies.

\subsection{Species present}

The numbers of fragments (number of individual specimens (NISP) and the minimum mumber of individuals (MNI) for each species is shown in Table 11.

Table 11 Animal bone NISP and MNI by Period

\begin{tabular}{|c|c|c|c|c|c|c|}
\hline \multirow[b]{2}{*}{ Species } & \multicolumn{2}{|c|}{ Period 2a } & \multicolumn{2}{|c|}{ Period 2b } & \multicolumn{2}{|c|}{ Period 3} \\
\hline & NISP & MNI & NISP & MNI & NISP & MNI \\
\hline Sheep & $\begin{array}{c}29 \\
\text { (50\% of } \\
\text { mammals) }\end{array}$ & $\begin{array}{c}2 \\
\text { (40\% of } \\
\text { mammals) }\end{array}$ & $43(52 \%)$ & $4(50 \%)$ & $253(55 \%)$ & $10(40 \%)$ \\
\hline Cattle & $26(45 \%)$ & $1(20 \%)$ & $37(45 \%)$ & $3(38 \%)$ & $127(27 \%)$ & $3(12 \%)$ \\
\hline Pig & $1 \quad(2 \%)$ & $1(20 \%)$ & $2(3 \%)$ & $1(12 \%)$ & $28 \quad(6.1 \%)$ & $2(8 \%)$ \\
\hline Cat & $2(3 \%)$ & $1(20 \%)$ & & & $34 \quad(7.4 \%)$ & $5(20 \%)$ \\
\hline Dog & & & & & $5(1 \%)$ & $2 \quad(8 \%)$ \\
\hline Roe deer & & & & & $7(1.5 \%)$ & $1(4 \%)$ \\
\hline Rabbit & & & & & $4 \quad(0.8 \%)$ & $2 \quad(8 \%)$ \\
\hline Chicken & 3 & 1 & 2 & 1 & 126 & 14 \\
\hline Goose & & & & & 8 & 2 \\
\hline Bird & & & 1 & & 9 & \\
\hline Cod & & & & & 48 & \\
\hline Haddock & 1 & & 3 & & 10 & \\
\hline Ling & & & 1 & & & \\
\hline Gadoid & & & 1 & & & \\
\hline Flatfish & & & 6 & & 6 & \\
\hline Ray & & & 1 & & & \\
\hline Frog & & & & & 2 & \\
\hline Total & 62 & & 97 & & 659 & \\
\hline
\end{tabular}


The assemblage is dominated by sheep and cattle, with a considerable number of chicken bones (19\% of all bones recovered from Period 3). The relatively low number of pig bones is typical of medieval and post-medieval sites in and around Edinburgh (Chaplin \& Barnetson 1975; Barnetson 1980; Chaplin \& Barnetson 1980; Henderson, in prep). A small quantity of roe deer was recovered from Period 3. Evidence of cat and dog was present not only in the bones, but in the form of carnivore toothmarks on some $9 \%$ of the Period 3 bones. Of the minimum of five cats represented, three were under a year old. Of the fish, cod was the most common species consumed, followed by haddock.

\subsection{Distribution of skeletal elements}

Only Period 3 provided sufficient material to analyse for evidence of carcass utilization. Table 12 shows the MNI for each skeletal element expressed as a percentage of the highest MNI.

Although the figures for cattle are low, it can be seen that most of the cattle and sheep bones came from the high meat areas of the carcass, with little 'waste' (mandibles, phalanges etc). This suggests that the sample derives from domestic refuse of joints of meat, slaughtered and butchered elsewhere. Two sheep metapodials show signs of possible boneworking: a distal end cut off just above the epiphyseal line, using several blows, and a shaft fragments with extensive 'shaving' of the anterior surface. These may represent craft waste. Similarly, a dog ulna and radius have knife cuts at the proximal end, suggesting that the carcass was dismembered. As it is culturally unlikely that the animal was intended for a meal, it may have been skinned for fur- or leatherworking.

\subsection{Age at slaughter}

A few general observations may be made, but with such a small sample the findings are necessarily tentative and limited. By counting fused and unfused epiphyses, only $10 \%$ of cattle in Period 3 were less than 2.5 years old when slaughtered, and the presence of fully fused vertebral bodies shows that some animals were over 8 years old. This would suggest that the bones were derived from cattle kept primarily for dairy products (and possibly traction). Pig bones, while very few, do not reveal any animals over 3.5 years old. One mandible was from an animal 1.5-2 years old. The sheep bones from Period 3 provide a fuller picture. Twenty-two per cent of the animals were under one year at death, and a further $25 \%$ were between one and three years old. This represents a much higher level of lamb slaughter than was found at St Mary's Street, Edinburgh (Chaplin $\&$ Barnetson 1980) where the $13 \%$ of sheep slaughtered before ten months of age was attributed to natural losses from the flock. The St Giles' material may therefore represent a deliberate cull of lamb (or
Table 12 Percentage of MNI

\begin{tabular}{lrr}
\hline & Cattle & Sheep \\
\hline Forelimb, high meat & & \\
Scapula & 0 & 28 \\
Prox humerus & 20 & 0 \\
Dist humerus & 100 & 71 \\
Prox radius and ulna & 60 & 25 \\
Dist radius & 20 & 28 \\
& & \\
Hindlimb, high meat & & 100 \\
Pelvis & 40 & 28 \\
Prox femur & 40 & 14 \\
Dist femur & 20 & 7 \\
Prox tibia & 20 & 28 \\
Dist tibia & 0 &
\end{tabular}

Low meat bones

Prox metacarpal 40

$\begin{array}{lll}\text { Dist metacarpal } & 40 & 7\end{array}$

Prox metatarsal $20 \quad 0$

Dist metatarsal $\quad 20 \quad 14$

Calcaneum $\quad 0 \quad 21$

Astragalus $\quad 20 \quad 14$

Phalanx

8

1

Body meat

Vertebral bodies

Cervical

24

20

Thoracic

3

Lumbar

$0 \quad 10$

Rib head

8

6

Head

$\begin{array}{lll}\text { Mandible } & 40 & 7\end{array}$

Zygomatic $20 \quad 0$

Horn-core $\quad 20 \quad 7$

kid) to provide prime, tender meat. Just over half the sheep were fully mature at slaughter. These animals had probably been kept long enough to provide some fleeces and for breeding, before being slaughtered for mutton.

\subsection{Butchery}

Little evidence for butchery practices was presented, but it was evident that carcasses were split into 'sides' of meat and that many of the cattle bones had been deliberately broken open, presumably to extract marrow. 


\subsection{Discussion}

The paucity of remains from Period 2 precludes any detailed analysis, although the numerical dominance of sheep fragments and the low numbers of pigs is clearly demonstrated. In the $15 \mathrm{th} / 16$ thcentury deposits (Period 3), the bones seem to represent domestic refuse, possibly with a small admixture of craft waste. There is some evidence (eg young lamb, roe deer) that the contributing households were of a higher than average social standing. The cattle bones, though representing good cuts of beef, derive from older animals, and may indicate husbandry practice based more on dairy products than prime meat products. If the ratio of a minimum of ten sheep to three cattle represents the true relative numbers of animals slaughtered, beef would have contributed three and a half times as much to the diet as mutton and lamb, based on Chaplin's estimate of a 12 to 1 ratio of dressed carcass weight for cattle and sheep (Chaplin 1971). 


\section{The Molluses by John A Lawson}

The excavation produced a small shell assemblage of 125 complete shells, comprising 11 marine mollusc species, of which $80.8 \%$ where from recognized edible species (Table 13).

The assemblage of shells recovered from St Giles' follows the general distribution patterns already established from previous excavated sites from Edinburgh (Heppel 1980; Heppel 1985) and eastern Scotland. The recovered species are all currently common within the Firth of Forth (Mckay \& Smith 1979), with the notable exception of Ostrea edulis (oyster). This species was, however, common in the Forth Estuary in the past and was commercially exploited throughout the medieval and postmedieval periods until overfishing of the beds killed off the fishery in the early 19th century. Archaeological evidence for the medieval commercial processing of oysters was recovered from excavations in Leith at both Burgess Street (Collard \& Reed 1994) and Ronaldson's Wharf (Reed \& Lawson 1997).

Although this small sample is indicative of domestic waste, the majority of the shells at St Giles' were found in redeposited contexts often associated with wall construction. Shells from both edible and non-edible species alike were also found with adhering lime-mortar, indicating their use predominantly as wall pinnings.
Table 13 Mollusc species and abundance

\begin{tabular}{lc}
\hline Species & $\begin{array}{c}\text { Total shell } \\
\text { count per } \\
\text { species }\end{array}$ \\
\hline Cerastoderma edula (cockle) & 27 \\
Ostrea edulis (oyster) & 24 \\
Buccinus undatum (common whelk) & 18 \\
Mytilus edulis (mussel) & 17 \\
Littorina littorea (edible periwinkle) & 15 \\
Patella vulgata (limpet) & 12 \\
Nucella lapinus (dog whelk) & 3 \\
Dosinus lupinus & 3 \\
Ensis siliqua (razor shell) & 2 \\
Ensis ensis & 2 \\
Venerupis senegalensis (carpet shell) & 2 \\
\hline
\end{tabular}




\section{Discussion by Mark Collard and John A Lawson}

Despite the clear accounts of the removal during the renovations of Chambers and Hay in the 1870s of large amount of human bones and burials from areas within the church, particularly on its south side and within the Choir, the results of the excavations in the South Choir Aisle in 1981 demonstrated that the majority of the deposits and burials in this area had remained intact. Limited disturbance to the upper levels of archaeological deposits and a general reduction of the surface of the later medieval phases had clearly occurred in Period 4, but the lower, medieval, levels remained in situ, disturbed only the excavation of localized, discrete intrusions.

Absolute dating for the great majority of deposits and structural remains encountered during the 1981 and other investigations was unfortunately lacking but it is possible to use the remains uncovered to present a clear and sustainable framework of the sequence of development in this area, linked to the historical and chronological framework of the rest of the building of St Giles'.

The earliest event recorded on site - the two mortared stone slabs observed at the base of the underpinning trench - remains tantalising and currently inexplicable in date and function. The location of the slabs does provide clear evidence for what must have been a very steep drop in slope to the south from the ridge where the High Street now runs, with a fall of almost $6 \mathrm{~m}$ in $20 \mathrm{~m}$ horizontally, based on the observation of the level of bedrock within the North Transept and the recorded depth of the stone slabs beneath the east wall.

The massive clay platform recorded across all the investigations in the southern and central parts of the church is clear evidence of action taken on a large scale to counteract the difficulties of construction on this steep slope. Clearly manmade, from the evidence of both the Choir Aisle and the organ foundation trenches within the South Transept, it is presumed, though not proved, that the clay observed within the centre of the Choir also formed part of the same deposit.

The most likely date for the creation of this terrace would seem to lie in the period around the creation of the burgh of Edinburgh by David I in 1124x1127, and it was probably created to accommodate the new 12th-century burgh church of St Giles'. It is clear that the upper surface of the clay was not at a uniform height, lying at approximately $89.05 \mathrm{~m}$ in the Choir, $88.40 \mathrm{~m}$ in the South Choir Aisle, $87.35 \mathrm{~m}$ in the South Transept and $86.70 \mathrm{~m}$ in the Choir Vestry, where its upper surface was observed sloping down towards the south (all heights AOD). This suggests that the area of the original Romanesque church may have formed a higher plateau above the rest of the terrace; if so, this may have been a deliberate manipulation of the landscape to enhance the architectural setting of the new church as well as the creation of a more gentle gradient allowing access to the south.

It seems clear that the excavation of the large ditch (C250) also belongs in this phase of activity. The physical placing of the ditch within the burgh is striking. It lies exactly midway between the top of Castlehill to the west and the Netherbow Port to the east, the two points which marked the legal limits of the medieval burgh of Edinburgh along the High Street ridge. On this basis the ditch could be interpreted as part of the planned set-out of the early Norman burgh, with the new burgh parish kirk of St Giles' placed at the heart of the new town. The alignment of the ditch suggests it was set out at right angles to the High Street; the later medieval kirk, which does not share this alignment, is distinctly skew to the street; the reasons for this are unclear. The evidence of the alignment of some of the burials in Period 2 suggest that this skewed alignment may have been a feature of the 12th- and 13th-century church building also.

The function of the ditch cannot be determined with any certainty, but the clear absence of any bank or structures on its western side and the use soon after of this area to the west for burial, and the unlikelihood that any bank or bank would be placed on the downhill side, suggest that it was not defensive in character. It seems more likely that it simply, but emphatically, defined the precinct within which the Norman church of St Giles' stood. The line of the eastern kirkyard boundary to the south, and the adjacent close (Kirkheugh Close) follow the projected line of the ditch down to the Cowgate (maps of Gordon of Rothiemay and Wiliam Edgar, illus 5 and illus 6, respectively) and can be seen as forming the southern part of the same early boundary. In this context it may be that the mortared slabs, which were seen below the clay in this area along the eastern boundary, were simply part of the initial setting out of the town plan prior to the construction of the clay terrace.

Excavations in Perth identified a ditch which was interpreted as forming part of a precinct circuit around St John's Kirk, although there it was dated to the 10 th/11th centuries by radiocarbon dating (Moloney \& Coleman 1997, 710). It does not seem likely on the balance of the archaeological and historical evidence from St Giles' that a similar date is likely.

The extension of the eastern end of the church in the late 14th/early 15th century went as far as the line of the ditch/close but no further, perhaps 
further suggesting that this marked the boundary to the land of St Giles'. The close is clearly depicted by Gordon of Rothiemay in 1647 as having to dog-leg around this eastern end of the late medieval church to allow access to the High Street.

To the west of the ditch, and outside the 12thcentury church, the clay terrace was used almost immediately as a cemetery. Graves from this period were recorded in the South Choir Aisle (BP1), South Transept and the Choir Vestry, cut directly into the surface of the clay, prior to any deposition or formation of soil deposits its surface. The graves which were observed cut into the clay within the Choir may also belong to this period; they certainly pre-dated at least the mid-15th-century extension of the east end. It is unclear how far the original Choir of the Norman church extended but if these burials can indeed be identified as external, this would indicate that the east end of the original church of David I may have lain further to the west. In this context the clear preference within all three phases of the Period 2 burials in the South Choir Aisle for alignment on the boundary ditch rather than the church building suggests that the ditch was a dominant local topographic feature and that the east end of the church building was not in the immediate vicinity to provide an alignment for the graves.

The area to the south of the early medieval church continued in use as a cemetery external to the church, with deposition of imported make-up containing midden material in all three of the areas investigated. The earliest dating material recovered was the pottery evidence from the deposits of BP2 (P2a). The date suggested for this, of no later than the 13th century, provides a useful terminus ante quem for the burials of BP1 and there seems little doubt that the burials of this earlier phase belong in the 12 th century.

While it is certain that the external cemetery was for the general burgh population of Edinburgh, the detailed analysis of the skeletal material from the South Choir Aisle has shown distinct and apparently significant variations in the population interred during this period (see Section 8-The Human Remains), although the small size of the samples must be remembered. Of particular note is the preponderance of males within Period 2a, and children in Period 2b, the latter representing half the interred population in that period. Among the former group, the males in Period 2a also contained a notable number (seven of $23,30 \%$ ) who had either leprosy or an injury that may have caused restricted movement. In this context, the recorded existence of the hospital in St Giles' in the area (see Section $3.2-$ The Parish Cemetery) to the south of the church may be significant. St Giles' was particularly associated as patron with the crippled and the lame, beggars and lepers (Butler 1987, 199-200), and the grouping of these skeletons may point to an early foundation date for the hospital, for which at present there is no evidence earlier than the 16th century.
The burgh kirk of St Giles' underwent considerable construction and extension work during the 14th century, and at some stage during this period, perhaps in the later decades of the century or early in the 15th century, the Choir was extended to the east, and at the same time the South Choir Aisle was also extended. The most important contribution made by the 1981 excavations to the elucidation of the structural history of St Giles' was the identification of the structural remains associated with this extension. Prior to 1981 it was assumed that the extended Choir and Choir Aisles were of only four bays and that the demonstrably stylistically later easternmost bays of the presbytery and associated clerestory were the result of further extension in the 1450s. However, the unequivocal evidence of the excavation - in the form of the massive wall footing (C246) - was that in fact the Choir was extended to almost its current length in a single phase before the mid-15th-century remodelling of the east end, and that the south wall of the aisle was built at the same time to the same length. The evidence of wall ESG91 (C5) in the South Transept suggests that the Transept may have been extended to the south around the same time to maintain the balance of the southern side of the kirk.

The excavations show clearly that this original east wall was demolished and systematically robbed to the base of its foundations and the new east wall constructed just to the east. The recovery of the penny of James I or II from the backfill of this robber/construction trench provides a firm mid15th-century terminus post quem for the work, and fits well with the date of $c 1453$ derived from the heraldry on the capitals of the new columns of the extension.

While the impetus for enhancement of the church at its east end was probably linked to the acquisition by Sir William Preston of the relic of the arm bone of St Giles', as well as an attempt to give greater emphasis to the presbytery, and certainly dates to the early $1450 \mathrm{~s}$, the reason for the slight shift in the wall line to the east, and the consequent respacing of the piers and bay widths may have been prosaically structural in nature rather than a deliberate aesthetic decision. The original east wall (C246) had been built in and over the large infilled boundary ditch (C249). Although much of the extent and depth of this ditch had been removed by the excavation of the foundation trench for the wall, the remaining, truncated ditch had been backfilled with clay, and the wall footings built clay-bonded rather than mortared, all measures presumably to assist in providing a stable footing. It may well be that these measures were simply not sufficient to carry the weight of this east wall. The evidence of the subsidence and the subsequent underpinning of the contemporary south wall of the Choir Aisle and the insertion of buttressing sleeper walls, identified by the excavator as being occasioned by the alterations for the construction of the Preston Aisle in 1454-55, suggest that there may in fact rather have been a 
general structural failure of the elements built in the 14th-century enlargement of the church, and the works of the 1450s in the Choir and the creation of the Preston Aisle took advantage of the opportunity presented by the need for repair and reconstruction in this area.

The extension of the church saw a change in the character of the burials made in the area of the South Choir Aisle (Period 3, BP4 and BP5). There was organization in the disposition of the burials within the church, with a series of clearly defined rows of graves, and little intercutting of graves within these rows; the existence of grave markers at ground level may be inferred from this and from the reference to the removal of decorated slabs in the 19th-century renovations. Parallels for this later medieval formalization of burial lairs, marked by inscribed grave slabs, can be found at Glasgow Cathedral where three clearly defined burial vaults or lairs were recorded (Driscoll 2002, 45), though at Glasgow these took the form of deep burial plots rather than individual lairs. The use of coffins for a significant number of the burials and the evidence of the decay and wear of the teeth from the skeletons are physical indicators of a change in social status from those buried outside the church in earlier phases, though the type of timber used and the manner of construction of the coffins may imply that it was the covering of the coffins during the funerary ceremonies that displayed the status of the deceased rather than the coffin.

Evidence recovered from the investigations for the internal arrangement of the church in this period was limited. Hay suggested 'a provisional plan of at least reasonable plausibility' for the positions of altars within the late medieval church (Hay 1975-6, 254-5), although detailed evidence for the position and character of these altars, and the associated liturgical arrangements of the church of this period, is lacking. However, as is the case within the nave of Glasgow Cathedral (Driscoll 2002, 158-60), the arrangement of the graves within the South Choir Aisle may be indicative of the physical position of altars here. Discrete rectangular areas at the east end of both the original and the extended aisle in Periods $3 \mathrm{a}$ and $3 \mathrm{~b}$, centrally placed against the face of the successive walls, had no burials within them, suggesting that an altar within the Lady Aisle lay here, and its position was simply shifted at the same time as the reconstruction of the east end in the mid-15th century. Hay identifies this area as the location of the altar of St Anne, the mother of Mary, whose altar was assigned to the confraternity of tailors (Driscoll 2002). Among her roles as patron saint, she was identified with women in labour, childless women and seamstresses, the latter perhaps most relevant to the association with the tailors of Edinburgh.
Unsurprisingly, dedications to St Anne are often associated with those to her daughter, and the main dedication of the South Choir Aisle was to Our Lady. Her altar would be expected to lie directly south of the high altar, at the junction of the first and second bays (Driscoll 2002). Within the excavated area, a clear area noticeably without burials can be identified in this location (illus 17; illus 21; illus 22), and this was generally maintained throughout the more than 150 years that this area was receiving burials. On the western side of the excavated area, a very distinct group of six burials (illus 17, SK8, SK10, SK13, SK16, SK21 \& SK27) are all arranged in a line, with a clear rectangular space to the east which corresponds in position to the presumed position of the original high altar prior to the extension of the Choir to the east. All six were female, and indeed a statistically significant majority of the burials within the Lady Aisle in Period 3 were female, evidence for a clear and direct link between the patron saints, their religious attributes and the demography of the burials. The area without burials also extended further to the east and may indicate a shift in the position of the altar at the time of the mid-15thcentury re-ordering of the east end, similar to that identified for the altar at the east end of the aisle.

The investigations in the Choir in 1993 provide possible evidence for the position of the reredos of the high altar, dedicated to St Giles', but the lack of any surviving above-ground structure, and the absence of detail in the limited accounts relating to the high altar (Hay 1975-6, 256-7), preclude further speculation.

The 1981 excavations produced a surprisingly small amount of material relating to the medieval decoration and ornamentation of the church, with only a limited quantity of small sherds of window glass and a few fragments of architectural stone, the only readily identifiable piece of which was the beaked corbel from the 12th-century Romanesque church. The architectural stone includes fragments of possible grave slabs, reference to carved memorials in the historical account.

The more plentiful assemblages of artefacts and animal bone derived from material which was generally introduced from outside the site as make-up and levelling. A rare glimpse of the domestic assemblages of the medieval Old Town of Edinburgh over several centuries is offered by the diverse character of the material recovered: the presence of higher status items such as the prunted glass vessel, imported pottery vessels and cuts of meat represented by their bones; the evidence for craft activities such as boneworking and the manufacture of decorative copper alloy objects; and the clearly random, though incomplete, sample which the assemblages represent. 


\section{Acknowledgements}

The post-excavation analysis and production of this report was funded by Historic Scotland and by The City of Edinburgh Council Archaeology Service. The report on the 1981 excavation in the South Choir Aisle was compiled by Mark Collard, using a draft typescript account prepared by the excavator Nicholas Holmes (written before the compilation of the spe- cialist reports), as well as analysis of the original site records. The remainder of the text not identified by author was also written by Mark Collard. John Lawson managed the project and edited the report on behalf of the City of Edinburgh Council.

Illustrations were edited for publication by Headland Archaeology. 


\section{References}

Adams, M \& Reeve, J 1987 'Excavations at Christ Church, Spitalfields 1984-6', Antiquity 61, 247-56.

Addyman, T \& Kay, W 2001 St Giles' Cathedral, Edinburgh. Conservation Plan. Unpublished typescript report.

Apted, M R \& Hannabuss, S (eds) 1978 Painters in Scotland 1301-1700: A Biographical Dictionary. Scottish Record Society, new series 7, Edinburgh.

Bain, S \& Clark, J. 1998 'Window glass', in Bain, $\mathrm{S}$ et al. 'Excavation of a medieval cemetery at Holyrood Abbey, Edinburgh', Proc Soc Antiq Scot 128, 1058-60.

Beckmann, B 1974 'The main types of the first four production periods of Siegburg pottery', in Evison, V, Hodges, H \& Hurst, J G (eds) Medieval Pottery from Excavations, 183-220. London.

Boyd, W E 1989 'Perth: the wooden coffins', in Stones, J A (ed), 117-18.

Boyd, W E, Hall, D W \& Holmes, N M McQ 1980 Slat-bottom Coffins from Mediaeval Scotland. Unpublished CECAS paper.

Brooks, C M 1980 'Medieval pottery from the kiln site at Colstoun, East Lothian', Proc Soc Antiq Scot 110 (1978-80), 364-403.

Burgoyne, I \& Scoble, R 1989 Two Thousand Years of Flat Glass Making, Pilkington plc. Chalon Press, St Helens.

Caple 1983 'Pins and wires', in Mayes, P \& Butler, L A S, Sandal Castle Excavations 1964-1973: A Detailed Archaeological Report, 269-78. Wakefield Historical Publications, Leeds.

Chenery, S, Haggarty, G, Hall, D W, Murray, J C \& Cameron, A 2005 A Draft Report on the ICPS Analysis of Scottish Redware Ceramics 2004 2005. Report prepared for Historic Scotland.

Clapham, A R, Tutin, T G \& Warburg, E F 1962 Flora of the British Isles, 2nd Edn. Cambridge University Press, Cambridge.

Clarke, P V 1978 'German stoneware', in Schofield, $J$ 'Excavations south of Edinburgh High Street, 1973-74', Proc Soc Antiq Scot 108 (1975-76), 203-13.

Collard, M \& Reed, D 1994 'Burgess Street/Water Street/ Shore Place, Leith', DES 1994, 48.

Corkhill, T 1979 A Glossary of Wood. Stobart \& Sons, London.

Cox, A 1997 'Bell-founding mould fragments', in Rains, M \& Hall, D W (eds) Excavations in St Andrews 1980-89: A Decade of Archaeology in a Historic Scottish Burgh', 40-63. Perth (=Tayside and Fife Archaeological Committee monograph 1).

Crone, B A \& Barber, J 1981 'Analytical techniques for the investigation of non-artefactual wood', Proc Soc Antiq Scot 111, 510-15.

Driscoll, S T 2002 Excavations at Glasgow Cathedral 1988-97. Edinburgh (=Soc Med Archaeol monogr 18).

Duplessy, J 1989 Les Monnaies Françaises Royales de Hugues Capet à Louis XVI. Platt, Paris; van der Dussen, Maastricht.

Eames, E 1983 'Floor tiles', in Wordsworth, J 'Friarscroft and the Trinitarians in Dunbar', Proc Soc Antiq Scot 113, 485-6.

Eeles, F C 1914-15 'Mediaeval stained glass recently discovered from the ruins of Holyrood Abbey Church', Proc Soc Antiq Scot 49, 81-91.

Egan, G \& Pritchard, F 1991 Medieval Finds from Excavations in London. Part 3: Dress Accessories c 1150-1450. HMSO, London.

Exchequer Rolls: The Exchequer Rolls of Scotland 1878-1908 (edited by Stuart, J, Burnet, G et al.), 23 vols, Edinburgh.

Ford, B 1987 'Bone objects', in Holdsworth, P (ed) Excavations in the Medieval Burgh of Perth 1979-1981, 150-1. Edinburgh (=Soc Antiq Scot monogr ser 5).

French, T \& O'Connor, D 1987 York Minster: A Catalogue of Medieval Stained Glass; Fascicule 1, The West Windows of the Nave. Corpus Vitrearum Medii Aevi, Great Britain, Vol III.

Gaimster, D 1997 German Stoneware 1200-1900. Archaeology and Cultural History. British Museum Press, London.

Gaimster, D 2001 'Life and lifestyle in the Baltic castle: patterns in ceramic consumption $c 1200$ 1600', in Skaarup, J et al. (eds) Castella Maris Batici V, 51-66. Archaeologia Medii Aevii Finlandiae VI, Rudkobing.

Gaimster, D, Goffin, R \& Blackmore, L 1990 'The Continental stove tile fragments from St Mary Graces, London, in their British and European context', Post-Med Arch 24, 1-49.

Gifford, J, McWilliam, C \& Walker, D 1984 The Buildings of Scotland: Edinburgh. Penguin, Harmondsworth.

Godfrey, E S 1975 The Development of English Glassmaking, 1560-1640. Clarendon Press, Oxford.

Good, G L \& Tabraham, C J 1981 'Excavations at Threave Castle, Galloway, 1974-78', Medieval Archaeol 25, 90-140.

Gordon, A 1984 Death is for the Living. Paul Harris, Edinburgh.

Graslund, A S 1980 Birka IV - The Burial Customs. A Study of the Graves on Bjorko. Birka-Untersuchungen und Studien RAA, Stochholm.

Graves, C P 1994 'Medieval stained and painted window glass in the Diocese of St Andrews', in 
Higgitt, J (ed) Medieval Art and Architecture in the Diocese of St Andrews, British Archaeological Association Conference Transactions for the Year 1986, 124-36.

Graves, C P 1995 'Window glass', in Ewart G \& Lewis, J (eds) Jedburgh Abbey: The Archaeology and Architecture of a Border Abbey, 110-13. Edinburgh (=Soc Antiq Scot monogr ser 10).

Graves, C P 1996 'The window glass', in Ewart, G 'Inchaffray Abbey, Perth and Kinross: excavation and research, 1987', Proc Soc Antiq Scot $126,505-7$.

Graves, C P 2000a 'Window glass', in Dixon, P, Rogers, I \& O'Sullivan, J (eds) Archaeological Excavations at Jedburgh Friary, 1983-1992, 28-31. Edinburgh (=STAR monogr 5).

Graves, C P 2000b The Window Glass of the Order of St Gilbert of Sempringham: A York-based Study. York Archaeological Trust, York.

Graves, C P 2002 'Window glass', in Lewis, J \& Pringle, D (eds) Spynie Palace and the Bishops of Moray: History, Architecture and Archaeology, 132-7. Edinburgh (=Soc Antiq Scot monogr series 21 ).

Gray, J M 1891-2 'Notes on examples of old heraldic and other glass, existing in, or having connection with, Scotland; with especial reference to the heraldic rondel preserved at Woodhouselee', Proc Soc Antiq Scot 26, 34-48.

Haggarty, G 1984 'Observations on the ceramic material from Phase 1 pits $\mathrm{BY}$ and $\mathrm{AQ}$ ', in Tabraham, C 'Excavations at Kelso Abbey', Proc Soc Antiq Scot 114, 395-8.

Haggarty, G 1999 'The pottery from St Nicholas Farm, St Andrews', in Hamilton, J \& Toolis, R 'Further excavations at the site of a medieval leper hospital at St Nicholas Farm, St Andrews', Tayside Fife Archaeol J 5, 98.

Haggarty, G forthcoming a 'The pottery', in 'Excavations at Calton Road, Edinburgh', AOC Archaeology Ltd Report.

Haggarty, G forthcoming b A Gazetteer and Summary of French Pottery Imported into Scotland c 1150 to $c 1650$.

Hall, D W 1995 'The pottery', in Bowler, D, Cox, A \& Smith, C (eds) Four excavations in medieval Perth 1979-1984', Proc Soc Antiq Scot 125, 952-9.

Hall, D W 1996 'Blind date - Scottish medieval pottery industries', Tayside Fife Archaeol J 2, 126-9.

Hall, D W 1997 'The pottery', in Rains, M \& Hall, D W (eds) St Andrews: A Decade of Archaeology in a Historic Burgh 1980-89, 40-63. Perth (=Tayside and Fife Archaeological monogr 1).

Hall, D W 1998 'The Scottish medieval pottery industry: a pilot study', Tayside Fife Archaeol J $4,170-8$.

Hall, D W forthcoming 'The pottery', in Stronach, S et al. Excavations at the Site of the New Scottish Parliament, Canongate, Edinburgh.

Hay, G 1975-6 'The late medieval development of the High Kirk of St Giles', Edinburgh', Proc Soc Antiq Scot 107, 242-60.
Henkes, H 1994 Glas zonder glans (Glass without gloss). Rotterdam Papers 9. Rotterdam Press, Netherlands.

Henderson, D in prep Human Remains from Magdalen Chapel, Edinburgh. Unpublished report for CECAS.

Heppel, D 1980 'The molluscs', in Holmes, N M McQ 'Excavations at St Mary's Street Edinburgh 1974', Post-Med Archaeol 14, 174-5.

Heppel, D 1985 'Shells', in Holmes, N M McQ 'Excavations at Bernard Street Leith 1980', Proc Soc Antiq Scot 115, 424.

Hirst, S M, Walsh, D A \& Wright, S M (eds) 1983 Bordesley Abbey II. Oxford (=Brit Archaeol Rep, Brit Ser 111).

Howard, D 1995 The Architectural History of Scotland: Scottish Architecture from the Reformation to the Restoration, 1560-1660. Edinburgh University Press, Edinburgh.

Hurst, J, Neal, D S \& Van Beuningen, H J E 1986 'Pottery produced and traded in North West Europe 1350-1650', Rotterdam Papers VI.

Lindsay, W J 1989 'Copper alloy objects', in Stones, J A (ed) Fiche 12:F9-G6: Louis XVI. Platt, Paris; van der Dussen, Maastricht.

McCarthy, M \& Brooks, C M 1988 Medieval Pottery in Britain AD, 900-1600. York.

McRoberts, D unpublished 'Rhind Lectures on the furnishings of medieval Scottish churches', delivered in Edinburgh, Spring 1970.

Marjoriebanks, Rev G 1882 'Note on the expenses of the funeral of Mrs Margaret Marjoriebanks 1697', Proc Soc Antiq Scot 4 (1881-2), 33-6.

Mitchener, M 1988 Jetons, Medalets \& Tokens, Volume 1: the Medieval Period and Nuremberg. Seaby, London.

Molleson, T \& Cox, M 1993 The Spitalfields Project Volume 2: The Anthropology; The Middling Sort. Council for British Archaeology, York.

Moloney, C \& Coleman, R 1997 'The development of a medieval street frontage: the evidence from excavations at 80-86 High Street, Perth', Proc Soc Antiq Scot 127, 707-82.

Nayling, N T 1988 The Archaeological Wood Survey. English Heritage, London.

Nicholson, A 1997 'The copper alloy', in Hill, P Whithorn and St Ninian: the Excavation of a Monastic Town 1984-91, 360-89. Tempus, Stroud.

Paterson, R 1853 'Note on human remains in wooden coffins found in the East Links of Leith', Proc Soc Antiq Scot 63, 98-100.

RCAHMS 1951 An Inventory of the Ancient and Historical Monuments of the City of Edinburgh. Royal Commission on the Ancient and Historical Monuments of Scotland, Edinburgh.

Richardson, J 1929 ‘A 13th-century tile kiln at North Berwick, East Lothian and Scottish medieval ornamented floor tiles', Proc Soc Antiq Scot 63 (1928-9), 281-310.

Seton, G 1886-7 'Notice of four stained-glass shields of arms and a monumental slab in St 
Magdalene's Chapel, Cowgate', Proc Soc Antiq Scot 21, 266-74.

Spicer, A 2003 'Iconoclasm and adaptation: the Reformation of the Churches in Scotland and the Netherlands', in Gaimster, D \& Gilchrist, R (eds) The Archaeology of Reformation 1480-1580, 2943. Maney, Leeds.

Stones, J A 1989a 'The small finds', in Stones, J A (ed), 147-65.

Stones, J A (ed) 1989b Three Scottish Carmelite Friaries: Excavations at Aberdeen, Linlithgow and Perth 1980-86. Edinburgh (=Soc Antiq Scot monogr 6).

Treasurer's Accounts Accounts of the Lord High Treasurer of Scotland (edited by Dickson, T et al.), 13 vols, 1877-1978, Edinburgh.

Turnbull, J 2001 The Scottish Glass Industry, 1610 1750. Edinburgh (=Soc Antiq Scot monogr 18).

Tyson, R 2000 Medieval Glass Vessels found in
England c $A D$ 1200-1500. Council for British Archaeology Research Report 121, York.

Verhaege, F 1983 'Low Countries medieval pottery imported into Scotland: notes on a minor trade', Medieval Ceramics 7, 3-44.

Will, R, Jones, R E, Haggarty, G \& Hall, D W 2003 Sourcing Scottish White Gritty Ware. Report prepared for Historic Scotland.

Wilson, D 1848 Memorials of Edinburgh in the Olden Time, 2 Vols. Edinburgh.

Woodfield, C 1981 'Finds from the Free Grammar School at the Whitefriars, Coventry, $c$ 1545-c 1557/58', Post-Medieval Archaeol 15, 81-159.

Works Accounts: Accounts of the Masters of Works for building and repairing Royal Palaces and Castles, I, 1529-1615 (edited by Paton, H M, 1957). Edinburgh.

Young, S M \& Clark, J 1982 'Medieval Britain 1981', Medieval Archaeol 26, 164-227. 